Portland State University

PDXScholar

Summer 7-31-2018

\title{
Selling Protest in the News? Movement-Media Framing of Occupations: an Exploratory Study
}

Andrew David Butz

Portland State University

Follow this and additional works at: https://pdxscholar.library.pdx.edu/open_access_etds

Part of the Journalism Studies Commons, Mass Communication Commons, and the Sociology Commons

Let us know how access to this document benefits you.

\section{Recommended Citation}

Butz, Andrew David, "Selling Protest in the News? Movement-Media Framing of Occupations: an Exploratory Study" (2018). Dissertations and Theses. Paper 4510.

https://doi.org/10.15760/etd.6394

This Dissertation is brought to you for free and open access. It has been accepted for inclusion in Dissertations and Theses by an authorized administrator of PDXScholar. Please contact us if we can make this document more accessible: pdxscholar@pdx.edu. 
Selling Protest in the News?

Movement-Media Framing of Occupations:

An Exploratory Study

by

Andrew David Butz

A dissertation submitted in partial fulfillment of the requirements for the degree of

Doctor of Philosophy

in

Sociology

Dissertation Committee:

Robert Liebman, Chair

Daniel Jaffee

Amy Lubitow

Lee Shaker

Portland State University

2018 
(C) 2018 Andrew David Butz 


\begin{abstract}
Using quantitative content analysis, this study explores social movement (SM) framing in commercial news media - by comparing how leading newspapers covered prominent protest occupations in 2011 and 2016. More than other SMs, anti-systemic protests like the 2011 Occupy Wall Street (OWS) and the 2016 Malheur Refuge Occupation (MRO) only have partial frame-setting agency, raising a broad theory question (to inform the research questions below): If SMs and media relate as interacting systems, are protest news frames more movement- or more media- driven; and do media not just enable but also constrain SMs?

With the movement-media theory question above, the study design adapts media opportunity structure (MOS) to model a hierarchy of influences on news coverage of ideologically opposed or "distant twin" OWS and MRO, as 40- to 60-day protest occupations. The focused research question - exploring media's constraining potential asks if commercial news framing of collective action: i) commercially frames or "sells" even anti-corporate protest; or ii) instead marginalizes or neutralizes such protest? Coverage from three top national or state newspapers (The New York Times, USA Today, and The Oregonian) was analyzed randomly from all protest stories during the occupations. Sampled time periods in 2011 and 2016, during actual encampments/ occupations in Portland, OR and New York City (OWS) and in Malheur National Wildlife Refuge, Oregon (MRO), also correspond with transitional years in print news.

The inductive-based comparative results, from 15 coding dimensions for news framing of collective action, dispersed passivity, and commercially-framed activism,
\end{abstract}


showed some evidence for the "selling protest" question. And the compiled summary Framing Advantages and Disadvantages yield this study's key finding: Although anticorporate OWS was far larger, with more widespread media coverage, the comparative overall media frame for the small, remote, anti-government MRO was far more potent and resonant.

Comparing media-and-movement framing of these distant twin 40-day protest occupations finds some support for the "selling (or underselling) protest" question. This comparative frame analysis helps bridge micro- and macro-theory levels, addressing an enduring dual gap in movement-media research literature - to yield insight on SMs' and media's respective roles in protest news framing and identify potential mechanisms for future research. 
Dedication

For Elizabeth, Charlotte, \& Mom 


\section{Acknowledgments}

Andrew Butz wishes to thank the following people \& organizations for their support of this research:

Damon Becker \& family

S. David Butz

I. Jane Butz

Keith \& Pam Ehrensing

Sam Adams of Portland, Oregon

Sy Adler

Dean C. Amadon

Bo Bartlett

Andrea Blazak-Barrios

Nathan Butz \& family

Jose O. Calderon

Clare Chevalier

Erika Collins

Jean Delmonico \& Bob Hibbing

Justin Denny

Chris Dugan

Russell Duren

Marvin \& Barbara Eby

First Unitarian Portland

Shirlee Geiger

Stephen Greene

Charlotte Hales

Andrea Hinze

KBOO Community Radio

Kickstarter.com

Stephen P. Knight
Jessica Lamb

Robert Liebman

William A. Long \& family

Maureen Morrison Long

April Mayers

Paul Nielsen

Leonard Oakland

Tony Obradovich

Tammy Paladeni

Kerry J. Pataki

K. Michelle Pendley

Portland Community College

Armin V. Quilici \& family

Kristy \& Tony Rodriguez

Chris Root

Julie Schlemmer

Jeremy Wilson Band

Carl Winter

Ethan Edwards

Anne Saker

University of British Columbia

Jennifer Chun

Amy Hanser

David Tindall

Rima Wilkes

Dan Zuberi 
Table of Contents

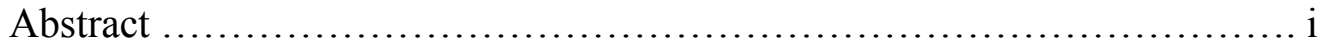

Dedication........................................................... ii

Acknowledgments ................................................. iv

List of Tables .................................................... vi

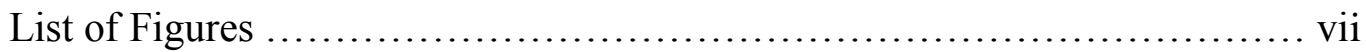

Chapter I

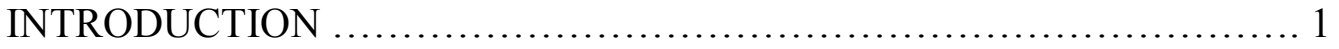

Chapter II

THEORY \& LITERATURE REVIEW ................................. 10

Chapter III

Movements \& Media Opportunity Structure:

AN ADAPTED RESEARCH MODEL ..................................... 66

Chapter IV

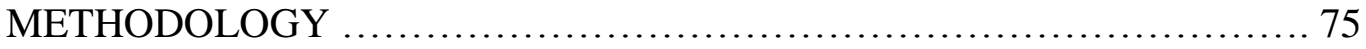

Chapter V

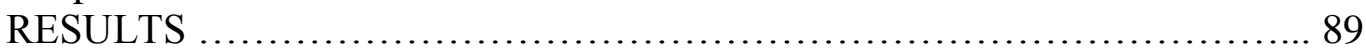

Chapter VI

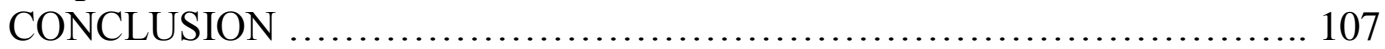

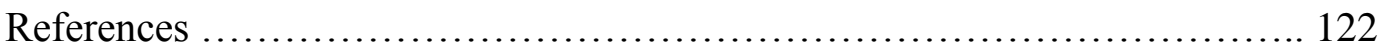

Appendix A. Transnational Social Movements ........................... 133

Appendix B. The Sample $(n=60)$..................................... 134

Appendix C. Sample Coding Glossaries .................................... 136

Appendix D. Coding Templates ......................................... 138

Appendix E. Summary Data (Code Sheets) .............................. 141

Appendix F. Pilot Study ................................................. 145 


\section{List of Tables}

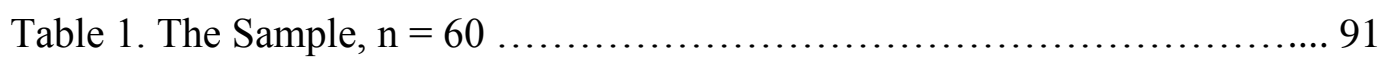

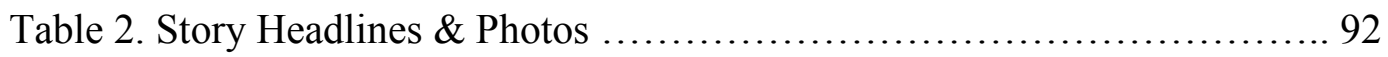

Table 3. Headlines \& Captions:

Collective Action Component Frequencies ................................ 92

Table 4. Headline-Story Disagreement ................................ 93

Table 5. Attribution Frequencies: Source Type by Protest News Sample ........ 95

Table 6. News Sources \& Unsourced Portrayals ............................. 96

Table 7. Attribution Frequencies:

Source Type by Preferred Commercial-Government Perspective .............. 98

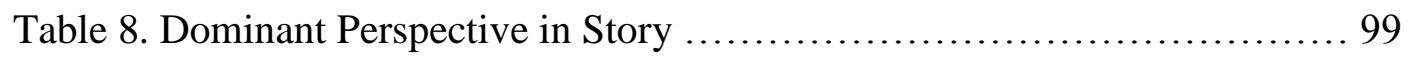

Table 9. Portrayal of Activists:

Collective Action Frame (C.A.F.) Components .......................... 101

(Frequency of C.A.F./Path X Components by Commercial-Gov. Perspective)

Table 10. Frequency of Complete Collective Action Frames .................. 101

Table 11. Portrayal of Activists:

Dispersed Passivity Frame (D.P.F.) Components ......................... 103

(Frequency of D.P.F./Path Y Components by Commercial-Gov. Perspective)

Table 12.

Ratio of Collective Action to Dispersed Passivity Frame Components .......... 104

Table 13. Portrayals of Rational SM Actors ............................. 105

Table 14. Commercially-Framed Activism ................................ 106

Table 15. Selling Protest? Summary Framing Advantages ..................... 108 (An enabling Media Opportunity Structure)

Table 16. Under-selling Protest? Summary Framing Disadvantages ............. 111 (A constraining Media Opportunity Structure) 
List of Figures

Figure 1. ADAPTED RESEARCH MODEL ................................ 74

Figure 2. NEWS STORY CODING TEMPLATE ........................... 84 


\section{Chapter I}

INTRODUCTION 


\section{A Story of Two Protests}

Are anti-systemic protest occupations on the Left and on the Right comparably covered by major media outlets? This study explores how social movement (SM) messages and claims are framed within commercial news. Any SM, especially if antisystemic or if anti-corporate, has only partial frame setting agency, which points to the core theoretical question. Seeing SMs and media as interacting systems, 1) are news frames and framing ${ }^{1}$ more media- or more movement-driven; and 2) do media at times constrain SMs as much as they enable them? With these underlying questions, a comparative discourse analysis will also ask how commercial news - shown by coverage of ideologically opposed or distant twin occupations - may "sell protest"; and so this study can offer broad movement-and-media framing research insights.

With Occupy Wall Street in 2011 (OWS) on the left and Malheur Refuge Occupation in 2016 (MRO) on the right, both protests encamped in Oregon (or beyond for OWS) for roughly 40 days before final evictions. Despite contradictory goals, of anticorporate OWS and anti-government MRO, their occupation strategies and duration were similar. So, beyond their opposing protest cultures (small, armed rightwing MRO vs. large, unarmed left-leaning OWS), were their news frames relatively comparable? Or do imbalances or inconsistencies external to the basic OWS-MRO protest culture differences (see below) perhaps reflect larger institutional patterns of commercial news? From such questions, this study develops a model and research design in Chapters II - III, to conduct an innovative news discourse analysis whose findings in Chapters IV - V may contribute theoretically and methodologically to future research.

${ }^{1}$ interpretive schema and meaning construction processes (also see Chapter II, Part A, section 1) 
To briefly review the two protests' overlapping stories: OWS and MRO had roughly 40-day, anti-systemic occupations in Oregon (60-day at some other OWS sites), accompanied by extensive online or social media activism - and considerable national/ international news coverage. They established unauthorized encampment occupations that, while publicly appearing as spontaneous, were initiated by planned protest rallies that grew from strategic organizing efforts. After ongoing news of locals' impatience, both occupations were then evicted, with federal authorities more visible at the armed MRO - which had more serious legal charges (and larger per capita costs/ casualties), although most were reduced or exonerated.

The two protests were four years apart and in many ways mirror opposites. Their mobilization backstories: The movement-named Occupy Wall Street (OWS) was an urban Left-leaning convergence of Adbusters' anti-branding web meme with local autonomous-anarchist organizing, that first occupied New York City's Zuccotti Park near Wall Street from Sept. to Nov. 2011, joined by hundreds of affinity sites such as Portland from Oct. to Nov. (Schwartz 2011) The media-named Malheur Refuge Occupation $(\mathrm{MRO})^{2}$ was a rural Rightwing offshoot of Patriot militia movements (especially a 2014 Nevada Bundy ranch standoff) and 1970s-80s Sagebrush Rebellion, that occupied federal public land at Malheur National Wildlife Refuge headquarters from Jan. to Feb. 2016.

These distant twins also had mirror SM cultures and goals (e.g., Lofland 1995): Anti-corporate OWS or the 99\% were intersectionally diverse (though mostly aged 2040), unarmed, unaffiliated pluralists, who occupied private space (in NYC) and used non-

\footnotetext{
${ }^{2}$ (Or self-named Citizens for Constitutional Freedom, with other Patriot militia affiliations. See Chapters II and VI, for further discussion of SM naming - including the name "occupation".)
} 
hierarchical democratic methods - among several hundred to a few thousand activists to especially demand prosecution of financial crimes and reforms such as debt relief (e.g., Schwartz 2011). Anti-government MRO, including the Three Percent, were mostly homogeneous middle-aged, armed white male Christians, who occupied (and restricted) public space and often used traditional authority and kinship affiliation - among a few dozen to one hundred activists - to demand public lands be transferred to states/localities for private resource use (The Oregonian 2017). Then immediately preceding their final Oregon evictions, OWS held large public protest rallies - while armed MRO holdouts had tense negotiations with FBI and state authorities, mediated by national \& regional political and religious figures.

\section{Occupy Wall Street (OWS) vs. Malheur Refuge Occupation (MRO): Comparative Timelines \& Objectives}

The OWS name was internationally launched online by Adbusters foundation, to begin occupying on Sept. $17^{\text {th }}$; yet the ensuing fall 2011 Wall Street encampment was built on the preceding summer's grassroots and online labor and anarchist organizing against economic corruption/ injustice, which was also inspired by anti-systemic springtime protests in the Arab world and Spain (Schwartz 2011; also Castaneda 2012). Within weeks, OWS protest spread worldwide to dozens of cities (mostly) and reflected a strategic tension between the aim of swiftly conveying a concise grievance versus the slow, horizontal process of consensually representing the diverse participants (Schwartz 2011; Calhoun 2013). By early October, with hundreds encamped or thousands rallied at many sites (from lower Manhattan to Portland, OR), news coverage especially grew as police increasingly surveilled and arrested protesters (ibid). Despite the "OWS" slogan's 
bold claim (Pickerill \& Krinsky 2012), news typically focused on lively antiauthoritarian protest cultures whose assembly-elected facilitators were often less plainly visible than conventional leader-spokespersons would be. As local business and government officials grew impatient with nascent reorganization of public spaces, such as by OWS general assemblies' varying degrees of participatory governance, authorities (often coordinating nationally) then evicted most Occupy encampments within 40 to 60 days. (Calhoun 2013; Halvorsen 2015; Matthews 2018)

The 2016 MRO began on Jan. $2^{\text {nd }}$ when a few dozen armed Patriot militia members, initially led by former rancher Ammon Bundy of Citizens for Constitutional Freedom, took over Oregon's Malheur National Wildlife Refuge headquarters - after splintering from a nearby Burns, OR protest of federal arson sentences for two Harney County ranchers (The Oregonian 2017). The mostly non-local militants declared that they would occupy, in protest of federal land policies, until the ranchers were freed or local property owners gained control of the Refuge (ibid; also Gallaher 2016; Rydgren 2018). Bundy and family, especially father and Nevada rancher Cliven Bundy who led a 2014 armed standoff with federal agents over his unpaid grazing fees, represented an older sagebrush rebellion converging with more recent anti-government Patriot militias (The Oregonian 2017). The mostly white male, conservative Christian activists of MRO used daily press conferences and also social media to demand that federal lands - especially Bureau of Land Management - be transferred to ranchers and loggers (ibid.). Beyond the Wild West style occupation tactics, news coverage emphasized local residents' and authorities' growing calls for occupiers' decampment (e.g., The Oregonian 2017). After 40 days of sometimes violent tensions with conservationists, Burns Paiute Tribal 
members, and law enforcement, the FBI - assisted by political and religious leaders negotiated the final occupiers' surrender. (The Oregonian 2017)

As these comparative timelines suggest, stark cultural and structural differences between OWS and MRO undoubtedly influenced how news media covered each occupation. For example, the subsequent chapters suggest that the movement-chosen “Occupy Wall Street” name was in itself linked with certain framing advantages - while MRO's small, unified protest culture was linked with others. Yet this study's theoretical model and methodology will in part aim to highlight those news framing dimensions that extend beyond a SM's direct influence - and require analysis of media's role as interacting systems.

\section{A Framing Research Model: Adapted MOS as a Micro-Macro Bridge}

Comparing how commercial news frames contrasting anti-corporate and antigovernment SMs can more broadly suggest how media-movement interactions affect message resonance - and help address gaps in the literatures for movement framing and for media framing. In this dual gap, the more influential movement framing models accent SM cultural narratives over structural contexts like media influence (Benford \& Snow 2000), while media framing models are more contextually embedded yet downplay movement agency as well as empirical measures (Scheufele 1999). ${ }^{3}$ The key context, from a production perspective on media's hierarchy of influences, sees global economic mechanisms putting profitability over cultural actors to thus over-commercialize news content. (Croteau \& Hoynes 2014; Lule 2015; Shoemaker \& Reese 1991)

\footnotetext{
${ }^{3}$ Also see Gamson (1998) and Gitlin (1980), versus Snow, et al. (1986) and McCarthy \& Zald (1977).
} 
To bridge this paradoxical dual framing gap, I adapt the research on SM collective action frames, in a context of media opportunity structure ${ }^{4}$ [MOS] (Gamson 1992; 1998). As detailed below, a preliminary MOS-based question is: If news often commercially frames key movement dynamics, and a SM does not sell (e.g. it has anti-corporate messages or is officially blocked), then is the frame neutralized such as by countervailing dispersed passivity frames? (Butz 1997) The dispersed passivity frame adapts Gamson's MOS, to detect media potential to not only enable but also constrain movement opportunity - allowing fuller comparison of framing for distant twin protest episodes. These left- $v s$.-right occupations, OWS in late 2011 and MRO in early 2016, thus offer compelling contexts to compare mirrored protest frames during turbulent years for traditional news - as closures or cutbacks left journalism gaps not yet filled by rising 'new media' (Gans 2018; McChesney \& Nichols 2010; Pew Research Center 2018).

With these constraints that media may pose for SMs needing further research (see Chapter II), the adapted MOS model (in Chapter III) guides news content analysis of the 'unequal twin' protest episodes (in Chapters IV - V). This study, seeing media as not only enabling but also constraining, specifically asks how commercial news framing of collective action may: 1) commercially frame or sell even anti-corporate movements; or 2) instead marginalize or neutralize such movements. Exploring these questions, by comparing the media-movement framing of the OWS-MRO distant twin protest occupations, thus bridges micro- and macro-level theory and may address the dual gap in movement-media research literatures further detailed in Chapters II and VI.

\footnotetext{
${ }^{4}$ (defined as the various linkages between mass media and carriers of symbolic interests)
} 


\section{Selling Comparative Protests in Transitioning News Media: Design, Methods, \& Findings}

This study's research design applies news frame analysis to compare OWS in 2011 and MRO in 2016. And the time period sampled, during the active encampments/ occupations in Portland and NYC (OWS) and in Malheur Refuge, Oregon (MRO), also corresponds with transitional years in commercial print news media. U.S. newspaper circulation has sharply declined, especially since 2011, to the lowest levels since the Great Depression (Pew Research Center 2018). Some outlets like The New York Times have had less severe declines during this period, yet record numbers of newspapers have closed or cut back - such as The Oregonian ending daily delivery and switching from broadsheet to tabloid. Despite such change, including readers and advertisers rapidly switching to online/digital news, total daily newspaper circulations still exceed the number of unique daily news website visits (Pew Research Center 2018). So the newspaper content central to this study, while also available online, remains essential to discourse in the wider public sphere.

The protest episode coverage, from three top national or state newspaper outlets (The New York Times, USA Today, and The Oregonian), was analyzed using random samples from the whole population of stories published during the occupation periods. A textual content analysis, based on inductive approaches, then yields both qualitative and quantitative findings - including frequencies of the constituent frames of MOS. These frequencies (see Chapter V Tables) in conjunction with framing glossaries (Appendix C) especially indicate the relative volume/prominence and resonance of a SM's collective voice (Johnston 2002, 2005; also see Michel, et al. 2011). 
Comparing the unequal or distant twin protests as covered by transitioning media, in part suggests how commercial news framing sells protest - and thus not only frames SM resonance but at times neutralization. As an initial, pre-analysis shallow frame, news often portrayed OWS (protesting economic injustice or corporate excess/ commercialism/ commodification $^{5}$ ) as 'sympathetic but silly rabble-rousers'; while MRO (protesting political injustice or government/ regulatory excess) was portrayed as 'disciplined and formidable opponents'. Yet beyond these initial frames, the deeper analytic results suggest a news frame for OWS - despite being the far larger, more accessible and widely covered protest episode - that was somehow less potent, vocal and resonant than for MRO. So in exploring how recent media framing may sell protest news, this study not only suggests potential framing mechanisms for future research - but also suggests that perhaps some protests are "more equal than others".

\footnotetext{
${ }^{5}$ i.e., transforming previously non-market, non-monetized things to commercial content and use, especially corporate profit. Marx popularized the term commodity, but commodify was not officially recognized in the U.S. until 1982 (Merriam-Webster). Also see Appadurai (1988); Ertman \& Williams (2005); http://www.rushkoff.com/commodified-vs-commoditized/ .
} 


\section{Chapter II}

THEORY \& LITERATURE REVIEW

Part A

SOCIAL MOVEMENTS in a GLOBAL MEDIA ERA: Integrating Framing and Political Process Perspectives, to Compare Contrasting Movement Episodes 


\section{INTRODUCTION}

Recent protest episodes, Occupy Wall Street in 2011 and Malheur Refuge Occupation in 2016, were strong reminders that news coverage is profoundly important for social movement (SM) struggles on the Left or Right (Rucht 1996: 212; Benford \& Snow 2000; Gamson 1992; Johnston \& Noakes 2005; Walgrave \& Manssens 2005). Research however has often suggested that mass media are as likely an obstacle to movements as an asset (McAdam 1996b: 346; Gamson \& Meyer 1996: 285-86; Gitlin 1980; Johnston \& Noakes 2005: 19, 89; Klandermans \& Goslinga 1996; Smith, et al. 2001; Tarrow 1998: 117). And questions about movement obstacles, whether due to news coverage or other factors, typically involve the crucial meso-level processes of social movement (SM) demobilization and also counter-mobilization.

Yet movement and media dynamics are most often studied from a micro-level framing perspective, emphasizing SM actors' agency, while neglecting "the constraints that 'culture out there' imposes" (Benford \& Snow 2000: 622; also Tarrow 1998). Alternatively, the macro-level political opportunity structure or political process theory (POS/PPT) emphasizes outside constraints but neglects actor agency (Johnston \& Noakes 2005). So, between the poles of micro-level framing and macro-level POS, is this gap filled by the traditional meso-level focus on SM mobilization processes? While movement demobilization and counter-mobilization are typically viewed at a meso-level, mass media's role is often under-analyzed (Fantasia \& Stepan-Norris 2007; Gamson \& Meyer 1996; Klandermans \& Staggenborg 2002; Meyer 2007; Tarrow 1998; Voss 1996). 
This chapter reviews literature to show how these commonly noted yet underdeveloped SM research areas - demobilization ${ }^{6}$, counter-mobilization and mass media as structural constraints - if applied to recent protests by connecting micro-level framing perspectives with macro-level POS/PPT can then offer new movement and media insights. Bridging the agency-centered framing approaches with the constraining structures of political opportunity can clarify mass media's role - and yield an innovative model of SM dynamics to apply to contrasting protest episodes in 2011 and 2016. Such an approach can also better conceptualize movements and SM actors, by characterizing them with a 'situated agency' or a 'less constraining structure'. ( $c f$. Giddens 1979)

To explore media as not only movement assets but also obstacles, and perhaps bridge the theory gap between symbolic framing dynamics and mass media structures, I develop the concept of media opportunity structure as an interactive link (Gamson 1998: 63; also Sampedro 1997). This approach analyzes SMs and media as "interacting systems" (Gamson \& Wolfsfeld 1993; also Benford \& Snow 2000; Gitlin 1980; Johnston \& Noakes 2005; Koopmans 2004). However, most such studies focus on ways that mass media help mobilize SMs. While recognizing that adverse or distorted media framing can also threaten movements (Boykoff 2006; Gamson \& Meyer 1996; Gitlin 1980; Klandermans \& Goslinga 1996; Smith, et al. 2001; Sobieraj 2011; Xu 2013), research needs to further specify and model the interactive mechanisms of such threats.

Before modeling such mechanisms for this study's empirical analysis (in Chapters III - IV), Part A of this chapter reviews major SM definitions and literature, focusing in Section 1 on the actor agency of meso- and micro-level resource mobilization and

${ }^{6}$ (as well as related processes of SM marginalization, suppression and neutralization - detailed below) 
framing theories; in Section 2, on the structural constraints of political process/ opportunity theories; and in Sections 3 and 4, on integrating theory with methodological approaches (bridging framing and political opportunity with demobilization perspectives) to outline a broad rationale for adapting Gamson's (1998) media opportunity structure (MOS) for this overall study. In Part B of this chapter, I situate my approach to MOS within news media's recent economic globalization contexts, to then devise a research model addressing elusive movement-media dynamics - especially neutralization. ${ }^{7}$

\section{REVIEWING SOCIAL MOVEMENT PARADIGMS: Toward an Integrated Model for How Movements \& Media Frame Opportunity}

Social movement scholarship - reflecting structural and cultural theory paradigms that highlight resource mobilization and contentious repertoires, political process or opportunity, and framing - has often emphasized theoretical integration (e.g. Benski, et al. 2013; Giugni 1999; Klandermans \& Staggenborg 2002; McAdam, McCarthy \& Zald 1996; McAdam, Tarrow \& Tilly 2001; Snow, Soule, \& Kriesi 2007; Tilly 1999). This is partly because each paradigm is limited by its associated level of analysis. The mesolevel, organizational focus on mobilization and repertoires tends to neglect both macrostructural context and micro-cultural processes (Klandermans \& Staggenborg 2002; Meyer 2007; Rucht 1996). The macro-level focus on political process, or political opportunity structures, can overemphasize a determining structural constraint while neglecting actor agency (Johnston \& Noakes 2005). And the micro-level framing

\footnotetext{
${ }^{7}$ Neutralization is when a movement frame of collective action is neutralized within media framing, while demobilization is a movement-centered dynamic that can occur independent of media. (Gitlin 1980: 238)
} 
perspectives' emphasis on movement actor agency is cited for failing to address the "constraints that 'culture out there' imposes on social movement framing activity" (Benford \& Snow 2000: 622; also Tarrow 1998a). At the same time, a major strength of the social movement $[\mathrm{SM}]$ literature is a general openness to new approaches and syntheses (Klandermans \& Staggenborg 2002).

Beyond synthesizing across theory paradigms, scholars continue to stress the need for more empirical research that especially explores movements' relational, contingent and comparative aspects (Caiani, Della Porta \& Wagemann 2012; McAdam, et al. 2001). Among the movement dynamics often noted for further study are processes of demobilization and counter-mobilization, in contrast with movement mobilization (Fantasia \& Stepan-Norris 2007; Gamson \& Meyer 1996; Klandermans \& Staggenborg 2002; Meyer 2007; Tarrow 1998a; Voss 1996). And while often theorized as a mesolevel organizational process, mobilization can hinge on crucial SM-related variables within mass media - which span the micro, meso and macro levels of analysis.

The media's importance to SM struggles "can hardly be overestimated" (Rucht 1996: 212). They are widely theorized as part of a SM's cultural tool kit for promoting mobilization and collective actor agency (Benford \& Snow 2000; Gamson 1992; Johnston \& Noakes 2005; Walgrave \& Manssens 2005). Yet many scholars also report that mass media are as likely a "detriment to the movement as an asset" (McAdam 1996b: 346; also Gamson \& Meyer 1996: 285-86; Gitlin 1980; Johnston \& Noakes 2005: 19, 89; Klandermans \& Goslinga 1996; Smith, McCarthy, McPhail \& Augustyn 2001; Tarrow 1998a: 117). 
My approach extends from the framing subfield in SM research that since the 1980s analyzes movements and media as "interacting systems" (Gamson \& Wolfsfeld 1993; also Benford \& Snow 2000; Gitlin 1980; Johnston \& Noakes 2005; Koopmans 2004). Yet most such studies, with a few exceptions (Boykoff 2006; Gamson \& Meyer 1996; Gitlin 1980; Klandermans \& Goslinga 1996; Smith, et al. 2001; Sobieraj 2011; Xu 2013), focus on how mass media mobilize social movements. And SM scholars who do note the threat of adverse media environments and distorted coverage to SMs, have rarely conceptualized or modeled the specific interactive mechanisms of these threats. ${ }^{8}$ In particular, such potential mechanisms may relate to the areas of: demobilization and counter-mobilization further detailed below. First I explore these by connecting themes in the research literature, to show how this study can fill a significant gap in the SM framing subfield (including by linking to mass media and communications theory).

\section{DEFINING SOCIAL MOVEMENTS}

Defined as sustained networks of collective challenges against powerful opponents (Tarrow 1998), social movements (SMs) are "profound structural change" agents (Rootes 2007: 609). Developing with the $18^{\text {th }}$-century rise of commercial print media (Tilly 1999), SMs are rooted in competing views of the individual to confront institutional structures amidst cultural and socio-political conflict (Touraine 2008 [2001]: 537-542). Thus, they act as schools of democracy and agents to restore the public sphere ${ }^{9}$ (Giugni 1998: xxv; also Habermas 2007 [1996]). Yet SMs and social change history will

\footnotetext{
${ }^{8}$ Such threats, of media undermining movements, have perhaps been more often addressed in communications and media studies literature (e.g. DeLuca, Lawson, \& Sun 2012).

9 (societies' distinct domains of cultural and sociopolitical discourse)
} 
be contested, as SMs "straddle" institutional and extrainstitutional politics, and institutional actors are always "better positioned to claim credit" (Meyer 2007: 74, 22).

Comparing various SM definitions, from the more expansive and synthetic to the more elemental, suggests the range of theory this chapter explores. Sidney Tarrow defines social movements as:

"[part a] ...sequences of contentious politics ...based on underlying social networks and resonant collective action frames, ... to maintain sustained challenges against powerful opponents." And [part b] "collective challenges, based on common purposes and social solidarities, in sustained interaction with elites, opponents, and authorities." (Tarrow 1998a: 2, 4)

Social movements are largely a modern creation, birthed in part by "cosmopolitan, modular, and autonomous" repertoires among class-based coalitions (Tarrow 1998a: 31, 51). Newspapers in the $18^{\text {th }}$-century often became intentional "agents of movement", and so connective structures of print and association (occupational and informal networks) created the national SM (Tarrow 1998a: 46, 52-53). Indeed, citizenship itself emerges by a "rough dialectic between movements - actual and feared - and the national state." (Tarrow 1998a: 66)

For Charles Tilly a SM is "a sustained challenge to power holders" in the name of a subject population - and by repeated public displays of their "worthiness, unity, numbers, and commitment" (1999: 257; also Wouters \& Walgrave 2017). Social movement displays include public meetings, demonstrations/marches, associations/ coalitions, mass media statements, pamphlets, etc. (Tilly 1999: 260). They mobilize in part by political entrepreneurs activating "detached identities" (typically a group identity that is inactive in everyday individual life) and engaging in various repertoires - or activists' usual public efforts (Tilly 1999: 264; also Bernstein 1997). McAdam, Tarrow 
and Tilly also stress that government is typically an object, a claimant or a party to the claims of SMs (2001: 5).

Snow, Soule and Kriesi define SMs as a "fifth estate" marked by episodes/cycles/ waves, that are relatively organized collectivities acting with some continuity beyond institutional channels to challenge or defend various levels of institutional or cultural authority (2007: 5, 11). For Manuel Castells a SM is organized collective action by which a class-actor struggles to "produce new historical meaning" (1983: 301, 331). Culture, collective consumption and politics interact as SMs create "social innovation", with political parties or coalitions as instruments of "social bargaining" (Castells 1983: 294). For McCarthy and Zald a SM is a population's set of opinions and beliefs which favors "changing some elements of the social structure" (1977: 1217-18). And structural as well as cultural change is promoted on three levels - systemic, policy, and power relations. (Giugni 1998: xxv)

Some of this definitional diversity reflects a traditional transatlantic divide, with a European focus on ideology in relation to social structures, versus a U.S. focus on specific protest actions (rooted in collective behavior more than SM theory). Yet as the literature reviewed here suggests, a simple split between American (micro-level, "nominalist and empirical") and European (SMs only as agents of "profound structural change") approaches is less salient today (Rootes 2007: 609). In the following pages, the perspectives (varying by philosophy more than by continent) are highlighted to probe SM paradigms' strengths and weaknesses - especially to conceptualize movement and mass media interactions. While this chapter's sections are initially divided by theory paradigm 
and associated level of analysis, this overall study moves toward an innovative synthesis of theory and method - which reflects wider trends in the SM field.

\section{RESOURCE MOBILIZATION and REPERTOIRES}

- Early Models for How Movements Make Change

Resource mobilization (RM), a meso-level organizational paradigm emerging with the 1960s-70s North American protest waves, focuses on resource access to explain SMs. Partly a response to collective behavior traditions that stressed grievance and strain/breakdown, RM's utilitarian, rational-choice behavioral models explain SMs largely through incentives. McCarthy and Zald defined RM as focusing on interactions between resource availability, "preexisting organization of preference structures, and entrepreneurial attempts to meet preference demand" (1977: 1236). The SM field has widely adopted RM's conceptualization of SM industry structure, centering on social movement organizations or 'SMOs' (McCarthy \& Zald 1977). RM scholars also emphasize tactics/ repertoires and strategy, for example seeing mass media as a resource for SMOs to connect to constituents (Gamson 1990, 2007; McCarthy \& Zald 1977). ${ }^{10}$ Yet the RM view neglects cultural values and wider political context as well as movement demobilization [see below], so it is now less prominent as a singular research focus.

Regardless, RM theory has been crucial to advancing research on SM structure and strategies (Klandermans \& Staggenborg 2002; Gamson 1990). And by highlighting opportunity instead of breakdown (from the earlier theory tradition), RM remains a “powerful explanation for collective action” (Buechler 2007: 61). William Gamson’s

\footnotetext{
${ }^{10}$ Tactics (particularly "embarrassing the target") heavily depend on effective mass media strategies. (Gamson 2007: 259)
} 
classic study of $19^{\text {th }}$ - and $20^{\text {th }}$-century SMOs stressed the decisive role of their strategies in struggles' outcomes, as well as how selective material incentives bind individuals to SMOs (Gamson 1990). The resource concept has also been stretched to include key SM resource attributes, such as moral and cultural resource fungibility and context dependence - reflecting how potential mobilization is "deeply embedded" in social and economic relations. (Edwards \& McCarthy 2007: 142)

SMO forms and tactical repertoires are situated in "everyday life micromobilization structural social locations" (McCarthy 1996: 141). Key dimensions of mobilizing structures include: informal non-movement (e.g. friendship \& work network, neighborhood) and movement (activist network, affinity group, memory community); and formal non-movement (church, union, association) and movement, e.g. SMO, movement school and protest committee (McCarthy 1996: 145). Composite structures facilitate survival and success (Minkoff 2002: 279, 261), such as in U.S. anti-toxics' grassroots SMO forms - following Alinsky's rule that SMs avoid tactics outside the people's experience (McCarthy 1996: 149). Additionally, nonviolent direct action and media strategies help environmental SMs (e.g. Greenpeace) ${ }^{11}$ avoid institutionalization and decline (Rootes 2007). Similarly, in $19^{\text {th }}$ - to early- $20^{\text {th }}$-century labor movements, ${ }^{12}$ political rather than fraternal (Knights of Labor) or military (Coxey's Army) SMO forms/ strategies prevailed, because they partly overlapped with "mobilizing structures embedded in society" - such as formal institutions and mass media that transmit scripts

\footnotetext{
${ }^{11}$ Also used by E.Bloc/Soviet activists to promote democratization, such repertoires were decisive in the regimes' collapse. (Rootes 2007)

${ }^{12}$ A turning point for media's role in SM "mobilization and influence" (Clemens 1996: 219)
} 
for action ${ }^{13}$ (Clemens 1996: 226). Thus organizational forms "must be familiar but not too much so" (Clemens 1996: 210; also Cornell 2011; Hewitt \& McCammon 2005). ${ }^{14}$

Structural transformations among new social movement organizations (NSM; see page 33) may include: institutionalization (e.g. party/interest group), commercialization (paid service provision), involution (social incentives, self-help, club) and radicalization or reinvigorated mobilization (Kriesi 1996). Subcultural movements tend to either commercialize or turn inward, and instrumental movements (especially ecology) tend to institutionalize (Kriesi 1996). Moreover, NSM structures are found to coincide with social networks, where denser networks have higher levels of collective action - although network analyses may overlook mobilization via cultural transmission [see below]. (Diani 2007: 347; Castells 2012; also McAdam et al. 2001)

RM research has shown how educated, middle-class activists joined SMs like civil rights (that were especially bolstered by mass media); and information/resources can proliferate protest and SMOs - which institutionalize as they function for advocacy as well as resource acquisition (Meyer 2007: 47, 159). To help prevent such institutionalization from "stifling protest” (after Michels’ Iron Law and Piven \& Cloward), Meyer suggests a loosely federated structure, e.g. War Resisters League, IWW, or 1980s antinuclear affinity groups $(2007: 36,66)$. Such alternative organizational models, with intensive cultures demanding individual commitment (e.g. Catholic Worker or SNCC), often follow a dual-track pattern: service provision (stressing professionalized stability) versus a political activism that often remains small/marginal (Meyer 2007: 74). SM

\footnotetext{
13 (also see Goffman 1974 and/or Bourdieu)

${ }^{14} \mathrm{SMs}$ " "major symbolic dilemma" is between forms so familiar they breed passivity, versus those too unfamiliar to activate. (Tarrow 1998a: 107)
} 
specialization also works by "cooperative differentiation", such as how Friends of the Earth spun off from Sierra Club and Sea Shepherd (and Ruckus Society) from Greenpeace (Meyer 2007: 78). ${ }^{15}$

SMs target activists, supporters, authorities - and the bystander publics whose response is often paramount (Meyer 2007: 12). And their strategy (combining claims/ demands, tactics and sites/venues) increasingly uses media - toward which performative tactics (from 'individual/ moralist' to 'collective/ instrumental' actions) are directed (Meyer 2007: 82, 94, 105, 87). Civil disobedience for example, often in affinity groups (e.g. anti-corporate globalization and the wider nonviolent direct action movement), can extend political conflicts' scope and punctuate protest cycles (Meyer 2007: 122, 117). Among SMs' key resources is potential disruption of daily life, so to maximize influence (e.g. via media) ${ }^{16}$ movements "diversify and innovate tactically" (Meyer 2007: 101, 118). Yet as more conventional actions may generate little attention (or 'critical discourse moments' of issue salience), SMs' "actual range of tactics...remains relatively narrow". (Meyer 2007: 100)

SMs are sustained by three major resources (Tarrow 1998a: 89) - two of which also imply theory beyond RM. First, contentious repertoires - such as marches that derived from ancient, somber religious processions - have often transformed especially since 1968 to "ludic symbolism, outlandish costume" and popular chorus (ibid: 103). Second, cultural frames represent SMs' alternative mobilizing beliefs and identities,

\footnotetext{
${ }^{15}$ While coalitions generally help advance a movement cause [see Rose 2000, below], they also may intensify movement dynamics of growth and decline. (Meyer 2007: 75, 79)

${ }^{16}$ Mass media contexts professionalize and routinize disruption - social movements' "strongest weapon". (Tarrow 1998a: 98)
} 
enacted through performances and mass media (ibid: 107, 119). Third, informal networks ("partly autonomous and contextually rooted local units linked by connective structures"), which are most effective in mobilizing as loose umbrella organizations, emerge in everyday life through webs of nonhierarchical relationships (ibid: 124, 128). Democratically decentralized SMs were theorized in the 1960s-70s to break the Iron Law, and American community organizers (e.g. Alinsky's community action organization) then extended models of "decentralized, segmented, and reticulated organization into practical activism" (ibid: 130). From extensive impersonal network-like connective structures or franchises (e.g. Greenpeace) to intimate affinity groupings, networks are delicately balanced between formal organization/institutionalization and autonomy/isolation. (ibid: 137-39)

These versions of RM suggest it is just a partial SM approach, and the critiques that its structural reification neglects power, culture, and demobilization - point toward the other paradigms below. For example, reification mistakes the organization, actors or actions (e.g. marches) for the wider movement, and it obscures larger socio-cultural forces (Giugni 1998; also Castells 1983). Also, stressing SMO incentives can neglect other key predictors of SM participation, such as peoples' prior community activity and relations. That is, a rational actor model neglects crucial alternative motivators, e.g. slack time, cultural capital, norms of delayed gratification, moral self-identity, solidarity (Meyer 2007: 50-51), that help counteract the free rider problem. ${ }^{17}$

\footnotetext{
${ }^{17} \mathrm{SM}$ free riders were found to be a problem only when a few initial participants sufficed to produce the collective good (Marwell \& Oliver in Klandermans, Staggenborg \& Tarrow 2002). And the alternative motivators typically come from idioculture [see Framing... section below] - nonmaterial resources and symbolic goods, e.g. ideology, ritual and physical action. (Fine 1995: 131)
} 
While RM was the first to highlight deliberate SM mobilization (as supply-side, organization-led "marketing mechanism"), it neglects the demand-side of how people are pushed to act (Klandermans 2007: 361). To connect demand with supply - the consensus mobilization processes that disseminate SM views - the cultural and framing approaches are explored next (ibid: 369). Yet, to explain why both supply and demand may weaken (when people disengage and SMs demobilize), more research is needed (ibid.; Tarrow 1998a). And the dynamics and structure of demobilization (as well as neutralization) require focusing not on the bounded SM group - but on "larger configurations" of institutional power relations (Fantasia \& Stepan-Norris 2007: 571). This comes later in this part of the chapter [see Structural Theories... section below], but RM theory's first inadequacy is in explaining subjective, cultural dynamics (Fantasia \& Hirsch 1995). In other words, RM downplays the content of the movement or 'the why behind the how', especially by neglecting the cultural narratives that transform biography into history and are "the greatest assets" of any SM to make change (Fine 1995: 142, 136-39).

\section{FRAMING \& CULTURE}

Cultural framing, the major stream in SM literature's cultural-linguistic turn, emphasizes micro-level mobilizing norms/values, cognitive processes, rhetoric and discourse - and is the dominant perspective (versus resource mobilization/RM or political opportunities/POS) linking movements and mass media. Emerging partly in response to American structural RM and European New Left/New Social Movement (NSM) perspectives, framing reasserted actor motivations/grievances, but its focus on movement actor agency - instead of on contexts for media discourse/framing - also has limitations. 
First, to explore this core perspective of frames (interpretive schema) and framing (movement-related signifying work and meaning construction), it must be situated within the wider cultural approaches to SMs (Benford \& Snow 2000: 612).

Cultural analysis - of subjective, cognitive SM elements within dominant culture's codes, institutions and values - is “difficult to define operationally" (Johnston \& Klandermans 1995: 3). Movements are a key source of cultural change, working in “cracks and fissures" [also see NSMs below] of dominant culture (ibid: 4-5). As a leading cultural perspective, framing strikes a balance between systemic (positivist, static, constraining) and performative (creative, changing, toolkit) views of culture (ibid: 8). Social psychology and cultural analysis converge to explore meaning construction through public discourse, persuasive communication (mobilizing consensus) and confrontational consciousness raising (ibid: 10). Organizational analyses often focus on how SMs strategize their actions toward mass media, while wider views [e.g. see Gamson below] explore media discourse impacts on movement collective action frames (ibid: 8 , 11). Regardless, any static descriptions of SM cultures (with their diverse subcultures, countercultures/ radical cells, consensus-based processes, and "checkbook movements") are inadequate. (ibid: $12-15$ )

Movement culture - which acts in (and is acted on by) a wider culture - is largely created performatively, as subcultural and SM processes yield mobilization. From Weberian 'nominalist' to Swidlerian individualist/ 'cultural stock' approaches, cultural framing scholars focus causally with evidence-based logic - to accent "key junctures" in movement development and relate cultural artifacts to subsequent change in collective action (Johnston \& Klandermans 1995: 15-17). While SMs are "shaped by culture", 
scholarship mostly highlights how actor agency forms and transforms culture (ibid: 20). Yet the core issues of SM lifecycles, beyond cultural factors, also involve economic and structural "determinants of mobilization" (ibid: 22). Thus, a balanced cultural framing view will ask how: 1) culture stimulates or frustrates SMs, 2) framing activities "penetrate the black box of mental life" to affect behavior, and 3) interacting individuals create SM culture - and how much that fosters or hinders mobilization. (ibid: 23)

Analyzing SMs within a wider field, Anne Swidler asked how culture may work "from the outside in" (1995: 39). After Geertz shifted to studying culture for meanings (not effects on action, like Parsons/Durkheim/Weber), more recent approaches see how culture influences action via symbols, vocabularies, and "emotional repertoire" (Swidler 1995: 27). Studying meanings of text/ ritual/practice and discourse entails grasping culture as public symbol and semiotic code - accenting where human agency and institutions intersect with power $^{18}$ (ibid: 28,30 ).

SMs formulate new cultural resources, demonstrating that culture and power are fundamentally linked. Sources of cultural power (effects from the outside in) include: codes, interactions, and institutions - which also shape SM cultures (Swidler 1995: 3237). And to analyze culture as a global collective property, Swidler's "Durkheimian suggestions" are that: "culture's power is independent" of people's beliefs, it shapes our interpretive knowledge, can consistently and coherently effect action in particular contexts, and can be shaped by institutions - "patterning channels for social action". (1995: 39)

${ }^{18}$ (e.g. see Weber, Foucault \&/or Bourdieu) 
Beyond a Swidlerian 'tool kit', culture is contested terrain where counterhegemonic cultural expression - e.g. a traditional Algerian 'veil' (or an Occupy tent) as "symbol of defiance" in socially structured havens of resistance - is a strategic decision for a SM's oppositional character (Fantasia \& Hirsch 1995: 145-157; also Benski 2013; Halvorsen 2015; Matthews 2018). Such "spheres of cultural autonomy” (e.g. havens, submerged networks, abeyance structures) show how SMs" "interpretive schemata" adapt to and modify dominant culture's elements (Taylor \& Whittier 1995: 163, 168). This agency-over-structure thesis sees how structures channel protests that, "paradoxically, break the bounds of the same structures" (Klandermans \& Staggenborg 2002: 17; also Matthews 2018). However, this study also considers the contrasting view - that people usually experience culture as constraining "rather than as optional tools for action." (McAdam, et al. 2001: 119; Halvorsen 2015)

How do we effectively analyze SM influence on culture (and vice versa), especially if movements contest a culture's conventional wisdom? (Billig 1995) Such structure-agency dualisms are central to exploring the crucial SM aspect of collective identity, conceived largely as an action (forming a 'we' that actors never fully control) in a solidarity network of emotion-invested interactive relationships (Melucci 1995: 42-62). A group's shared self-definition derives from common interest, experience and solidarity - shaped and deployed by interaction rooted in SM communities as well as political opportunity and resources (Bernstein 1997; Taylor \& Whittier 1995: 172). Often expressed as an oppositional 'we' versus 'they' (Gamson 1995), a collective identity (CI) has micro and macro structural consequences and outcomes, as self-naming affects 
strategy, resources and discursive boundaries, from aboriginal to anti-corporate SMs (Jenson 1995: 115; Klein 2002).

Such contested processes, in SM naming and other movement identifiers, suggest certain structural constraints on CI and movement culture ${ }^{19}$ (Lofland 1995: 197). For a social constructionist view of how SM members may think in relation to the wider society: discursive psychology probes language as action in repertoires within social context; and rhetorical psych finds that within argument/discussion we can observe "thinking in operation," as meaning depends on context, and positions develop in argumentation - so "one often discovers what one thinks by hearing oneself argue" (Billig 1995: 64-66, 70-71). Moreover, a key paradox is in the creative yet repetitive basis of rhetoric, in that common sense themes can "pull in contrary directions" (ibid: 73). Gramsci cautioned that "philosophies of past ages become sedimented in commonsense thinking"; and so SMs, as "arguments against prevailing versions of common sense" (Billig 1995: 77-79), have long affected prevailing ideologies - from democracy and feminism to labor rights and ecology.

While SMs' radical challenges to the status quo were traditionally analyzed by focusing on activists' impassioned behavior (still a common focus in popular media), such analyses have receded (e.g. on ritual and emotions, see Taylor \& Whittier 1995). Then, a shift to deliberate, strategic SM activity partly reflected research showing an inconsistent role for extreme/dramatic or emotional displays in movement success (Cadena-Roa 2005: 73; Goodwin, Jasper \& Polletta 2007; Hewitt \& McCammon 2005;

\footnotetext{
${ }^{19}$ For example, the 'dilemma of movement culture' - is of having typically strong-but-authoritarian [e.g. MRO] or weak-but-democratic [e.g. OWS] group forms. (Lofland 1995: 206, 215)
} 
Tarrow 1998a: 111; but also Gamson 1990). Research still addresses emotions (e.g. Benski, et al. 2013), but as part of larger interactive cultural enactment, where SM idioculture (belief, knowledge, meaning, behaviors, customs, CI) is constructed via narratives - particularly as talk or as action in SM communication networks (Fine 1995: 128-132). And such elements may then be interpreted as text [see below] for analysis among wider cognitive mobilization processes (ibid: 135; Tarrow 1998a: 111).

\section{Movement Framing vs. Media Framing}

Culture and individual cognition are bridged by the framing paradigm (Gamson 1992) - movement related signifying work and meaning construction to influence interpretive processes (Benford \& Snow 2000; Noakes \& Johnston 2005). Frames, as interpretive cognitive schema defining a situation (Goffman 1974), were applied to SMs by Snow and colleagues for an ideologies focus (1986) - and by Gamson (1992) for a schema focus (Noakes \& Johnston 2005; Zald 1996). The movement framing emphasis (movement as frame-setting variable) - stressing SM action for cognitive liberation and to air grievances (Snow, Rochford, Worden \& Benford 1986: 467) - has been more influential than the media framing approach (mass media as frame-setting variable, e.g. Gitlin 1980). Between the former (micro-cultural agency) and latter (mass media structural constraint) approaches, this framing literature asymmetry or dual gap also reflects wider SM debates such as between RM and political process theories. The next chapter then outlines my research model to compare protest framings - and thus help bridge this theoretical disjuncture between the core movement paradigms.

Frame and discourse analyses accent culture and language by employing close textual, rhetorical, narrative, dialogic, or story-grammar analyses of SMs [see Chapter IV 
Methodology]. Discourse analysis (from semiotic, structuralist, postmodern and poststructuralist approaches to institutions as contested domains) underscores SMs as agents of cultural change through interpretive packages and discursive strategies that frame, give meaning to or reinterpret contested issues in public discourse (Taylor \& Whittier 1995: 182-186). Inextricably linked to cognitive processes, frame and discourse approaches emphasize interactions and grievances; and so these micro-frame analyses help explain SM content and success (Johnston 1995: 234, 244) - yet they can lack conceptual clarity, theoretical coherence and reliable measures. (Johnston 2002)

The framing scholarship, after Gitlin's classic analysis of the antiwar New Left and media frames ${ }^{20}(1980)$, shifted from a media to a political actor emphasis - in conjunction with the wider critique of SM literature as overly structural (Noakes \& Johnston 2005: 3). Scholars Gamson and especially the more influential Snow and colleagues shifted focus from negotiation of meaning, toward SM entrepreneurs' strategic activities (ibid: 5). These activities include diagnostic, prognostic and motivational framing (Benford \& Snow 2000: 615), while Gamson instead describes identity, agency and injustice frame components (1992). The theorists differ most over injustice (often from structural sources), as Benford and Snow argue that not all collective action frames have an injustice component (2000: 615), ${ }^{21}$ yet many scholars posit that real SM frames are always oppositional and therefore stress injustice (Tarrow 1998; Tilly 1999; Touraine 2008). Moreover, while entrepreneurial SM frames deploy

\footnotetext{
20 "persistent patterns of cognition, interpretation, presentation" (Gitlin 1980: 7)

${ }^{21}$ Such as in religious or self-help movements
} 
cultural symbols, seeing frame resonance ${ }^{22}$ as coming only from its makers, receivers and the frame itself, thus neglects structures like mass media and the state - with their often distinct advantage as framing opponents. (Noakes \& Johnston 2005: 15-17)

For observing movement outcomes, Snow and colleagues acknowledged neglecting external factors like framing hazards (1986: 477); and so framing is sometimes narrowly defined only as conscious strategies to promote mobilization (McAdam, et al. 1996: 6-8). For example, frame alignment (of individual-with-SMO interpretive frameworks) is crucial to participation and includes bridging, ${ }^{23}$ extension, transformation and foremost amplification - and all are factors for SM frame resonance and thus success (Snow, et al. 1986: 467; Noakes \& Johnston 2005). While it is widely agreed that framing outcomes and overall perceptions of movements are also shaped by mass media's structure and processes (McAdam, et al. 1996: 17-19), such aspects need fuller explication for framing research models [see Part B and Chapter III below].

Gamson pioneered comparison of SMs' external with internal factors (Giugni 1999), seeing SM actors as particularly focused on public discourse in general-audience media (Gamson 1995). His analysis of focus group responses to public issue news coverage found collective action frames ${ }^{24}$ - action oriented beliefs and meanings that promote SM activities and are crucial to SM outcomes - emerge in movement-mediaopponent-bystander interactions (Gamson 1992; 1995: 89). With a news media context that combines the cultural with the personal to convey cultural resonance or potency, the

\footnotetext{
22 i.e. narrative credibility and relative salience (Benford \& Snow 2000: 617)

23 of "ideologically congruent, but structurally unconnected" frames (Snow, et al. 1986: 467)

${ }^{24}$ also defined as an "aggregation of numerous individual interpretative schemata around an average" (Johnston 2005: 239)
} 
movement-media collective action frame has three components - injustice (a "hot cognition"), agency, and identity (Gamson 1992; 1995: 90). Yet the issue-specific news portrayals of collective agency (i.e. practicable volition) are inconsistent, often favoring personality and drama over factual analysis and portraying collective actors as an indistinct (and disempowered) aggregate such as the "blurry 'they"' of 'citizens' (Gamson 1992; 1995: 101). So to avert media's possibly confounding effects, Gamson suggests an "integrated resource strategy" where SM actors use experiential knowledge relevant for broader collective action frames - or create situations where actors acquire “experiential knowledge of injustice.” (ibid: 105)

Similar to media effects scholars and Gitlin (1980), who ask how media may influence movements, Gamson stresses media's role in meaning construction and collective action frames (1995). More specifically, as media images interact with audiences' varied cultural and personal meanings (ibid: 87), for resonance the related SM injustice frames need concrete narratives rather than structural abstractions such as 'the system’ or ‘society' (Gamson 1992; 1995: 91). However, an overly specific or personalized focus can fragment meanings and obscure power relations and underlying structural conditions; so sustaining collective action requires bridging concrete "hot cognition" with abstract "cold cognition" (Gamson 1992; 1995: 92).

Media promotion or obstruction (or neglect) of collective action frames is thus complex. Oliver and Johnston argue that while framing (akin to SM marketing \& resonating) differs from ideology (as education and thinking), both are empirically observable (2005: 199). Only framing is, argue Snow and Benford, partly because collective action frames reside in "situated social interactions" (2005: 207-210). Indeed, 
measuring ideological statement 'strength' is empirically demanding (e.g. story grammar analysis), but to insist on "primacy of emergent processes above all is to trap social scientists in an interactionist bubble" (Johnston \& Oliver 2005: 214-216). For example, Gamson found what really conveys actor agency, instead of positive or negative framing, is overall media salience - and that media disparage or marginalize SM action at least as often as portraying it as effective (1995: 92-99). Regardless, actors can interpret political opportunity rather than constraint, choosing 'Swidler's toolkit' (Gamson \& Meyer 1996: 287). Yet since mass media can potentially obstruct collective agency, SMOs are often ambivalent toward them as a means of change - even at times seeing them as targets representing what is being opposed. (Gamson 1995: 95, 104; also McChesney 2004)

Departing from Gamson's approach to external constraints like injustice, Benford and Snow's more micro-level focus instead stresses movement agency in framing (2000: 615-622). Yet in acknowledging that framing research had neglected constraints from "culture out there", they described some of its contested processes including counterframing (by opponents/bystanders/media), frame disputes (about reality), frame resonance disputes (how reality should be presented), and the dialectic between frames and events - where discourse affects events or vice versa (ibid: 622-626). Citing the media framing research, ${ }^{25}$ Benford and Snow recognized the need for more nuanced synthetic models of contextual constraint (2000: 626) - and that political opportunity is crucial to collective action frames (Gamson \& Meyer 1996: 285). Still, they maintain that frames mean opportunity more than constraint for movements (Benford \& Snow 2000: 631). In particular, the concept of a master frame or the overriding frame defining a

${ }^{25}$ Such as Gamson \& Wolfsfeld 1993; Gitlin 1980; Klandermans \& Goslinga 1996; McCarthy, et al. 1996 
movement (ibid.; Taylor \& Whittier 1995) links most directly to political opportunity structure (POS) - typically interpreted as political constraint. And while framing and POS are often seen as competing SM paradigms, some theorists argue that framing avoids the risk of "complete depoliticization by its intellectual alliance with political opportunity theory" (Oliver \& Johnston 2005: 200; or see Westby 2005: 229).

\section{Media-Movement Framing, Revisited}

From a pivotal 1960s political context, Gitlin's classic study of media-movement framing explored how movement and media developed an interactive language that all "opposition movements to come would inherit" (1980: 246). He argued that everyday awareness is shaped by media frames,${ }^{26}$ which are negotiated among sources, editors and reporters. For resonance and newsworthiness, frames must adhere to news-making norms such as a narrative structure highlighting conflict (a story's most reliable selling point), and Gitlin further posited that all major social conflicts are partly conflicts over what is news (ibid: 90, 268). Media coverage can be an invaluable affirmation of SM efforts, but in an 'oligopolized' corporate economic context, media often lead rather than follow public opinion. (Molotch in Gitlin 1980: 243; ibid: 8-12; also Part B below)

To approach the varied framing challenges then, research can benefit from comparative frame analysis - stressing causality over description, participation over recruitment and discerning 'frame’ from ‘ideology’ (see Oliver \& Johnston 2005; also Zald 1996) - in order to better operationalize by textual analysis the SM-related variables like mass media (Johnston 2005: 237-238). Since any frame is partly located in a social

\footnotetext{
26 "persistent patterns of cognition, interpretation, and presentation, of selection, emphasis, and exclusion, by which symbol-handlers routinely organize discourse" (Gitlin 1980: 7).
} 
actor's memory, methodologically grounded analyses require rigorous, contextually aware approaches such as time comparisons of texts to help identify key mechanisms of mobilization (Johnston 2005: 243-255; also see McAdam et al. 2001). Texts thus relate to wider contexts of conflicting interests, from movement actors' to mass media outlets' frame inputs (Meyer 2007; Tarrow 1998).

In framing dynamics,${ }^{27}$ media - partly by market and production routines transform more than they transmit and thus are not neutral [see Part B of this chapter]; so research should aim to carefully note the "extent to which movements operate in hostile environments" and how media can promote mobilization but also suppression (Gamson 2007; Zald 1996: 268-274). Gamson and Wolfsfeld (1993) found that SM disadvantages in symbolic/cultural meaning contests are rooted in asymmetric/structural interactions that instead favor news media - with even the most powerfully focused SMs affected more by media than vice versa. ${ }^{28}$ And so, as McAdam argued, if media are detriments as often as assets, then SM research must transcend "the prevailing movement-centric view”. (1996b: 346-355)

Media, especially their direct impacts on mobilization, have at times been neglected in SM theory (Koopmans 2004; Walgrave \& Manssens 2005: 117; also Cottle 2008). Now, despite the rarity of isolating media effects (Walgrave \& Manssens 2005: 134), analyses of "mobilization through media" (Gitlin 1980: 175) are reemerging

\footnotetext{
${ }^{27}$ From SM use of cultural themes brought into active contradiction by events, to bystander frames shifting to reflect disinterest or issue fatigue. (Gamson 2007; Zald 1996)

${ }^{28}$ E.g., large elite audiences and entertainment-over-news values shape SM leadership/strategy, and visual emphases mean more tactical confrontation, spectacle and drama in news. (Gamson \& Wolfsfeld 1993)
} 
(Anduiza, et al. 2014; Eltantawy \& Wiest 2011; Walgrave \& Manssens 2005). ${ }^{29}$ And as Gitlin's protest paradigm (1980) argues, elite media accounts of protest are "inevitably distorted" and often denigrate SMs; so research should widen to consider cases of opposite framing that impair mobilization (Walgrave \& Manssens 2005: 117; also Andrews \& Carena 2010). Moreover, if most frames support the status quo instead of collective action (Noakes 2005: 89) - and if scholars also find that framing contests between state, elites and SMs mostly advantage official frames - then further research extending beyond the movement-centered literature is indeed warranted (ibid: 106).

\section{NEW SOCIAL MOVEMENTS}

\section{- An Early Bridge between Cultural \& Structural SM Paradigms}

Before moving beyond movement-first cultural paradigms to review structural contexts, it's crucial to first recall the SM perspective that initially and most explicitly aimed to bridge agency-vs.-structure dualities (Melucci 1995). Emerging since the 1960s1970s as a departure from European structural class-based traditions, the new social movements (NSM) perspective emphasizes values over material interests and issues "relevant to the entire society", as well as strengthening of the public sphere (Habermas 2007 [1996]: 395). NSMs particularly hinge on mobilizing collective identity in 'struggle against technocracy' (Touraine in Rucht 1996; also Bernstein 1997; Roszak 1969), over issues ranging from peace and ecology to feminism - and sharing approaches of “participatory democratization” (Giugni 1998: xxii).

\footnotetext{
${ }^{29}$ Contexts favoring media mobilization include: people-vs.-elite disagreement, public confidence in mediaas-watchdog, emotionally symbolic and simple/consensus issues, a commercial/depoliticized media sphere, or scandal/crisis (Walgrave \& Manssens 2005: 135-136). Yet such analyses often accent SM-generated and social media, rather than elite/major mass media (Downing 2008, or DeLuca, et al. 2012).
} 
Many sociologists have been accused of applying reductionist interpretations to NSMs' progressive agendas; yet what was often labeled 'identity politics' in the US was commonly seen in Europe as a more diffuse, culturally transforming 'movement of movements' - crossing paradigms and levels of analysis to defy clear conceptualization (Touraine 2008 [2001]: 534). As an important disciplinary cultural turn (before the framing perspective), NSM activist-theorists targeted the basic institutions that transmit cultural codes, e.g. school/family/religion (Taylor \& Whittier 1995: 181). Residing in "cracks and fissures" of dominant culture and embedded in everyday lives of adherents (Johnston \& Klandermans 1995: 4), NSM interests are nonetheless seen as values-based "distant issues" (Rucht in Meyer 2007:12); and thus such conflict can be more disruptive and difficult as it is "less amenable to compromise" (Meyer 2007: 13). As a notable counterpoint to an identity-politics view of NSMs, a study of Vancouver, BC-area SMOs found a political-economy account of injustice was the master frame or "common language" for cross-movement activism, e.g. peace, feminism, labor - while an identitypolitics frame was associated with localism but not with cross-movement activism (Carroll \& Ratner 1996: 601, 618). So, as my study recognizes NSM features within movements like Occupy Wall Street (Benski, et al. 2013; Calhoun 2013; Castañeda 2012), this can also be a way to address and bridge - rather than overstate or perpetuate the SM discipline's structure-culture binaries (see also Gans 2012). 


\section{STRUCTURAL THEORIES, REVISITED Political Opportunity Structures and Political Process Theory}

Social constructionist, micro-level approaches like framing theory are only meaningful if situated in specific social structures, yet the SM paradigms do not consistently combine both macro and micro-level analyses (Klandermans 1992: 78-81). Such shortcomings will be further addressed, following this section's review of the macro-level or more collective SM paradigms. The political opportunity and process theories (POS/PPT), distinct from resource mobilization (RM) and framing paradigms that also emerged in the 1970s-80s, highlight institutional structure and power-holder ideologies (McAdam 1996a; Smith \& Fetner 2007). Various POS typologies typically assume that in the unlikely event collective action succeeds, there are a host of alternative explanations - which highlight how state policies channel SMs (Tarrow 1996).

Structures of political opportunities include the contested issue, in a context of unresponsive yet relatively open institutional politics (Meyer 2007: 28-29). ${ }^{30}$ As opposed to framing views, POS scholars critique social constructionism for neglecting the contexts for making meanings, such as networks or connective structures, and they instead view culture as structurally embedded (Tarrow 1998a: 199; also Piven \& Cloward 1979). While other SM paradigms acknowledge the influence of political context, rarely does framing activity directly alter institutional structure; so further research is needed to accurately measure structural (comparative factors like time) versus framing inputs (Noakes \& Johnston 2005: 22-23). Further structures explored in this chapter include the

\footnotetext{
${ }^{30}$ Adapting research on 1950s-1980s anti-nuclear arms movements, political opportunities for mobilization are "inversely related to... prospects of working through more conventional politics" - and can also hinge on elite experts (Meyer 2007: 87, 28-29). The most conducive contexts generally are weak states with strong civil societies, e.g. Tocqueville's America. (Tarrow 1996)
} 
state and policing (especially in the section on Demobilization) and corporate entities, especially mass media news (in Part B).

\section{Comparative Contexts}

Most broadly, political structure and process are part of a wider context structure of intersecting political, social and cultural spheres (Rucht 1996: 188; Tarrow 1998a). Scholars have argued that while political process is a top influence on SM repertoires (della Porta 2002), the literature has periodically neglected extra-movement, structural bases for mobilization (Rucht 1996: 191; Tarrow 1998). As a whole, structures and cultures are of course deeply interwoven, as people protest when political opportunity changes, yet they also strategically employ collective action repertoires to make new opportunities (Tarrow 1998: 19-24). ${ }^{31}$ External, structural (and increasingly global) forces shaping SM success or failure include strategic hurdles such as recruitment, bystander publics, the state, corporate ownership/management, and mass media coverage (ibid.; McAdam1996b: 339; also Rose 2000; Voss 1996).

In further research, political opportunity may be more fully analyzed by using the broader concept of political context, with related variables operationalized as mechanisms to link structures with agency and action (Kriesi 2007: 68-85; also see McAdam et al. 2001, below). Mass media is crucial in such contexts (Gamson \& Meyer 1996). And the overall historic trend, shown in Castells' comparative research on contexts where cultural values “match market pressures" (1983: 105), appears to be one of growing SM protest

\footnotetext{
${ }^{31}$ Dimensions of changing opportunity include: increasing ( $v s$. full or blocked) access, shifting alignments $\&$ divided elites, influential allies, and repression ( $v s$. facilitation) which can be radicalizing - as potential cost/threat is more energizing than hoped-for gain. (Tarrow 1998: 77, 86)
} 
against corporate dominance mediated by nation states $^{32}$ - with media decisive to the outcomes (ibid: 295; Tarrow 1998a). Castells' classic study prefigured broader outlooks on political context - where actual reforms come less from SMs' direct demands than from ad-hoc coalitions between reformer-insiders and the outside challengers who initiate protest (Tarrow 1996: 60). And to optimize these political context models, they should be extended (or culturally embedded), to better reflect mass media roles (Kriesi 2007: 86). ${ }^{33}$

\section{INTEGRATING THEORY: On Comparative Movement Mobilizations and Mass Media}

THEORY SYNTHESIS

- RELATIONAL CONTINGENCY \& COUNTERMOBILIZATION

In order to deploy an exploratory model for comparative SM frame analysis, this section of the chapter highlights the need to better integrate framing with political process approaches - particularly to analyze interactive and contingent contexts such as mass media and counter-movements (see Gamson 1995; Klandermans 1992; Koopmans 2004; Tarrow 1996). Research during the 'post-Cold-War/pre-social-media' era (1990s and early 2000s) emphasized synthetic comparative perspectives. This reflected: i) the cultural critiques, that the resource and the political process models were overly structural (Giugni 1999; Klandermans \& Staggenborg 2002; McAdam, et al. 1996, 2001; Taylor \& Whittier 1995), as well as ii) overlaps in the U.S. institutional (POS) and European comparative cross-national (PPT) research. (McAdam, et al. 1996)

\footnotetext{
${ }^{32}$ At the same time, protests in the early internet era were seen as growing less contentious or militant, due to easier mobilization (with media access and certain post-1960s policing reforms) perhaps dulling SMs' "capacity to disrupt" - and yielding a "domestication of movements" (Tarrow 1998a: 207-209).

${ }^{33}$ For example, a media-enabled success of the nuclear freeze movement was seen in U.S. President Reagan adopting a $2^{\text {nd }}$-term arms control platform, over his own party's objections. (Marullo \& Meyer 2007: 654)
} 
The value of studying this intersection of movement claims (frames), action effects (mobilization repertoires) and external effects (POS/PPT) is well recognized (Giugni 1999; Tilly 1999: 270). For example, the interactions between SMs and the media access that can then expand SM political opportunity, has been shown especially in comparative and longitudinal studies ${ }^{34}$ (della Porta 1999, 2007; Gamson \& Meyer 1996). So, SM framing should be analyzed in broader contexts such as discursive opportunity structures (also see Media Opportunity Structure below), consisting of the interplay of ideology, events and discursive processes. (Snow 2007: 402-404)

\section{Toward a Relational (\& Synthetic, Comparative) Paradigm?}

A notable example for analyzing such structures (plus agency), is McAdam, Tarrow and Tilly's synthetic cross-disciplinary approach to SM relational mechanisms which in sequence form processes emerging within wider episodes where "mobilization and demobilization intersect" (2001: 30). Mechanisms such as category formation coalesce in processes like polarization (ibid: 147; also see Tilly 2003), or like actor constitution - that forms self-defined, publicly recognized identities (McAdam, et al. 2001: 306-326). Political identities form in dynamic interactions - including framing with socially constructed mobilization emerging also from environmental changes; and SM actors within networks have multiple contextual identities, from routine to contentious and from embedded to the more predominant detached identities such as party ties. (ibid: 132, 141; also see Bernstein 1997)

\footnotetext{
${ }^{34}$ Yet some case studies have suggested that mass media is of no more than mixed importance for SM outcomes (See Oberschall 1996, vs. Zdravomyslova 1996).
} 
McAdam and colleagues' interactive approaches avoid the static and 'structuralist/ rationalist/ culturalist' standard SM agendas - that also exaggerate the role of "deliberate strategic decisions" (2001: 15). And in comparing 15 uncommon cases ("similar mechanisms, radically different outcomes"), they show contentious episodes as contingent, interactive, and context dependent (ibid: 83, 119). Overall, while the causal mechanisms and processes offer valuable analytic tools, ${ }^{35}$ their synthetic model somewhat neglects the movement-media framing dynamics - that will be developed in the coming sections.

\section{Class-Based Activism and Countermovement Dynamics}

For interclass coalitions (e.g. labor/justice, ecology) to counter corporate power, activist or action research has proposed hybrid organizing models as practical frameworks for dialogical relationship building within contingent contexts (Rose 2000: 213, 30). To bridge cultural gaps between working class and middle class SMs, Labor's "language of interests" learns to speak 'values', and a middle-class "language of values" learns to speak 'interests' (ibid: 32; also Rootes 2007). To organize against global corporate mobility, hybrid SMs (Labor/ Enviro/Peace) need relational, informal networkbased techniques - with broad media framing efforts - to find common cause (Rose 2000: 111,133,163). These hybrid models combine interest organizing (Alinsky/RM) and values-based organizing in "practical strategic compromises" that emerge situationally ${ }^{36}$ (Rose 2000: 188, 199-200). Such SM convergence, framing and transforming quality-of-

\footnotetext{
${ }^{35}$ Basic mechanisms (involving actors, identities, \&/or actions) among SM contentious episodes include: brokerage/brokers, category formation (creates identities), object shift (alters relations between claimants $\&$ objects of claims), and certification by external authorities. (McAdam, et al. 2001: 147)

${ }^{36}$ Also see Paulo Freire's 'limit-situations', and Turner \& Killian in Klandermans \& Smith (2002: 8).
} 
life agendas toward broader global justice, suggests that SMs' potential as "schools for democracy" relies also on theoretical convergence and synthesis. (ibid: 207, 213; also Agarwal, et al. 2014)

Beyond coalition and convergence, the overall logic of movements requires consideration of countermovement activity as well - the most contingent and relational SM dynamic (Fantasia \& Stepan-Norris 2007: 561). From corporate repression of the Knights of Labor or 'Wise Use' anti-environmentalism, to abortion conflicts and Tea Party vs. Occupy Wall Street (ibid: 559; Agarwal, et al. 2014; Meyer \& Staggenborg 1996; Rootes 2007: 634; Skocpol \& Williamson 2011), recurring counter-mobilization is often provoked by SM victories - as a counter-movement (or reactive movement) simultaneously makes claims opposing those of the original movement (Caiani, et al. 2012; Meyer 2007: 179; Meyer \& Staggenborg 1996: 1631). For example movementcountermovement pairs often protest at political conventions and thus impair governance and policy reform (Meyer 2007: 159, 122). Movement opponents also employ various concessions and sanctions to divide SMs, often provoking a radical flank anomics to "tar the larger movement" with activities of the most zealous (ibid: 59). At peak mobilization, connections between "the margins and the mainstream" define SM politics (ibid: 172); and during countermovement attack, frame alignment processes become especially vulnerable. (Snow, et al. 1986: 478)

Countermovement interactions, from value cleavages or SM threats versus the status quo, increase when states "enable but do not satisfy challengers" (Meyer \& Staggenborg 1996: 1628); and such interactions need further research. Conditions promoting countermovements include: movement success that is tentative, states with 
divided political authority, critical events, elite allies, and news media coverage along with its 'balancing' norm (ibid: 1639, 1632). Countermovement threats usually discourage movement demobilization, and opposing SMs that politically engage in the same venues develop organizational structures isomorphic to each other ${ }^{37}$ (ibid: 1644 , 1649; also Agarwal, et al. 2014). So, the threat of an opposing SM is a mixed blessing, as countermovement interactions often provoke innovation and prevent full “institutionalization of tactics" yet also preempt developing new claims after SM victories (ibid: 1651). In general, this most contingent and relational of SM dynamics needs further study, such as by comparative media discourse analysis in Chapters III - V.

\section{INTEGRATING MOVEMENT RESEARCH METHODS}

This section reviews literature on methodologies most applicable to studying SM and mass media interactions. The data and theory relationship, traditionally seen as a dialectic between the particular and the general, is well served by diverse SM scholarship that avoids "methodological dogmatism" (Oliver \& Myers 2002: 50-60; Klandermans \& Staggenborg 2002). Yet for RM and POS organizational and protest event analyses, and especially for framing analysis of movement texts, some "unresolved methodological and measurement problems" persist (ibid: xii). One major strategy for methods to test and build theory has been via comparative approaches (ibid: xiii; also della Porta 2002; Giugni 1999: xxvii; Klandermans \& Smith 2002; McAdam, et al. 2001; Williams 2007: 108). And by including both quantitative ("data condensers") and qualitative ("data

\footnotetext{
37 "Reciprocal adaptation and innovation" between protest and police repertoires partly led competing Left versus Right master-frames to converge on a 'democracy" "metaframe" (della Porta 1999: 92, 70); yet such Left-Right convergence was less evident in organizing during the social media era. (Agarwal, et al. 2014)
} 
enhancers") approaches, interpretive discourse methods are especially useful to bridge SM framing with political process approaches. (Blee \& Taylor 2002: 109)

The dominant view of our society comes through mass media, yet comparative news content/discourse analyses have found that protests often go unreported - as of course "media do not mirror" society entirely (Koopmans \& Rucht 2002: 252; Swank 2000; also Lee 2007). Regardless, protest event data from newspapers have demonstrated some reliability - so that the factors found to most shape protest coverage are the size, duration and novelty of the event (Koopmans \& Rucht 2002: 247, 250; also Earl, Martin, McCarthy \& Soule 2004; Snyder \& Kelly 1977) ${ }^{38}$ So, partly in response to an early research tradition of "actor-system dualism" which reified the collective actor, discourse analysis methods developed (Melucci 1995: 55-57). This in turn expanded how research could also serve as "metacommunication, a second-degree learning process" that enables actors to learn how to learn and "to produce their own codes." (ibid: 63)

To focus on texts, a micro-discourse or micro-frame analysis (rather than a macro view that lacks specific document reference) offers more empirical grounding and systematic reliability and validity (Johnston 1995: 219). More research should also focus on the context of textual production (often neglected in the social sciences) and on the structures of movement-media frames - which need clearer analytic criteria (ibid: 223). Frames are represented as hierarchically organized by content, and an operative SM frame will be relatively consistent between participants or organizational texts (ibid: 237). A frame analysis scheme will code for concepts, relations between concepts, bases

\footnotetext{
${ }^{38}$ Newspaper data for protest event analysis (while useful and relatively accurate) was subject to selection bias (over which events are covered) and description bias - notably, the veracity. (Earl, et al. 2004)
} 
for connections, carryover to other levels and types of participation, and situationally varied interpretations. Such analysis also expects to find broad parallels between the structures of media texts and SM documents and speech. (ibid.)

Key challenges of frame and discourse analysis include conceptualization and verification (showing influences of frames \& discourses), which require "clear references to the texts" (Johnston 2002: 67). A more qualitative approach, with greater validity than reliability, often precludes longitudinal analysis; but more quantitative content and storygrammar analyses are becoming empirically fruitful (ibid: 69; also Aiden \& Michel 2013; Michel, et al. 2011). To observe a frame's social basis, texts and spoken narratives from micro to macro - are examined as hierarchically organized, memory-based and linguistic (Johnston 2005: 240). Analyses of deep structures, by story grammars' setting, theme and plot (semantic essence), employ the most compelling empirical data - original texts showing "how speech and text are structured" (ibid: 245). Principles of intensive textual analysis include: production context, pragmatic intent, role perspectives, and the whole text as well as nonverbal cues. Comparative frame analysis, with movementrelated dependent variables, correlates with changes in SM ideational content - and frequency measures can indicate the "frame's generality" (ibid: 243$).{ }^{39}$

Alternatives to discourse analysis include the more immersive ethnographic as well as case study strategies. For example, semi-structured interviews, life histories, and focus groups can offer detailed data and nuanced semantic context, without prolonged SM involvement (Blee \& Taylor 2002). An extended case method (Burawoy 2000), as a

\footnotetext{
${ }^{39}$ Gitlin (1980) argued however that his SM participant-observer position justified a qualitative textual analysis that excluded content frequencies or other quantitative measures.
} 
field- and theory-driven, micro to macro approach, is also useful to "extract the general from the unique" and synthesize participant observation evidence with macro-social/ cultural theories (Lichterman 2002: 122). As with other 'small n' research strategies, case studies should also triangulate multiple methods longitudinally to track historic sequence (Snow \& Trom 2002: 146-47; Clemens \& Hughes 2002: 220-230). This study however, besides Appendix F, applies only discourse analysis as outlined in Chapters III - V. Social movement research methods have grown more empirically advanced, especially with comparative and longitudinal approaches, yielding micro to macro theoretical insights (Klandermans, Staggenborg \& Tarrow 2002). Key SM processes studied (with associated methodologies) include: i) mobilization potential, e.g, consensus mobilization (framing); ii) participation, e.g. targeting (network analysis) and motivating (surveys); and iii) sustained participation and withdrawal, or demobilization (an underanalyzed research area outlined below). Methodological innovation has enabled three broad phases of theory building: movement career models, protest cycle models, and trajectories of contention (see McAdam et al. 2001) - which often contextually embed movements as an "iterative dance of mobilization and demobilization" (Klandermans, et al. 2002: 328). To reflect this contingency, research still needs to better incorporate time, as well as focus on mass media discourse to evaluate cultural change (ibid: 329). Again, a great strength of the SM field is its "syncretic impulse", and interpretive methods like discourse analysis - specified in Chapter IV Methodology - offer robust data needed to test the integrated movement-and-media interaction approach articulated in the remainder of this chapter. (ibid: 334$)$ 
An Area for Further Research:

DEMOBILIZATION and OTHER MOVEMENT OUTCOMES

All SMs, if they reach the aim of transforming their stake in societal decisions into political standing (Meyer 2007), thus promote their own eventual demobilization (Tarrow 1998: 89). Research on demobilization, suppression, marginalization and other SM outcomes rarely explores media's role, so this section reviews these areas - which pertain to this chapter's subsequent concluding sections on media opportunity structure and on neutralization of SMs. With success such as altering major policy, ${ }^{40}$ movements often go uncredited and/or downplay their own impact, due partly to SMs' common framing as "inevitable or mystical" - and this 'immaculate conception' frame (a recursive media-movement feedback process) undermines prospects of further mobilization (Meyer 2007: 175-177; or see White 2016). Moreover, movements that achieve the most are paradoxically the most likely disappointed, because claiming credit for broad, collective benefits is more difficult than for narrowly targeted ones (Meyer 2007: 179).

Regardless, SMs - whose victories or sharp defeats both have demobilizing effects (Meyer \& Staggenborg 1996) - indeed influence how politics are done today (Smith \& Fetner 2007: 38). While many introduce crucial new ideas, particular movements' broad cultural and structural effects are difficult to specify, partly due to a ‘moving finish line' (Meyer 2007: 177; Tarrow 1998b). Widely studied outcomes with 1960s SMs include reverberating "postcycle networks", e.g. informal activist networks or movement social capital (Meyer 2007: 169). For example, after Spring 1968 uprisings, the backlash masked the "slow and capillary process" of transforming cultural values and

\footnotetext{
${ }^{40}$ Activist influence peaks earlier in a policy process. Reforms include: replacement (elect, impeach, etc.), conversion (of members), creation (of venue) \&/or reconfiguration (new policy actors) [Meyer 2007: 168].
} 
practices for the next protest cycles, such as 1970s-80s ecology and anti-nuclear SMs. (Tarrow 1998b: 51; also Cornell 2011)

Major factors in movement demobilization (i.e., less participation and depoliticized awareness) include repression and institutionalization ${ }^{41}$ (Tarrow 1998), which especially demobilize through marginalization (often mass media-related) and cooption (Meyer 2007: 130-131). Governments can coopt via demobilizing frames, such as by US institutional access "designed to invite, but also to frustrate" - that tends to dissipate conflict (Johnston \& Noakes 2005: 5; Meyer 2007: 113-114; or Jaffee 2012 for the corporate case). Still, SMs construct collective action frames to oppose a "prevailing political rhetoric" that stresses the risks of SMs (Meyer 2007: 52). And demobilization's contractive mechanisms, an "iterative and interactive process", are often provoked by third parties whose interests are threatened by continued contention (Koopmans 2007: 40-41). News media may also play a demobilizing role by reinforcing ritualized, institutionalized displays of dissent as well as by highlighting extreme and polarizing action for mass audiences (Meyer 2007: 89-101). And while some scholars suggest that reduced tactical innovation is "a symptom, not a cause" of demobilization (Koopmans 2007: 37), others find that a lack of innovative master frames prompts demobilization (Snow, et al. 1986: 477; White 2016).

The broad, post-1960s trend of proliferating but often less disruptive protest can appear as "clutter" in mass media and politics (Meyer 2007; Tarrow 1998a: 175; also

\footnotetext{
${ }^{41}$ Repression usually provokes radicalization and perhaps weakens the moderates' position (Tarrow 1998a: 158). Institutionalization occurs along three dimensions - claims, constituencies, and tactics/processes; and mechanisms for this generally are via policy consultation (e.g. governmental [see footnote 33]) and broader culture. (Meyer 2007: 142, 130)
} 
McAdam 1998). During this postcolonial and globalization period, western political economies mostly shifted rightward; and while the shift may have been worse without SMs, their overall activity has become more policed, professionalized, "tame" and perhaps ineffective (McAdam 1998: 231-233; also Dauvergne \& LeBaron 2014; Gitlin

2012; White 2016). ${ }^{42}$ So if SMs are becoming a more routine, less disruptive and perhaps less decisive part of American political life (Dauvergne \& LeBaron 2014; Meyer 2007: 159-186; White 2016), then how does this paradox relate to their news media framing?

\section{MEDIA as OPPORTUNITY STRUCTURE? (Or Media Frame Neutralization?)}

\section{MEDIA OPPORTUNITY STRUCTURE}

In between the basic micro and macro movement-media paradigms (where framing sees mass media as mostly aiding SM mobilization/agency, and political process theory [PPT/ POS] often sees media as constraining), the media opportunity structure (Gamson 1998) is a meso-level interactive approach bridging POS' structure with the agency of framing - akin to 'framing in context'. Media routines and structure (especially television) can be crucial mechanisms for SM meaning and collective identity construction as well as tactical innovation (Earl 2007; Gamson 1992; Tarrow 1998; Taylor \& Van Dyke 2007); but media frames that are explicitly motivational are rare (Noakes \& Johnston 2005: 6; or see Lubitow 2013). Moreover, the media system is

\footnotetext{
${ }^{42}$ The SM form may be losing potency in the 'democratic West' while diffusing rapidly worldwide (Meyer 2007: 245; also see Appendix A). Moreover, long-term effects of 1960s SMs may have included lost faith in governments and more individualist policy responses to social problems (ibid: 167). Other research finds certain SM strategies may unintentionally promote a neoliberal model of business self-regulation - versus governmental regulation. (Bartley 2003)
} 
widely seen as not neutral (Gamson 2007; Klandermans \& Goslinga 1996; Koopmans 2007; Meyer 2007; Rucht 2007) - for example often omitting a movement's intended identity (Gamson 1995) - and so further research should consider how news coverage may adversely affect movements. (Koopmans 2004: 369)

In related research on SM strategies for dealing with media selection bias (Walgrave \& Manssens 2005: 116), newspaper macropropositions revealed generally incomplete media representations of movement contention (Klandermans \& Goslinga 1996: 337; also Rootes 2007). Media remain more centralized than the wider public arena [see Part B below], thus SM activists are more marginal to agenda-setting or gatekeeping than are reporters, editors, official news sources or corporate profits - and so issues that may threaten these interests are often underreported (McCarthy, et al. 1996: 293-97). Such constraints on SM discursive opportunity structure are reflected in systematically selective coverage (Gamson 2007: 254; Meyer 2007; Koopmans 2007: 32). For example, news often initially ignores protests (Gitlin 2012: 22-25; Marullo \& Meyer 2007). Yet despite mainstream media's advertiser-led, pro-business bias, SMs can perhaps manage the disadvantage by rigorously attending to media processes. (Meyer 2007: 92-94)

One aspect of this, as a key movement research issue, is how the structure of biases in media content pre-shapes audience and activist interpretations of POS; and so research to address this dynamic can help resolve the question of opportunity structures' linkage with movement action (Koopmans 2004: $369-379) .{ }^{43}$ The way this linkage is

\footnotetext{
${ }^{43}$ Koopmans' (2004) interactionist, evolutionary model includes: i) bounded (e.g., undemocratic) communicative space and ii) related selection mechanisms of visibility (of speakers via gatekeepers); resonance (supportive consonance \& negative dissonance, e.g. with countermobilization, both of which increase salience); and legitimacy (yet must be controversial for resonance).
} 
mediated in the wider public sphere can then help explain why only some SM messages succeed (ibid: 379 ). While corporate media often distort the public sphere (Habermas 2007 [1996]), its generally weak institutions in the U.S. may also allow SM opportunities to shape media discourse (Gamson 1998: 72-76; also Part B below). So, akin to when progressive social movements both convey their message and revitalize the public sphere (Habermas 2007 [1996]), a media opportunity structure (MOS) links a mass media system with SMs that carry symbolic interests (Gamson 1998: 60-63). While media discourse is rarely a level playing field for SMs, their cultural acceptance and thus some elements of success can be quantified from their media standing. ${ }^{44}$ (ibid: 66-76; also see Chapter III ... Research Model, and Chapter IV Methodology)

Thus MOS, within a wider discursive opportunity structure, includes the media system as a political opportunity variable and site of struggle that frames movement opportunity within constraints - such as media's "double-edged effect" of both promoting and discouraging injustice frames (Gamson 1998, 1995: 92; also Chapters III and IV below). Media power over opposition movements is visible when conglomerate corporate journalism promotes "elite definitions of reality", such as news principles of 'objectivity', seeing audiences as consumers, and pressuring SMs to focus narrowly on single grievances (Gitlin 1980: 12, 35). The news, similar to commercial advertising, routinely decontextualizes major issues - and SMs are also typically marginalized if they

\footnotetext{
${ }^{44}$ A frame's general media success factors include: i) the sponsor's activities; ii) media norms/practices (journalistic narrative form \& balance norm "reduce controversy to two competing positions"); iii) cultural resonances (themes/counter-themes); and iv) narrative fit, from frame contests. (Gamson 1998: 72-76)
} 
are too oppositional, unconventional or unskilled in media processes. ${ }^{45}$ (ibid: 193-291; also Andrews \& Carena 2010; Calhoun 2013; Juris 2008)

\section{Beyond Movement Marginalization or Cooptation:} NEUTRALIZATION by MASS MEDIA?

Despite the conflicting role evident in SM research literature, mass media are still commonly assumed to primarily enable mobilization - while only rarely are media analyzed for factoring in SM constraint, demobilization (typically seen as movement-led) or frame neutralization. So, given the difficulty of separating media impacts (Gitlin 1980: 127), can news content be effectively analyzed as factors in neutralizing SM frames and/or in demobilization? Research finds how forces like power-holder “counterstrategies” may neutralize frames or suppress movements (Rucht 1999: 211; also Dauvergne \& LeBaron 2014; Earl 2003), such as by cognitive encumbrance yielding a "broken collective action frame" (Voss 1996: 256). Yet if mass media demonize (Noakes \& Johnston 2005: 19-20), obstruct or actually suppress SMs, this is uncommonly studied - and more often noted as a non-methodical aside (see DeLuca, et al. 2012; Gamson 1995: 94; Gitlin 2012: 207; Tarrow 1998: 116). The few studies that directly analyze media obstructing or even suppressing dissent highlight news media routines and structures. $^{46}$ (Boykoff 2006: 203-205; Gitlin 1980; Klandermans \& Goslinga 1996; Sobieraj 2011; Xu 2013)

\footnotetext{
${ }^{45}$ Commercial journalism norms include: cover the event not the condition, the conflict not the consensus, and the fact that 'advances the story' not the one that explains it. (Gitlin 1980: 122-123; also see Part B) ${ }^{46}$ Gitlin warned of a "movement dependency" on media - and that interplay of SM and media actually helped mobilize State repression (1980: 285, 95). Yet publicity over repression of protest has also been found to "fuel the globalization of movements". (Ericson \& Doyle 1999: 606)
} 
More broadly, scholars have argued that structural forces, from conglomerate corporations to police, impede collective agency and that mass market culture has mostly undermined oppositional political culture (Gamson 1995; Gitlin 1980: 259; also Frank 1998). For example, television especially promotes apolitical, private visions of the world (Gamson 1995: 96); and broader media, in maximizing audience and/or profits, typically presents frames where "public life is corrupt" (Tarrow 1998: 116) - which then justifies inaction and neutralizes most visions of collective action toward the mere status quo (Gitlin 1980: 238; Noakes \& Johnston 2005: 6-7). And for SMs, the news “often obstructs" and only rarely promotes collective action frames - but often frames where activists fall for the "well-laid cultural trap" of promoting their movement as if marketing a product (Gamson 1995: 104-105; also Dauvergne \& LeBaron 2014).

Such a profound potential obstacle in movement-media dynamics suggests activists should recall the classic research finding - that creating real collective agency requires direct, not mass-mediated, relationships (Gamson 1995: 106). This further recalls this study's key preliminary questions: How might socio-cultural frames and mass media perhaps constrain movements? (Tarrow 1998: 117) And more pointedly, when an opposition movement deeply challenges the social order, to what extent do major news media reflect a core rhythm of U.S. political history - whereby SMs that are outside dominant discourse are consequently marginalized, "trivialized" and/or tamed largely by that media? (Gitlin 1980: 291)

To operationalize these questions for this study's research model in Chapter III below, I have so far reviewed the major movement-media perspectives. Literature in each of the core movement paradigms reveals news media as a key SM variable, but none 
of them fully analyze the oft-suggested potential for mass media to interact with movements as constraining or neutralizing factors. The framing and the political process paradigms' contrasting views of media (the former viewing media as enabling and the latter as often constraining) suggest that a useful approach lies in bridging these two. Among the few approaches to conceptualize this is Gamson's media opportunity structure (MOS), which I develop in order to further analyze mass media's potentially neutralizing role within contrasting SM cases. Applying this integrative movement-media perspective first requires a brief overview - in Part B below - of related research on shifting patterns of commercial mass media and public discourse within recent economic globalization contexts. 
Part B

\section{GLOBAL NEWS MEDIA, COMMERCIALIZING PUBLIC DISCOURSE? Composite Patterns of Contested Change}

\section{INTRODUCTION}

Mass media's systemic structures and processes, such as persistently concentrated and conglomerating corporate news ownership (Croteau \& Hoynes 2014; Sklair 2006: 60 ), can be a revealing lens on globalization as a vast, contested metaprocess (Guillen 2001: 238; Lule 2015: 22). The practical, sustained effects of globally changing news media remain hotly debated, and a concept like media globalization raises questions of whether media's systemic patterns are a globalization cause or effect (Reese 2010: 345; Lule 2015: 6). For example, at the same time that broad resistance to such globalization was growing, new media technology was shifting the debate. So, just as many began to grasp the recent scale of corporate economic forces, certain old media empires were receding to a rising social media tide. These ambiguities are reflected in the overall research model (in Chapter III, while Chapter VI discusses how new media are largely beyond the scope of this study) - of globalizing news media and social movements (SMs) as interacting and interdependent systems or processes. ${ }^{47}$

I argue that research related to changing news media, beyond the basic debates between structural (see Habermas 2007 [1996]; Ritzer 2015; Sklair 2006) and cultural (see Appadurai 1996; Nederveen Pieterse 2004) perspectives on globalization, should further probe how patterns of over-commercialization may distort news content. In

\footnotetext{
${ }^{47}$ Or systemic, reciprocal processes, such as mass media increasingly depending on globalizing technology and corporate finance - while diffusion of technologies and corporate finance also depend on mass media.
} 
particular, scholars have often found that commercialism eclipses non-market viewpoints within media content that is commodified (Anderson 2009: 179; Appadurai 1996: 41-44; Croteau \& Hoynes 2003: 50; Lule 2015; Shoemaker \& Reese 1991: 141), but such findings can be obscured by the binary debate or gap between structural and cultural globalization perspectives (Gans 2012). Studying media framing of SMs or 'globalization from below' can address this gap (Kellner 2008 [2002]), as movements are traditionally seen as domains where cultural and structural features are often equally visible.

Structural perspectives typically see economic globalization yielding cultural uniformity yet inequality while also commodifying, disrupting and atomizing social life (Chase-Dunn 2006; Korten 1996; Ritzer 2015) - which provokes resistance, from anticorporate 'globalization from below' (Juris 2008; Wallerstein 2004) to reactive militant nationalism (Van Dyke \& Soule 2002). ${ }^{48}$ Other structural views accent how corporate media dominate and hyper-commercialize the wider public sphere, ${ }^{49}$ which narrows or distorts news content (see Bagdikian 2000; Habermas 2007 [1996]; Lule 2015: 106; McChesney 2004). Cultural perspectives instead emphasize how globalization yields benefits, partly by intermixing/diversifying/ hybridizing cultures - with a new global public sphere emerging from high-tech communication networks (Appadurai 1996; Nederveen Pieterse 2004; also Castells 2008; Reese 2010). Bridging the cultural and structural approaches are what I term composite perspectives, on globalization as an historic project of uniform, corporate-led, global policy templates that yield commodifying effects yet uneven local-to-global impacts - especially potential

\footnotetext{
${ }^{48}$ Yet for some structuralists, globalization is primarily liberating. (Castells 2008; Giddens 2007 [1990])

${ }^{49}$ (societies' distinct domains of cultural and sociopolitical discourse)
} 
democratization by transnational counter-movements (Beck 2000; Burawoy 2000a;

McMichael 2012; see also footnote 37, \& Appendix A). Composite views on news media examine how varying cultural and structural influences on news practices and content, while not uniformly limiting, still commodify the overall system (see Croteau \& Hoynes 2014; Lule 2015: 92; Shoemaker \& Reese 1991).

INTEGRATING MEDIA \& GLOBALIZATION PERSPECTIVES (To Model Mediated Movement Discourse)

Integrating contrasting perspectives on news media and economic globalization, to see them as interdependent systemic processes shaping each other, ${ }^{50}$ then informs this study of how these processes provoke SM resistance and shape subsequent commercial news content. If the structural-cultural debates may distract from the commodifying effects revealed by all three perspectives (structural, cultural \& composite), then studying how news content is commodified or 'sold' can illuminate mechanisms by which broader discourses are also commodified (Kellner 2012). While it may be obvious that corporate capitalism commodifies key parts of society, how it is reflected in news media content needs further analysis. ${ }^{51}$ For example, both cultural and structural scholarship theorizes collective action to counterbalance globalization's dysfunctions (see Appadurai 1996 or Wallerstein 2004), with the former attributing the action to cultural values (e.g. Black Lives Matter, \#MeToo, or Patriot Prayer) and the latter to material self-interest (e.g. Occupy Wall Street or Tea Party). Yet the common theme of resistance to globalization's commodifying processes is thus diluted by the culture/structure divide; and so this is

\footnotetext{
${ }^{50}$ Such as mainstream news disproportionately magnifying business and financial viewpoints.

${ }^{51}$ Especially due to limiting factors noted in Chapter IV Methodology. (see Berg 2007; Johnston 2002)
} 
partly bridged by the composite view that globalization yields material insecurity or inequality, as well as disrupted or hybrid cultural identities and commercialized social life and discourse (see Beck 2000; Burawoy, et al. 2000; Croteau \& Hoynes 2014; McMichael 2012).

The collective resistance - a protective response to global capitalism's antisocial effects described by Polanyi’s double movement (2001 [1944]: 3-30) - is intertwined with the public sphere which mediates between society and the state through egalitarian communicative networks to form social space (Habermas 1989 [1964]; 2007 [1996]: 389393). Today's public sphere, partly maintained by civil society non-economic organizations such as NGOs and social movements, remains dominated and thus distorted by conglomerate for-profit mass media - undermining discursive communication and constraining civil society's problem solving capacity (Habermas 2007 [1996]: 398-404). This reflects the late $20^{\text {th }}$-century shift away from a political viewpoints press, toward corporate media and public relations, which refeudalizes the public sphere. ${ }^{52}$ (Habermas 1989 [1964]: 236)

Some scholars challenge this view, seeing media globalization as mostly empowering for individuals (Giddens 2007 [1990]), such as by info-communication technologies enabling countercultural liberation discourses (Castells 2012; also Garrett 2006). Despite this potential for alternative network-based, global-local interactive new media systems (Castells 2008 [2000]: 556), others argue that this is an overly determinist reliance on technology (Burawoy 2000a). Cultural perspectives focus less on technology

\footnotetext{
52 (weakening democracy by dampening voices of the many and amplifying elite voices). Some argue this pattern intensifies with the internet (McChesney 2004), while others argue the opposite. (Castells 2008)
} 
and more on global migrations, highlighting new diasporic public spheres that enable subversive change including via transnational mass media (Appadurai 1996). So, is commercializing media content growing more culturally diverse/ hybrid or more narrow and uniform/ homogenized? (ibid; also Nederveen Pieterse 2004) While both patterns occur in certain locales, and global commerce sometimes re-localizes (e.g. custom Nikes or local/regional New York Times), research also finds that mass media generally blur the distinctions between 'global' and 'local' (see Beck 2000; Lule 2015: 107; Ritzer 2015).

In particular, conglomerate media often promote transnational corporate libertarianism that, with major corporations consolidating global dominance since the 1970s, has been among history's most sweeping institutional transformations (Korten 1996). This elite policy consensus - of corporate finance, consumer culture, globally competing workers and localities, and market-defined relationships over democratic institutions - became dominant ideology largely via mass media advertising and public relations (ibid: 131-152; also Klein 1999). ${ }^{53}$ Although globalizing media are powerful, from a composite perspective they are also asymmetrical - thus neither monolithic nor inevitable (Guillen 2001; Lule 2015). For example, extended case methodology uses contextualized or grounded globalization, to center on a cosmopolitanism from below of transnational social movements that require global media access. (Burawoy 2000b; also Appendix A)

\footnotetext{
${ }^{53}$ Traditional elite fora include: The Council on Foreign Relations, Bilderberg \& Trilateral Commissions, and the Washington D.C.-centered business lobby, e.g. Business Roundtables which first mobilized in 1972 partly in response to 1960s-70s youth countercultures (Korten 1996: 144). Yet youth-centric, popular media like $M T V$ were also instrumental in globalizing consumer culture - and youth culture's commercialization likely inhibits counterculture. (ibid: 153-154; also Frank 1998)
} 


\section{Globalization From Below}

While globalization from above is often a contested policy project that yields both economic gaps/instability as well as uniformly consumerist culture, from below it yields alternative meanings and social organization (McMichael 2012). This reflects a basic conflict between structural profits and cultural meaning (that people are global consumers but not yet global citizens); and developed, consumerist culture is conveyed especially through commercial media (ibid). Since Keynesian development was largely dismantled since 1980 (ibid.), ${ }^{54}$ the ongoing shift to neoliberal policy has also deregulated and defunded U.S. public interest media (McChesney 2004). The composite approaches see these methods of globalization as uniform/homogenous - but not the outcomes (McMichael 2004: 153-155), such as the diverse countermovement struggles to socially re-embed markets and resist homogenous commercialism. (ibid: 308; also Granovetter 1985; Polanyi (2001 [1944])

Yet these global transformations have been widely seen as more often impeding rights, social protections and discourse (e.g. Blum, Gowan \& Haney 2000), such as commercial media simplistically presenting subcultures especially of the global South (Bello 2004). And so - from Brazil's Worker Party revolts against 1970s corporate neoliberalism (Mertes 2004; Stedile 2004) and Seattle's 1999 anti-WTO, to Mumbai's 2004 World Social Forum and 2011 Occupy Wall Street - a global anti-corporate movement of movements has both magnified and problematized media's potential effects (Calhoun 2013; della Porta \& Mosca 2005; Klein 2004, 1999; Mertes 2004: xii). The

\footnotetext{
${ }^{54}$ (especially impacting the less developed nations by strategic economic, rather than pro-democracy, interventions from the West)
} 
diverse global justice movements, named 'anti-globalization' by critics/ dominant media despite resulting from globalization (Graeber 2004: 204), may also have their diversity serve to distract from their most essential common goal of decommodification (Sader 2004; Wallerstein 2004: 273). Moreover, anti-corporate movements from below often subversively re-appropriate corporate infrastructure and may thus raise shrill media alarms (Ngwane 2004: 134; Klein 2004: 229). Yet despite such potential barriers to effective movement-media framing, creative messaging and tactics, like training to navigate corporate news filters, helped make the anti-systemic protests of 1999 SeattleWTO and Occupy Wall Street among history's most televised. (Calhoun 2013; Mertes 2004; Sellers 2004; White 2016)

\section{Cosmopolitan Democracy: By Media and/or By Social Movement?}

To address the tensions between globalization from above and from below may require new transnational boundaries, first by distinguishing globalism (marketdominance ideologies) from globality (world society such as through mass media) ${ }^{55}$ and from globalization - where transnational economic actors undermine national states (Beck 2000: 10-11). Using a multi-dimensional world risk society approach, ${ }^{56}$ global (and local) risks can be exposed or assessed by a new media-enabled world public sphere (Beck 2000: 51-57; also Appadurai 1996). Yet with current media-constructed selfperceptions, is civil society becoming a global spectator society more than a cosmopolitan democracy? (Beck 2000: 91-95) The dominant patterns of neoliberal globalism, including culture industries and global media that symbolically nullify the

\footnotetext{
55 (interlinked geographies/human rights/conflicts, economies, info/communication/media, and eco-crises) 56 "Threats create society, and global threats create global society." (Beck 2000: 38)
} 
state-society-identity equation, thus undermine the welfare state and democracy (ibid: 7481). And such mediated transnationalism may then be rupturing humanity's 'place' and 'community-society' connection, to create a "place polygamy" that requires regulation by transnational states and/or via cosmopolitan social democracy (ibid: 131-139).

This recalls how media can both boost and impair democracy, such as when U.S. newspapers conglomerated, from $80 \%$ independent in 1944 to $98 \%$ corporate chain ownership by 1999 (Bagdikian 2000: 91-99). Conglomeration into newspaper chains, with daily print monopolies in more than $98 \%$ of U.S. cities, was a key way that media globalization degraded news quality (ibid: 124), such as shifting content toward corporate values and away from a historically often adversarial stance on corporate expansion (Gans 1979). This conglomeration - from deregulation, mergers, shifts to advertising dependence and in technology - is also blamed for narrowing major news media content toward conservatism and "complacency" (Bagdikian 2000; Lule 2015: 108; McChesney 2004; Shoemaker \& Reese 1991). So if these processes have degraded U.S. news content and community discourse (Bagdikian 2000: 133; McChesney 2004), can this be further observed by comparing oppositional SM discourses in the current global electronic media era? (Reese 2010: 349)

News media deregulation and conglomeration especially since 1980 are among the factors seen as yielding unaccountable corporate media that trade journalism for commercialism $^{57}$ (McChesney 2004: 7-18; or Peters \& Broersma 2013). With six firms

\footnotetext{
${ }^{57}$ Following the 1996 U.S. Telecomm Act, most surveyed journalists - although more economically conservative and hawkish than average Americans - believed their news organizations emphasize profits over journalism. (McChesney 2004: 97-114)
} 
holding a majority of U.S. mass media markets (Lule 2015: 94-96), ${ }^{58}$ such oligopoly can distort media content (McChesney 2004; also Bagdikian 2000; Shoemaker \& Reese 1991). Further, while scholars may differ (Argarwal, et al. 2014; Castells 2008; DeLuca, et al. 2012; Langman 2005), an over-commercialized internet also threatens technology's subversive potential (Croteau \& Hoynes 2014; McChesney 2004: 208-221). At the same time, ongoing protests show that media access remains integral to global justice movements, from 1999 anti-WTO Indymedia to 2011 Arab Spring Tweets and Occupy Wall Street Livestreams (e.g., Robertson 2015); but their goals - of advancing justice remain elusive. (McChesney 2004: 297; also Gitlin 2012)

\section{CONCLUSION}

Applying an exploratory research model of SM dynamics, to compare contrasting protest episodes in 2011 and 2016, can offer new insights on movement-and-media interaction. To develop my model, this chapter reviewed social movements (SM) and mass media literature, accenting areas needing further research such as news media commercialization and SM demobilization ${ }^{59}$ - which helps bridge micro-level framing perspectives with macro-level political opportunity theories. Bridging the agencycentered framing approaches with the constraining structures of political opportunity can especially help conceptualize media's potentially constraining role - along with more practical 'situated agency' of movements and SM actors.

\footnotetext{
58 (including TimeWarner, Viacom, News-Corp $/ 21^{\text {st }}$ Century Fox, Disney, CBS, and Comcast)

59 (as well as related processes of SM marginalization, suppression and neutralization)
} 
To explore media as not only movement assets but also obstacles, and bridge the theory gap between symbolic framing dynamics and mass media structures, I develop Gamson's (1998) concept of media opportunity structure (MOS) as an interactive link between the two. While building on the SM area that analyzes "movements and media as interacting systems" (Gamson \& Wolfsfeld 1993), most such studies focus on ways that mass media help mobilize SMs. Research has nonetheless found that adverse or distorted media framing can threaten movements (e.g., Boykoff 2006; Xu 2013), but further analysis is needed to specify and model the interactive mechanisms of such threats.

The next Chapter III details my analytic research model, by extending and completing this chapter's approach - that adapted MOS to ask how news frames, if 'selling protest', might actually undercut larger movement goals. In Part A, macro-level political opportunity theories were integrated with meso-level demobilization and microframing (including methodologies), to outline a rationale for adapting the MOS model for this overall study. Part B then situated the MOS approach within news media's recent economic globalization contexts, to devise in Chapter III an exploratory research model addressing movement-media dynamics - especially neutralization by media framing. 


\section{Chapter III}

MOVEMENTS \& MEDIA OPPORTUNITY STRUCTURE:

AN ADAPTED RESEARCH MODEL 
Drawing from the previous chapter's literature review on movements and the news media that cover them, this chapter establishes an integrated research model to compare news framing of contrasting protest episodes in 2011 and 2016. The opposing political agendas of these SM episodes, anti-corporate Occupy Wall Street (OWS) and anti-government Malheur Refuge occupation (MRO) $)^{60}$, present compelling contexts for this critical content analysis - during periods of systemic change especially economic and mass media (e.g. Gans 2018; Pew Research Center 2018). In the literature review, both the cultural and structural views - with the latter positing far more constrained movement-media interactions - see economic globalization as a force that commodifies or commercializes the public sphere in which media and SM interact.

Alternatively, composite views of mass media - with an adapted model of media opportunity structure for movements (see below) - can ground the commodifying global processes in specific local and historic contexts such as the anti-systemic protests, OWS in 2011 and MRO in 2016. To study these contrasting SM protest frames, the composite model to compare news content, as socially constructed and not objective, can reveal key patterns or inconsistencies. For example, while news framing of financial globalization discourse grew more nuanced or critical (Fiss \& Hirsch 2005; Gitlin 2012: 143), other complex issues like climate change or anti-corporate protest saw weakening news coverage quality (Anderson 2009: 179; Lule 2015; Xu 2013).

\footnotetext{
${ }^{60}$ MRO (also Patriot militia or self-described Citizens for Constitutional Freedom) is designated antigovernment for their core SM grievance versus US federal land management (Gallaher 2016; Rydgren 2018; Skocpol \& Williamson 2011). OWS is designated anti-corporate for their core grievance versus Wall Street, as center of corporate commerce. (Gitlin 2012; Tilly \& Tarrow 2015)
} 


\section{Global Media Contexts for Modeling Research}

Whether globalization degrades or distorts journalism (Bielsa 2008; Mumford 1970) or instead opens media channels to better represent citizens (Reese 2010: 346-350), profound changes come as old national public spheres shift to a new global public sphere (Castells 2008: 90; also, Chapter VI discusses aspects of new media, which are largely beyond the scope of this study). And even if technology's liberating potential may be constrained by economic and social structures (Alexander 2007; Gladwell 2010; Habermas 2007 [1996]), the public sphere retains crucial functions. For example, major media content is a core means by which we critically interpret cultural meanings (Croteau \& Hoynes 2014), yet audiences’ often fatalistic interpretations can still undermine democratic social change (Gamson \& Modigliani 1989; also Smith, et al. 2001). Thus, globalization's public sphere impacts are more complex than either a "benign pattern of hybrids" between global and local, or simply a Western transnational corporate domination of media (Reese 2010: 349; also Lule 2015: 79).

\section{Uneven Media Playing Fields for Social Movements?}

The media frames for major issues that news cover are especially contested around social movement issues; and since SMs often lack their own framing/ imagemaking resources, they increasingly use alternative and new media and internet (Croteau \& Hoynes 2014; DeLuca, et al. 2012). Thus, debate persists about global media's potential for empowerment (Anduiza, et al. 2014; Robertson 2015). For example local or indigenous capacities to defiantly interpret media (e.g. 'culture jamming') often then face the countervailing media capacity to marginalize or repackage that resistance as just 
another fashion. (Croteau \& Hoynes 2003: 260-293; Xu 2013; also Carragee \& Roefs 2004; Gamson, et al. 1992; Gitlin 2012; Klein 1999)

Indeed, globalizing media trends are ambiguous (Lule 2015). There are countertrends to the dominance of major nations' centralized, nondemocratic conglomerates - as socially constructed new media technology can foster plurality and engagement (Castells 2012; DeLuca, et al. 2012). ${ }^{61}$ Yet with globally standardized economic forces, the internet may not really revolutionize mass media but instead fragment mass audiences and thus society (Croteau \& Hoynes 2003: 324-354; Lule 2015: 81; McChesney 2004). So, do globalizing media standardize as well as diversify cultures, and constrain as well as liberate activism, depending on which pattern is most readily commercialized - or 'sells best'? Global media's still centralized ownership and Western dominance are neither inevitable nor final social constructions (Croteau \& Hoynes 2003: 365; Gamson, et al. 1992; Lule 2015); and they can be decoded by rigorous analytic models.

\section{MEDIA OPPORTUNITY STRUCTURE, ADAPTED}

My overall model, to compare how commercial news frames SMs that are politically disparate but with similar protest forms and durations (anti-corporate OWS and anti-government MRO), adapts Gamson's (1998) media opportunity structure ${ }^{62}$ to the recent media contexts detailed below and previewed in Chapter II. The adapted model in part predicts that voices/sources attributed within news stories will overrepresent pro-

\footnotetext{
${ }^{61}$ The nature of the medium is crucial, according to McLuhan and medium theory, such as the 'new media' that may actually enable 'electronic gated communities'; but overall, "the message cannot be reduced to the medium" (Croteau \& Hoynes 2003: 75, 308).

62 (defined as the various linkages between mass media and carriers of symbolic interests)
} 
corporate, commercial and/or anti-regulatory/neoliberal perspectives; and the most resonant SM messages will be those that are most commercially marketable (Dauvergne \& LeBaron 2014). Beyond potential patterns of news content that is commodified, I ask if analysis may reveal a paradoxical, double-edged framing (Gamson 1995). That is, while commercial news will at times portray a SM with its preferred collective action frame (Gamson 1992), if this does not also include a 'selling' frame (i.e., commercially framing key SM action), then is the frame neutralized - such as by countervailing dispersed passivity frames? (Butz 1997)

To compare news framing of the contrasting protest episodes, this study adds three key elements to adapt media opportunity structure (MOS) as a research model (Gamson 1998; Sampedro 1997; see Figure 1 below). First, combining MOS with crossdisciplinary models of mass media structures, outlined below, helps accent recent journalism/ news industry patterns. Second, developing coding schemes and glossaries that highlight frame component frequencies (see Chapter IV - Methodology) can offer more quantitative precision than many content analyses. And third, coding for my concept of dispersed passivity frames (Butz 1997; also below and in Chapter IV), as a counterpart to collective action frames, can better sensitize the MOS to the limiting, marginalizing and/or neutralizing potential of framing influences like media outlets.

According to Gamson's qualitative typology of media standing for movement frames within MOS (1998), SM challengers who win media standing and a prominent "preferred frame" gain full response; while no standing "nor increased prominence" for their preferred frame is collapse; media standing but no preferred frame is co-optation; and increased media prominence of the SM's preferred frame but no media standing is 
preemption (ibid: 72). The varied factors for a frame's mass media success include: i) a sponsor's activities; ii) journalistic norms/practices, e.g. balance norm and narrative form reduce controversies to two competing positions; iii) cultural resonances (themes/ counterthemes); and iv) narrative fit from frame contests - occurring on playing fields that are "rarely level" (ibid: 72-76). These factors are reflected in my adapted model; but I modify Gamson's typology to focus more granularly on strength/frequency of preferred frame, using a coding scheme to quantify components of collective action frames - as well as the countervailing dispersed passivity frames (see Figure 1 below and Chapter IV - Methodology).

I further situate Gamson's MOS, using a hierarchy of influences model for mass media, which posits that more research should address systems and structures behind the content which shapes the wider public sphere (Shoemaker \& Reese 1991; also Lule 2015; Scheufele 1999). From journalistic routines and economic organizational influences such as corporate conglomeration, to outside influences such as advertising and government policy, the most consistent content influences are the values of corporate liberalism within commercialized consumer culture - which also shapes or constrains social change (Shoemaker \& Reese 1991: 175; also Bagdikian 2000; Korten 1996; McChesney 2004; Ritzer 2015). While news media contents about SMs have long been analyzed with framing approaches (Entman 1993; Scheufele 1999), they have often neglected links between media frames and contexts of socio-political power (Carragee \& Roefs 2004; also see Chapter II, Framing section). And so this framing study, which models SM opportunity as bounded by media's hierarchy of influences, also explores ideology and power - echoing a media hegemony thesis whereby mass audiences shape the media that 
are nonetheless dominated in key policy domains by elite frames. (ibid: 214; also Croteau \& Hoynes 2014; Gramsci 2005 [1971]; Shoemaker \& Reese 1991)

The most critical approach to the hierarchy of influences is a production perspective, which emphasizes how industry-level mechanisms such as corporate concentration often constrain the media voices that might critique or oppose institutions of capitalism (Croteau \& Hoynes 2014; also Bagdikian 2000; Lule 2015; McChesney 2004). Yet while major media may often favor power-holder ideologies, media texts are contested cultural sites rather than uniform messages (Croteau \& Hoynes 2003: 159-161; also Carragee \& Roefs 2004; Gamson, et al. 1992; Meyer 2007; Shoemaker \& Reese 1991; Tarrow 1998). At times they challenge the status quo, but more often the dominant media marginalize critical voices and minority views by commercializing the wider content field - within a global media culture that most consistently promotes mass consumerism via advertising (Croteau \& Hoynes 2003: 189-193; Lule 2015: 87; McChesney 2004). Thus, media only partly represent society, with commercial news accentuating concerns of the affluent, disparaging underrepresented groups, and wielding the most influence when topics are beyond audiences' direct experiences (Croteau \& Hoynes 2003: 196-224; Kellner 2012).

With this production perspective on the hierarchy of influences over SM media opportunity structure (MOS) - the adapted model in Figure 1 below - this study applies novel analytic dimensions to contrasting protest news frames (anti-corporate OWS 2011 and anti-government MRO 2016). To conduct a more precise and quantifiable version of MOS analysis, the comparative dimensions include: news frame prominence shown by story placement and graphic features; narrative alignment, especially headline-and-story 
agreement that may reveal omission or distortion as well as polarization between actors/sources; source attribution, with source category frequency reflecting a hierarchy of influences; strength/ frequency of a SM's preferred frame, especially of rational activist voices framed with components of collective action versus dispersed passivity (see below); and commercially-framed SM action. These dimensions are further detailed in Chapters IV and V - Methodology and Results.

This version of the MOS analytic model is most notable for introducing dispersed passivity (DP) as the countervailing dimension to collective action (CA) framing (see Figure 1 below). The model emerges from my prior study of urban environmental movements' shifting news frames within Portland's conglomerating newspaper market (Butz 1997; also Molotch \& Logan 1984); and that CA frame analysis revealed that daily newspapers' consolidating ownership correlated with dramatic shifts from the early1970s to mid-1990s toward news portrayal of more neutralized movement actors - a pattern I labeled the dispersed passivity frame (Butz 1997). The current study's more elaborated research model comparing SMs and news outlets, more than time periods, may better suggest to what extent - and how - media framings (or media effects) align with SMs' preferred framing (or mobilizing frames). Beyond bridging this longstanding gap in the literature (see Gitlin 1980 versus Snow, et al. 1986), this study helps identify or decode key media-movement mechanisms for 'selling protest'.

The adapted model to explore movement-media interactions, adding the countervailing DP frame to detect media's potential to constrain (and not just enable) movement opportunity, particularly allows comparison of framing for ideologically disparate protests like OWS and MRO. The DP frame's fate, passivity and dispersion 
components directly contrast with the CA frame's injustice, agency and identity components. Analyzing strengths/ frequencies or resonance for these and other content dimensions will then indicate results based on this double-edged or dual research question: 1) If dimensions such as polarization/conflict narrative and commerciallyframed activism ('selling' themes in corporate liberalism, news media's dominant frame) are found more frequently, then do movement-media frames also reflect more of the SM's preferred CA frame (Path X in Figure 1 below)? Or instead, 2) if polarization and commercially-framed activism are less frequent, then do movement-media frames reflect the SM's less preferred DP frame (Path Y in Figure 1) - including movement action portrayed as more marginal, futile/ fateful/ inevitable, abstract, and thus neutralized?

\section{AN ADAPTED RESEARCH MODEL}

My research model adapts media opportunity structure (MOS, see Figure 1 below) to analyze movement-media interactions within the wider context. The contrasting anti-systemic SM episodes, anti-corporate OWS 2011 and anti-government MRO 2016, also coincide with years when traditional news was struggling for position in the digital revolution (Gans 2018; Pew Research Center 2018). For example, The Oregonian dramatically reduced daily delivery and print news content; while more broadly, rising 'new media' had not clearly filled the journalism gap (McChesney \& Nichols 2010; Peters \& Broersma 2013). So, comparing the parallel yet contrasting protests - with grievances that also parallel core political-economic issues for a shifting commercial media - can suggest how news framing may ‘sell' (or undersell) protest. Thus, the MOS model (shown in Figure 1 below) can newly illuminate paths or perhaps 
mechanisms by which media not only frame SM success/ potency/ resonance but may also present neutralizing or de-mobilizing frames for movements.

\section{Figure 1}

ADAPTED RESEARCH MODEL

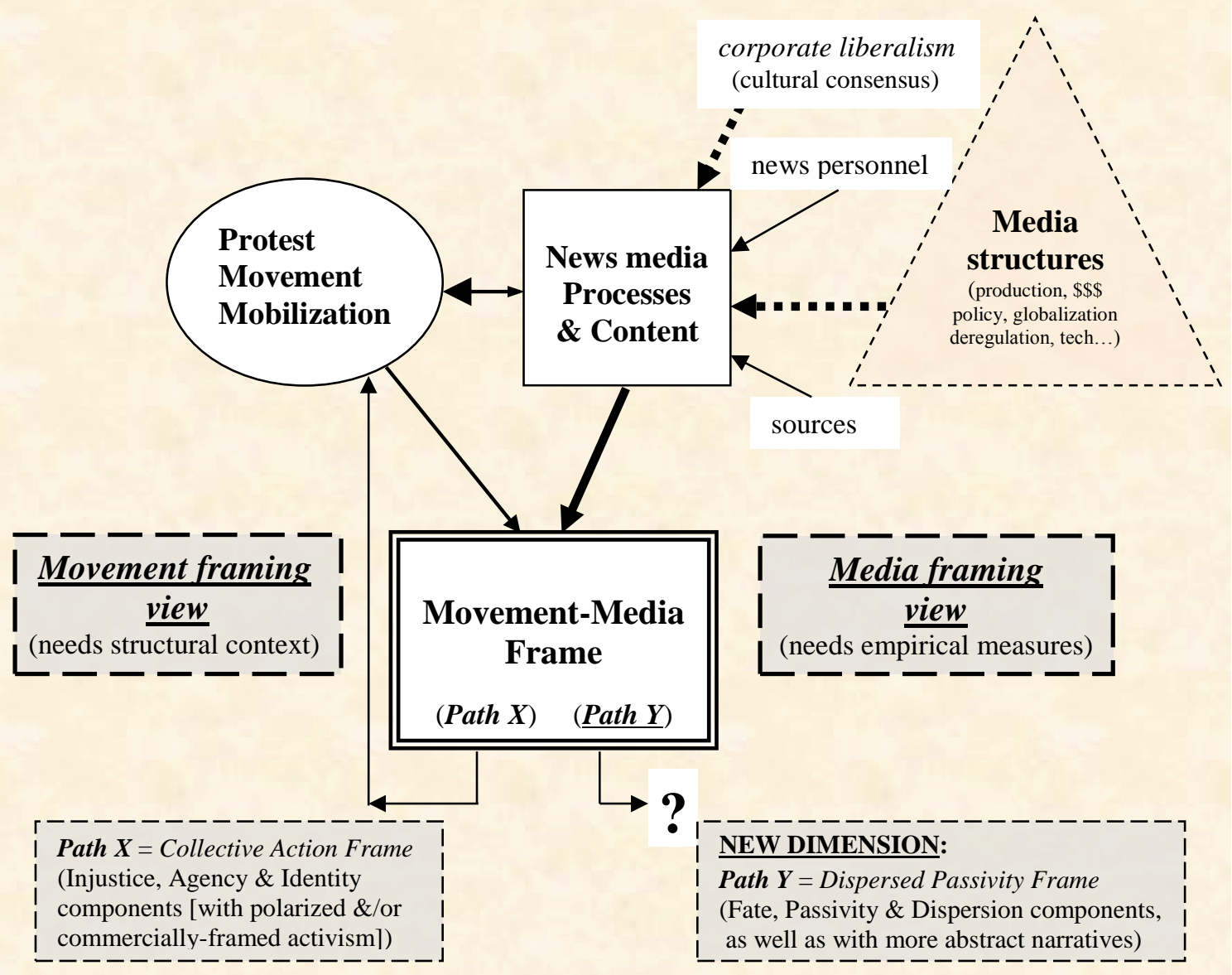

\section{Media Opportunity Structure*}

(within discursive \& political opportunity structures)

* (adapted from Gamson 1998) 


\section{Chapter IV}

METHODOLOGY 


\section{INTRODUCTION}

This study comparing disparate SMs' coverage by news outlets in a shifting media industry, beyond exploring how consistently news standards apply to the SMs, more broadly explores how news framing not only enables but may also constrain movement messaging. My adapted media opportunity structure (MOS) model to study SM media standing (Gamson 1998; see also Chapter II, Part A Integrating ... Methods \& Chapter III) uses content analysis methods to compare news framing of the contrasting 2011 anti-corporate and 2016 anti-government protests. These anti-systemic SM protest episodes on the left and the right, Occupy Wall Street [OWS] in 2011 and the 2016 Malheur Refuge occupation [MRO], were selected to highlight emerging poles of recent national and international political-economic grievance areas. ${ }^{63}$

\section{Expected OWS vs. MRO Influences on News Framing?}

The textual and other news content data include print and online coverage by major newspaper outlets during the OWS and MRO occupations, whose disparate grievances nonetheless had similar durations and forms - as unauthorized encampments protesting perceived systemic injustices. With their similarities (of anti-systemic protests intending indefinite occupation but getting eviction after 40 days) one could then expect comparable news framing. Yet, as introduced in Chapter I, OWS and MRO's notably contrasting SM cultures and structures can also be expected to have key news frame differences, beyond the seeming advantage of a cogent name like "Occupy Wall Street".

\footnotetext{
${ }^{63}$ MRO (also Patriot militia or self-described Citizens for Constitutional Freedom) is designated antigovernment for their core SM grievance versus US federal land management (Gallaher 2016; Rydgren 2018; Skocpol \& Williamson 2011). OWS is designated anti-corporate for their core grievance versus Wall Street, as center of corporate commerce. (Gitlin 2012; Tilly \& Tarrow 2015)
} 
Both protests engaged in extensive media relations. The populous, urban, consensus-based Occupy Portland (OWS) hosted an info/media booth, a KBOO community radio booth, and website/ social media/ livestreams online (see Appendix F interview transcript). Such voluntary resources varied across locations such as NYC's Zuccotti Park, and instead of a conventional media spokesperson, they were often a less visible or consistent facilitator (elected by assembly). Another expected news framing disadvantage for the diverse, anti-corporate OWS came from dividing audience attention by a 'thematic heaping' of many diffuse SM issues under the broad tent - such as outlined in the bold yet sprawling Declaration of the Occupation of NYC. Moreover, some open distrust or antipathy was mutually expressed between both OWS and media persons, such as a USA Today headline "Millennials, don't just 'occupy'; do something" (see Appendices B and also F - transcript).

On the other hand, the small rural, traditional (simple command structure yet some majoritarian voting) MRO hosted daily press conferences, some media tours, the conservative radio host Pete Santilli, as well as social media and livestreams online (The Oregonian 2017). Unlike OWS, the homogeneous, rightwing anti-government MRO maintained tight control over the occupation site (especially for being unauthorized) - as well as over their antiregulatory message promoting resource extraction (ibid.). However, mutual distrust or antipathy was expressed also between MRO and media, such as the 2016 USA Today headline "Takeover of federal refuge in Oregon breaks the law" (see Appendix B). Overall, MRO's most visible expected framing advantages, more than any special media savvy or cooperation, came from its small, unified culture and 'simple' goal of using "these lands as free men" - who were also armed (The Oregonian 2017). 


\section{Expected News Framing Influence of 2011-2016 Media Context?}

In a wider discursive context, the protest episodes in 2011 and 2016 also coincide with years when traditional news were struggling for position in the digital media revolution, while ascendant new media had not clearly filled the journalism gap (Gans 2018; McChesney \& Nichols 2010; Peters \& Broersma 2013). U.S. newspaper circulations - now at their lowest levels since the 1930s - have had their sharpest declines since 2011 (Pew Research Center 2018). And while some outlets have fared better than others during this period, the record newspaper closures and cutbacks hit locally when The Oregonian since 2011 ended daily delivery and also switched from broadsheet to tabloid format.

Such change, especially due to readers and advertisers moving to online/digital news, brings some notable considerations for OWS vs. MRO coverage. First, in late 2011 as papers rapidly went digital and otherwise innovated to retain advertisers and readers (e.g., see Appendix F - transcript), this unusually turbulent moment in U.S. news production could perhaps offer OWS no more than a 'sympathetic but silly' frame. Then by 2016, given that The Oregonian had gone tabloid and dramatically cut its daily print news content compared to 2011, their coverage of MRO was therefore especially ample: 143 stories, versus 87 on OWS (see Appendix E). The likely rationale for this difference is the obvious Oregon human interest story, of $\mathrm{MRO}$ as remote and rugged 'formidable opponents'.

Instead of a transnational popular uprising, which OWS seemed to represent, the well-armed MRO could be dramatically framed as deviant event-with-personality - for journalism's supposedly perfect story to woo audiences (Gans 2018). Indeed OWS and 
MRO coverage might be prototypical examples for two of the top news framing devices for SMs - in 2011, trivialization and in 2016, polarization (Gitlin 1980). So, to assess such potential news media influence and identify key framing mechanisms, a text-based comparative frame analysis - detailed below and justified in Chapter II (Part A Integrating...Methods) - is the leading methodology (Johnston 2005: 243-255).

\section{SAMPLING PROTOCOL}

Comparable sample frames were derived from the encampment occupations that for OWS lasted 38 days in Portland, OR and 60 days in New York City, and that for MRO lasted 40 days in Oregon's Malheur National Wildlife Refuge. By the principle of triangulation, where analytic patterns require at least three instances (Berg 2007), OWS and MRO protest news coverage was sampled from the three top-circulating national and state publications - The New York Times (NYT), USA Today (USAT), and The Oregonian $(O R G N)$. Comparative analysis, of news coverage spanning 60 to 75 days (of the antisystemic occupations spanning 40 to 60 days), was then conducted for 60 stories published by the three commercial print news outlets (experiencing systemic changes).

The total populations of published news stories and editorials, controlled so that specific protest sites and SM actors are actual subjects and sources within a story, were compiled by advanced keyword searches of LexisNexis and Newsbank full-text online databases. ${ }^{64}$ For coverage of OWS 2011 by NYT and USAT (in LexisNexis Academic:

\footnotetext{
${ }^{64}$ Newsbank full-text $O R G N$ access is via Multnomah County (and Univ. of BC) Libraries. A pilot sample frame containing all OWS news stories (part of a larger population of 1,955 stories on anti-systemic SM protests in NYT, ORGN, CNN, The Christian Science Monitor, The Guardian UK, and NPR) was compiled by advanced keyword Boolean search in Lexis-Nexis and Newsbank online databases in 2013.
} 
headline-lead search) and by $O R G N$ (in NewsBank America's News: all-text search), keyword Boolean search terms to establish the sampling population/sample frame included: "occupy (OR) wall street (AND) protest". Search terms for MRO 2016 were more varied, reflecting a more localized media frame. For NYT and USAT, search terms included: "Malheur (OR) armed (OR) militia (OR) Bundy (OR) Burns (AND) Oregon". Search terms for $O R G N$ included: "Malheur (AND) protest (OR) Burns (NOT) after $2 / 29 / 16$ ", with the date parameter to control for some currently ongoing local/ regional news coverage of legal proceedings (and Newsbank's recently revised database format).

\section{The Sample}

The 60-story sample was drawn randomly ${ }^{65}$ from the whole population of news about the contrasting protests published in NYT, USAT and ORGN. Thus, each protest episode had 30 news stories sampled, with 10 stories from each newspaper. These were analyzed in successive study stages, including a preliminary 12 stories (six on OWS 2011 and six on MRO 2016) and an intermediate 42 stories (21 on OWS and 21 on MRO). Also, an initial story that was convenience-sampled for a Pilot Study (see Content Analysis below and Appendix F) was coincidentally included in the final random sample.

The search criteria yielded 500 to 600 stories total that, controlling for protest sites and actors as noted above, was culled to 255 stories on OWS and 213 stories on MRO. From NYT's total population of 134 stories on OWS 2011 published during 75 news days, random draws were repeated until each of 10 stories came from each of 10 successive weeks of news. From USAT's population of 34 OWS stories during the same period, 10 were drawn randomly so that they came from each of 9 weeks of available

65 (using Random.org to draw from numbered, chronological lists of each newspapers' story populations) 
news. And from $O R G N$ 's population of 87 OWS stories published during 59 news days, 10 were drawn so that they came from each of eight successive weeks of news coverage.

Next, 10 news stories each on MRO 2016 were drawn randomly from: ORGN's total population of 143 stories, USAT's population of 14 stories, and NYT's population of 56 stories. These outlets' 59-news-day sampling windows (in 2016, and also in 2011 for $O R G N$ ) correspond with sampling from initial coverage of protest until two weeks after the encampments' evictions by authorities; and the 75 news days for NYT and USAT in 2011 reflected the longer encampment at the original OWS site in New York City. Overall, news stories were re-sampled until every week of NYC's 10-week (in 2011) and Oregon's eight-week (in 2011 and 2016) encampment periods were represented; however, USAT had relatively fewer weeks of news coverage (during nine weeks in 2011 and during just four non-contiguous weeks in 2016). Given the punctuated life course of any protest (Koopmans 2007; McAdam, et al. 1996), sampling to include every week of the contrasting encampments thus strengthens this study's analytic validity.

\section{CONTENT ANALYSIS}

The analytic model and sampling protocol outlined above especially reflect principles of intensive textual analysis including context, intent and role perspectives for the text's production (Johnston 2005). Next, through largely inductive stages of widening samples, from Pilot and preliminary to intermediate analyses, I developed framing glossaries and coding templates to analyze the final sample of 60 news stories (see Appendices B to E; Figure 2 - News Story Coding Template; and next section below). This mostly manual process used hand annotation, including color-coded abbreviations 
and symbols, for the emergent (as well as theorized) coding dimensions. With further multistage refinements, including re-coding of early samples, all story coding templates were then quantitatively summarized in frequency tables such as in Chapter V. (ibid; also Aiden \& Michel 2013; Johnston 2005)

\section{Pilot Study with Exploratory Interview}

During initial sampling and coding, a Pilot Study was done to begin refining the news content analysis scheme (see Appendix F) - and which subsequently ruled out other methodologies. For example, the Pilot included a semi-structured phone interview with one OWS activist and with The Oregonian reporter who covered their protest. From one published story sampled, each was identified and initially contacted online, for a 30minute phone interview regarding key elements of media-movement framing. Responses were documented by simultaneous interviewer note-typing (Appendix F - Transcript).

Both the OWS activist and the journalist each re-read and reflected on their common news story - and without any knowledge of the other, they expressed awareness of complex tensions in movement-media interactions. For example, the activist wished the story had omitted fewer voices, saying there was "a lot of animosity toward news, after the stories ran... Part of what we're protesting is this corporate-controlled media." Indeed, the reporter recognized that the story "didn't mention the broader movement; [and] that was a flaw". Suggesting constraints yet also advantages from wider news production: the activist said "we can talk to the media if we find the right people, [or]...we have our own social media". And about new media (with greater deadline pressures as newspapers went further online in 2011), the reporter recalled "learning to be more nimble..., [to] feed the beast earlier in the day." 
Interviewing those directly linked to the news content thus elicited, with minimal involvement, contextual data to further develop the coding schemes (Blee \& Taylor 2002). And exploring these otherwise inaccessible media and movement settings helped further ground and humanize the overall analysis (Charmaz 2001; Weiss 1994). So, while the Pilot interviews are not part of this study's Results in Chapter V, they helped situate and specify the global perspective on SM-media interactions at the core of the MOS research model.

\section{Coding Process \& Coding Dimensions}

Before fully deploying a Coding Template (Fig. 2), conventional content analysis or open coding (Hsieh \& Shannon 2005) - used mainly in Pilot or preliminary analysis and following inductive methods informed by grounded theory - first identified patterns such as in vivo journalistic and SM actor narratives (Berg 2007; Strauss \& Corbin 1998; also Gamson 1992; Gitlin 1980). The subsequent axial and selective coding, or directed content analysis (Hsieh \& Shannon 2005; Strauss \& Corbin 1998), is the best suited for standardized stories like news - and thus developed the Template used for most sample coding (Fig. 2). As outlined below, this template was used to: first categorize sources by institutional type (government, business, citizen/independent, academic); identify sources' economic/ regulatory perspectives (anti-corporate to anti-government); note story placement; and tally source attribution frequencies in a story.

Eventually applied to every sampled news story, the Coding Template (Fig. 2 and Appendix D) includes key dimensions for media-movement frames such as: the sources, the preferred SM perspective, as well as collective action frames. These are among other dimensions previewed below, along with examples of coding judgments. And to use the 
finalized template (emerging from multiple prior versions), the average coding time per story - including re-checking and re-coding - was from one to two hours.

\section{Figure 2}

NEWS STORY CODING TEMPLATE

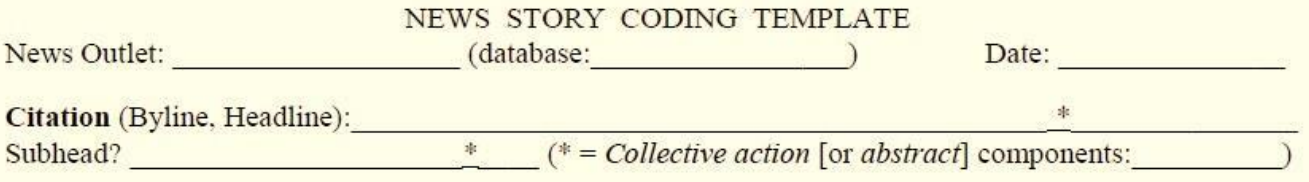

Summary:

Photo? _ caption? _ collective action components? abstract components? _ WC Agreement:...Headline-Story? yes_ (no__) (mixed__...Lead-Story? yes_ (no__) (mixed_ ),

Sources:

Un-sourced Portrayals:

Frequency of Attributions ('source type' by 'commercial-gov. perspective'):

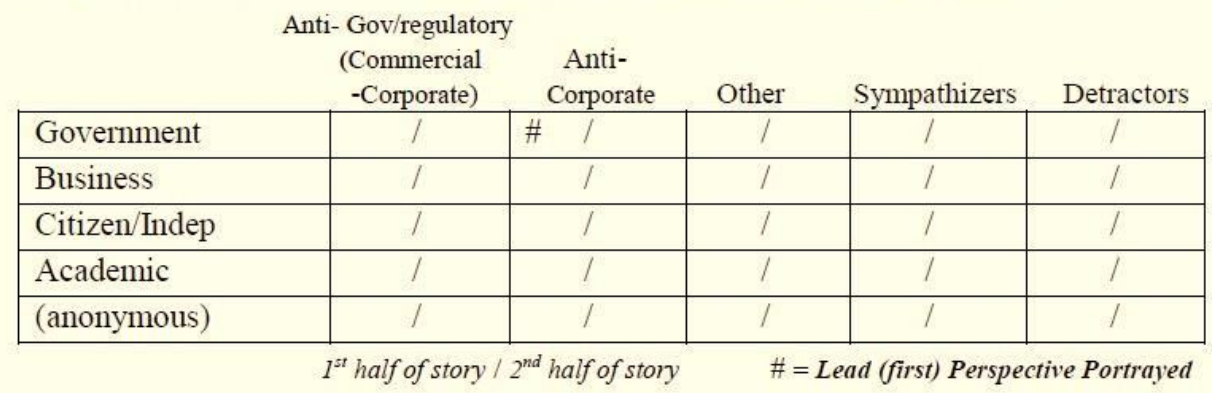

Portrayal of Activists:

(Dispersed Passivity [path $\boldsymbol{y}$ ] or Collective Action [path $\boldsymbol{x}$ ] Frames by 'commercial-gov. perspective')

\begin{tabular}{|c|c|c|c|}
{$[y] \ldots$...... $[\boldsymbol{x}]$} & A-G & A-C & Other \\
\hline Fate..........Injustice & $/$ & $/$ & $/$ \\
\hline Passivity......Agency & $/$ & $/$ & $/$ \\
\hline Dispersion....Identity & $/$ & $/$ & $/$ \\
\hline (Abstract) & $/$ & $/$ & $/$ \\
\hline (complete C.A.F.s) & $/$ & $/$ & $/$ \\
\hline \multicolumn{4}{|c|}{$1^{\text {st }}$ half of story / $2^{\text {nd }}$ half of story }
\end{tabular}

Dominant Perspective in Story:

\begin{tabular}{|l|l|l|l|}
\multicolumn{1}{c}{ A-C } & \multicolumn{1}{c}{ Other } & \multicolumn{1}{l}{$\begin{array}{l}\text { Between } \\
\text { Perspectives }\end{array}$} \\
\hline & & & \\
\hline
\end{tabular}

Polarization (instances):

Rational SM actor/statement (instances):

Irrational /dramatic/emotional SM actor/statement (instances):

Commercially-framed activism (market metaphor/terminology), instances: 
So, this coding approach prioritizes who speaks, how prominently or frequently, and their portrayed political-economic perspectives, from anti-corporate to antigovernment ${ }^{66}$ (see Figure 2 below and Appendices $\mathrm{C}-\mathrm{D}$ ). Coding of story Attributions requires tallying each time a source gives info (i.e., how frequently a source speaks), and so this notably reflects news processes and journalistic norms (Bennett 1996; Boykoff \& Boykoff 2007). A 2011 example of one 'anti-corporate citizen' attribution is:

“...a facilitator who has been at the campsite since Oct. 6, said demonstrators walk a blurred line between protesting the nation's economic disparities and caring for the chronically homeless...." (see Appendix F).

Coding even this basic attribution frequency is a nuanced process, as the above excerpt is actually a double attribution - with "demonstrators...protesting...". And this further attribution is anonymous, which is expected to be more frequent for communal and crowded OWS than for individualist and small MRO - with big framing implications.

Central to my MOS model and selective coding are news content dimensions of collective action versus dispersed passivity frames - and their suspected associations with commercially-framed activism or instead SM frame neutralization. Mobilization needs news with complete collective action frames - where identity, agency, and injustice components all appear jointly (Gamson 1998). For example, a 2016 headline "Armed Protesters Vow to Stay on Oregon Refuge Indefinitely” (Appendix C) has clear agency ("armed...vow") and contextually subtle identity ("Protesters ...on Oregon Refuge") and "Protesters" also signifies injustice. ${ }^{67}$ (Or, see paragraph above as another example.)

\footnotetext{
${ }^{66}$ This dimension's 'Other' category, to reflect more nuance within the range of Anti-corporate to Antigovernment perspectives, may include views such as 'vertical- and 'horizontal-regulatory commercial' where regulated (national or local/regional) commerce is advocated. (e.g. Molotch \& Logan 1984)

${ }^{67}$ Abstract targets ('the system') discourage injustice frames and are immobilizing (Gamson 1995:91-92).
} 
More broadly, any MOS will have competing rhetoric, such as rhetoric of change (e.g. 'urgent') - versus rhetoric of reaction (e.g. 'jeopardy', 'futility') or of inaction that is neutralizing or signals demobilization (Hirschman in Gamson \& Meyer 1996: 285287). And such patterns show the logic of my dispersed passivity frame dimension. Its dispersion, passivity and fate components, for example, were coded from these 2011 headlines: "NYC protesters vow to defy order to leave park" (dispersion); "Eight arrests, but peace reigns" (passivity); and "Other Sites Hope N.Y. Raid Will Energize Cause" (fate). Such frames (especially all three components jointly) are expected to be rare with any SM mobilization - as they instead signify demobilization. Likewise, though perhaps not as uncommon, news stories with more attribution to official government or business sources - than to SM participants - may indicate demobilization.

The code dimensions central to 'selling protest' are polarization (conflict narrative) ${ }^{68}$ as well as commercially-framed activism. And the armed, resource-extracting MRO is expected to yield more instances, such as "...these men had alternative motives to attempt to overthrow the county and federal government..." (polarization, see Appendix C). Yet for commercially-framed activism (framing activism with commerce/ market terminology), a key question is if OWS - although anti-corporate - still displays media's dominant story frame of corporate liberalism. For example, a 2011 USA Today headline was "Wall St. rallies are new brand of tourism..." (Appendix B). Further examples of these and other coding dimensions - in order to compare OWS-MRO frame

\footnotetext{
${ }^{68}$ A related coding category emerged inductively - protest Sympathizers versus Detractors - echoing research on the importance of establishment sympathizers, especially for right-wing SMs (Blee \& Creasap 2010; Koopmans \& Muis 2009).
} 
resonance and illuminate the selling protest questions - are outlined in subsequent Chapter V Results.

\section{CONCLUSION}

Comparative content analysis, with an adapted media opportunity structure (MOS) model to assess media standing (Gamson 1998), is used to illuminate movement and media interactions for OWS in 2011 and MRO in 2016. This methodological approach has several strengths and a few limitations. Overall, a comparative study - a research strategy rather than a method - offers a fruitful approach to yield empirically meaningful results and advance theory while applying largely qualitative methods (della Porta 2002; Klandermans \& Staggenborg 2002; McAdam, et al. 2001; McCarthy, et al. 1996: 311; Snow \& Trom 2002: 146). Also, the broader interpretive discourse methods have especially been suggested to help bridge SM theory's framing with political process approaches (Blee \& Taylor 2002; Melucci 1995).

Combining discourse methods like content analysis, with a comparative approach that triangulates data sources (three news outlets), helps track protest events in historic sequence and thus reflect SMs' context of cultural change - for which news media discourse is a key indicator (Clemens \& Hughes 2002; McAdam, et al. 2001: 329). Content analysis, as a field- and theory-driven, micro to macro approach, also fits logically to see the general in the unique and synthesize evidence with macro-social theory (Lichterman 2002: 122). This study's comparative content findings (in Chapter V - Results), from random samples and largely summarized in frequency tables, can thus indicate the SM-media frame's generality (Johnston 2005). Quantitative content analysis 
is also more empirically robust than other less generalizable qualitative approaches (Johnston 2002: 69). And so, applied comparatively, the limitations of content analysis for testing causality are offset by its strengths - of being unobtrusive, inexpensive and revealing of time-series movement framing trends. (Berg 2007; Johnston 2005) 
Chapter V

$R E S U L T S$ 


\section{MEDIA FRAMING \&/or PROTESTER FRAMING?}

Comparing the framing of contrasting protests within transitioning media outlets suggests in part how commercial news 'sells protest' - not only movement (SM) frame resonance but also neutralizing or demobilizing frames. These results extend from contrasting news frames initially identified (pre-analysis shallow reading) as follows: Occupy Wall Street in 2011 (OWS), protesting economic injustice or corporate excess/ commodification (see Chapter I, footnote 5), was typically portrayed as 'sympathetic but silly'; while Malheur Refuge Occupation in 2016 (MRO), protesting political injustice or government/ regulatory excess, was portrayed as 'formidable opponents'. Beyond these initial frames, deeper analytic results suggest a general news frame for OWS - despite being a far larger protest episode than MRO - that was surprisingly less potent, vocal and resonant than for MRO. These results, across 15 news framing dimensions, may then suggest potential mechanisms for how certain media-SM contexts frame some activists as "more equal than others".

This comparative framing study analyzes 60 stories published in The New York Times (NYT), USA Today (USAT) and The Oregonian (ORGN) - drawn randomly from 255 total stories on OWS in 2011 and from 213 stories on MRO in 2016. During this study's Proposal, Pilot, Preliminary, and Intermediate analytic stages, a coding scheme was iteratively developed using open, axial and selective coding. Following successive revisions, in consultation with my Portland State University dissertation committee, a News Story Coding Template was used to analyze each of 60 stories (see Chapter IV, Figure 2). Coding Templates from the 60 different stories (30 for 2011 and 30 for 2016) were then compiled into two Summary News Code Sheets (one for 2011 and one for 
2016), each consisting of 15 analytic dimensions. The results highlighted here, from noteworthy news content patterns found in two Summary Code Sheets (Appendix E), thus comprise final analytic results for comparative study of news framing of OWS in 2011 and MRO in 2016. While these are quantitatively presented in tables, this study's basis in multiple comparisons precludes the use of more advanced calculation of statistical significance or p-values (Gelman \& Loken 2014; Simmons, et al. 2011)

Table 1

The Sample, $n=60$ news stories

Occupy Wall Street Malheur Refuge Occupation (OWS 2011) (MRO 2016)

\begin{tabular}{|l|c|c|}
\hline The New York Times (NYT) & 10 & 10 \\
\hline USA Today $($ USAT) & 10 & 10 \\
\hline The Oregonian $($ ORGN) & 10 & 10 \\
\hline
\end{tabular}

\section{Lead Frame Prominence (prevalence/placement/visibility \& Story Citation)}

Clearly OWS had more national news coverage (168 stories during 75 news days in NYT and USAT) than MRO (70 stories during 59 news days in NYT and USAT). This difference (averaging 2.24 news stories per day for OWS and 1.19 for MRO) presumably reflects the more populous and widespread OWS encampments, as well as the prominent NYC original location. Regardless, OWS and MRO protest story placements within the newspapers were similarly prominent, so story placement is not featured among the dimensions in the Summary Codes Sheets (but see Chapter VI Conclusion).

Notable contrasts yet also continuities between OWS and MRO are evident for the dimension of Story Citations (Byline, Headline, \& Photo), especially for frequency of named/personified activists as well as collective action components in photos/captions 
and headlines (see Tables 2 and 3 below). Activists were named or otherwise personified in most MRO story headlines (20 of 30) - but in only nine out of 30 OWS headlines.

Photos revealed another surprising contrast, as they accompanied most MRO stories (19 out of 30) but only six OWS stories. ${ }^{69}$ (Also see Corrigall-Brown \& Wilkes 2012.)

Table 2

Story Headlines \& Photos $(\mathrm{n}=30)$

\begin{tabular}{|l|c|c|}
\hline With activists named /personified & 9 & 20 \\
\hline With photo(s) & 6 & 19 \\
\hline
\end{tabular}

Similarly, headlines or captions portrayed MRO activists with collective action components of 'agency' in 24 instances (e.g. "ranchers seize"), versus 16 for OWS. However 'injustice' components were portrayed for OWS activists in 18 instances, versus only six instances for $\mathrm{MRO}^{70}$ (e.g. "protest begins"; see Table 3 and Appendix E). Yet the headlines' total collective action component (injustice, agency, identity) frequencies had striking continuity between protest episodes, with 46 for OWS and 45 for MRO. At the same time, for contrasting 'abstract' components (passive and/or abstract portrayal, e.g. "crowd", "arrests"; see Table 10), OWS had 16 while MRO had nine.

\section{Table 3}

Headlines \& Captions: Collective Action Component Frequencies

\begin{tabular}{|l|c|c|}
\multicolumn{1}{c}{} & OWS & MRO \\
\hline Injustice & 18 & 6 \\
\hline Agency & 16 & 24 \\
\hline Identity & 12 & 15 \\
\hline TOTAL & $\mathbf{4 6}$ & $\mathbf{4 5}$ \\
\hline
\end{tabular}

\footnotetext{
${ }^{69}$ This dimension reveals a database limitation, where ORGN Newsbank and USAT LexisNexis stories have less photo-related data (e.g. omitting caption text) than NYT LexisNexis stories have.

${ }^{70}$ While this may factor in MRO's small size (Gamson 1998), its remote protest location was paramount.
} 


\section{Word Count, Headline-Story Agreement, \& Lead Perspective}

Before comparing the interior semantic contents of OWS and MRO news stories, largely as coded dimension frequencies, comparing story word counts can suggest how to begin interpreting such frequencies. The word counts (provided only for NYT and USAT) average 569.5 for OWS stories, versus 648.5 for MRO stories - a modest $14 \%$ difference. This may reflect journalism norms, as more MRO stories were a feature-style (more straight-news for OWS), more suited to MRO's smaller protest crowd sizes and selfidentified leaders - as largely middle-aged, white male 'rugged individuals'. Yet MRO stories' somewhat larger word counts, that perhaps suggest 'deeper' news coverage, do not account for most of the still larger differences in comparative frequencies of analytic dimensions (from Source Attributions to Collective Action components) explored below.

Headline-Story Agreement, a dimension that codes where headline content disagrees with the story, may reveal news imbalance, distortion or bias. Notably equal proportions of OWS and MRO stories (17 out of 30; see Table 4 below) showed some Headline-Story (H-S) disagreement. Yet in most MRO cases of H-S disagreement (nine of 17), the headline more positively framed MRO than the story did; while for OWS' 17 disagreements, 12 were headlines that more negatively framed OWS than the stories did.

Table 4

Headline-Story Disagreement $(n=30)$

\begin{tabular}{|l|c|c|}
\hline Headline frames more positively & 3 & 9 \\
\hline Headline frames more negatively & 12 & 2 \\
\hline Neutral disagreement & 2 & 6 \\
\hline TOTAL & $\mathbf{1 7}$ & $\mathbf{1 7}$ \\
\hline
\end{tabular}


For example in 2016: a NYT story headlined "Fervor at...Refuge, Concern Just Outside It" actually covered area residents' vocal and organized opposition to MRO, far beyond mere concern; and in a USAT story headlined "A bizarre end...; Last holdout...rambling phone call...", only in the conclusion did it reveal the MRO holdout was actually armed and threatening suicide. In contrast for 2011: an ORGN story headlined "Eight arrests..." actually stressed that Portland police were "stunned" by OWS activists' cooperation; and a USAT story headlined “...Arrests drive interest..." made no mention of actual arrests in the OWS story. (See Appendices B and E.)

After the headline, a story's Lead (first) Perspective Portrayed will also impact frame resonance. The preferred frame for OWS is Anti-Corporate, and for MRO it is Anti-Government. And these were the Lead Perspectives in equal numbers of stories (nine of 30) for both OWS and MRO. This even balance, for a highly visible (and also readily coded) content dimension, may reflect the hierarchy of influences in the news as defined in Chapter III. First, protests like OWS and MRO are usually minority perspectives (thus featured first in only nine of 30 stories); while relevant authorities or dominant cultural norms typically have the first or dominant perspective in news. Next, these patterns also reflect traditional journalism norms; and further results below comprise coding dimensions that highlight these norms and structural patterns.

\section{Sources \& Attributions}

As they indicate who speaks and how loudly, the Source Attribution frequencies and prominence within news stories are among the most quantitative and 'democratic' dimensions of content analysis. For example, citizens/protesters are often attributed or cited more frequently (yet anonymously) while official sources are more often named and 
otherwise emphasized (Bennett 1996). And the comparative news samples reflect some noteworthy aspects of these patterns.

Indeed Citizen/Independent (C/I) were the most frequently attributed source types in both OWS and MRO news stories, comprising from 1/3 to $1 / 2$ of all attributions (see Table 5 below and Appendix E). While C/I were larger portions of the total in OWS stories, the MRO stories had more total attributions than OWS had (802 versus 623). Yet this $29 \%$ difference is tempered by recalling that MRO stories (often feature news) had $14 \%$ longer average word counts. Perhaps more notable, the total difference mostly reflects MRO stories having much larger numbers of attributions to Business and Government source types. This likely relates to MRO's explicitly armed, antigovernment agenda and remote location, as well as activist-leaders' promotion of or stated involvement in resource extraction businesses like ranching.

Table 5

Attribution Frequencies: Source Type by Protest News Sample

SOURCE TYPE
\begin{tabular}{|l|c|c|}
\hline Government & 94.5 & 234.5 \\
\hline Business & 32 & 104 \\
\hline Citizen/Independent & 287.5 & 287.5 \\
\hline Academic & 19 & - \\
\hline (anonymous) $^{71}$ & $(190)$ & $(175.5)$ \\
\hline TOTAL & $\mathbf{6 2 3}$ & $\mathbf{8 0 1 . 5}$ \\
\hline
\end{tabular}

Adjusting for average word count, total OWS and MRO news story Attributions are quite similar (remarkably so for $\mathrm{C} / \mathrm{I}$ and for the nearly absent Academic source type

\footnotetext{
${ }^{71}$ A portion of attributions are both anonymous and Citizen/Independent (C/I); for example, "protesters demand" is coded as half anonymous and half C/I. This also occurs, but less often, for anonymous and Government attributions, for example "police report...". Thus, some frequency tallies are fractional.
} 
in Table 5 above); yet recall that compared to MRO, OWS had far more participants who were in much more populated areas and thus more accessible to journalists. So, rather than the two protests being proportionately represented in news, the small, homogenous rightwing MRO actually had approximately as much voice per story (in 'liberal' NYT, USAT and $O R G N$ ) as the far larger, diverse left-leaning OWS. At the same time, with more total stories published per news day, OWS can be described as having more aggregate media reach or news volume. Yet MRO's far greater attributions per story relative to protest crowd size (a few dozen MRO versus hundreds or thousands of OWS participants per site) suggest a media density or per-story volume of human actor voices that can be interpreted as very high levels of humanizing frame resonance.

Table 6

News Sources \& Unsourced Portrayals

\begin{tabular}{|l|c|c|}
\hline Total Discrete Sources & OWS & MRO \\
\hline Frequency of Unsourced Portrayals & 338 & 340 \\
\hline
\end{tabular}

Similar to the attributions pattern noted above, Table 6 shows that MRO stories had $20 \%$ more total discrete sources named - but $82 \%$ more unsourced portrayals than OWS had. (Each instance where a source is cited constitutes an attribution, while an unsourced portrayal is an instance where an actor/entity is named but does not 'speak'.) Again, this MRO versus OWS difference partly reflects longer word counts per story (covering self-described leaders and more individualist MRO culture compared to the often 'leaderless'/autonomous OWS collectives). Yet given that MRO's remote location and smaller population clearly mean fewer potential sources to cite, their stories' notably greater density of named or cited actors again shows a more resonant protest frame than 
would be expected. News frame resonance is also associated with conflict and polarization (noted further below), shown in part by the Attributions category of Sympathizers versus Detractors $^{72}$ (see Appendix E); and MRO had 47 Detractor attributions while OWS had only 20, recalling MRO’s initial frame of 'formidable... opponents' noted in this chapter's introduction.

\section{Commercial-Government Perspectives}

This is the dimension that most directly indicates if a SM's preferred protest frame becomes the media frame. In broad terms, activists' preferred frame in 2011 OWS was Anti-Corporate, while in 2016 MRO was Anti-Government. Also, an alternate 'Other' Commercial-Government Perspective was coded, which can include vertical- or horizontal- regulatory commercial, an ambivalent source, or an unclear story narrative. These Perspectives were coded based on explicit source statement/ attribution or portrayal, as well as by semantic or contextual narrative elements. (See Appendix C: Sample Coding Glossaries and Appendix D: Coding Template.)

This reveals a further sharp contrast between OWS and MRO (see Table 7 below). While neither protest's preferred perspective became the dominant one in the news, MRO's Anti-Government perspective was attributed nearly 250 times (and framed with collective action components 324 times; see Table 9), versus Anti-Corporate OWS that was attributed 96 times (and framed with collective action 113 times). Again, such a dramatic $170 \%$ contrast far exceeds the modest OWS-vs.-MRO word count gap, nor

\footnotetext{
${ }^{72}$ While government officials such as law enforcement are not typically portrayed as SM sympathizers, for MRO (and less so for OWS), a notable few did voice sympathies.
} 
would it seem to be fully explained by MRO's 'charismatic authority' versus the OWS autonomous/'leaderless crowd’ structure (see Chapter VI - Conclusion).

Table 7

Attribution Frequencies: Source Type by Preferred Commercial-Government Perspective

\begin{tabular}{|c|c|c|}
\hline SOURCE TYPE & $\begin{array}{l}\text { Anti-Corporate } \\
\text { (OWS) }\end{array}$ & $\begin{array}{c}\text { Anti-Governmt } \\
\text { (MRO) }\end{array}$ \\
\hline Government & - & 29 \\
\hline Business & - & 33 \\
\hline Citizen/Independent & 56 & $121-$ \\
\hline Academic & 1 & - \\
\hline (anonymous) & (39) & $(66.5)^{-\prime}$ \\
\hline TOTAL & 96 & 249.5 \\
\hline
\end{tabular}

Consider that each time a news story cites or names the cogent phrase 'Occupy Wall Street', this is coded as an Anti-Corporate frame. That is, OWS activists' preferred frame could potentially be reinforced whenever news media simply state the 'Occupy Wall Street' meme/brand name (also see Chapter VI Conclusion / Future Research). Yet, in an emergent pattern favoring MRO, the small band of armed Malheur occupiers remarkably had their preferred Anti-Government frame attributed more than twice as often per news story compared to Anti-Corporate OWS. To compound this framing pattern, nearly half of the Anti-Corporate attributions for OWS were anonymous sources (lesser frame resonance), while less than 1/3 of MRO's Anti-Government attributions were anonymous. ${ }^{73}$

\footnotetext{
${ }^{73}$ A portion of attributions are both anonymous and Citizen/Independent (C/I); for example, "protesters demand" is coded as half anonymous and half C/I. This occurs less often for 'half anonymous' and 'half Government' attributions, for example "police report...". Thus, some frequency tallies are fractional.
} 
Table 8

Dominant Perspective in Story $(n=30)$

\begin{tabular}{|c|c|c|c|c|}
\hline & $\begin{array}{r}\text { Anti- Gov/Regul } \\
\text { (Commercial } \\
\text {-Corporate) }\end{array}$ & $\begin{array}{l}\text { Anti- } \\
\text { Corporate }\end{array}$ & Other $^{74}$ & $\begin{array}{l}\text { Balance } \\
\text { Between } \\
\text { Perspectives } \\
\end{array}$ \\
\hline OWS & - & 7.3 & 22.7 & - \\
\hline MRO & 14.66 & - & 15.34 & - \\
\hline
\end{tabular}

The news stories' dominant Commercial-Government Perspectives, summarized under the Dominant Perspective dimension, were coded by proportionally tallying the attributions (which were weighted if they were from the story's first half, especially the headline or lead). On one hand, this proportional approach controls for the gap in word counts between OWS and MRO stories. Yet assessing these totals (from attribution and frame component frequencies, including prominence in a story, across four of the coding dimensions) requires estimations expressed as fractions. So, although stories' Dominant Perspectives are quantified (see Table 8 above), the method renders it as a fairly interpretive meta-dimension. And it suggests framing that again strongly favors MRO.

\section{FRAMING OCCUPATIONS in a MEDIA OPPORTUNITY STRUCTURE}

While the previous dimensions accent lead framing and SM-activist goals within protest news, the next dimensions also highlight portrayal of strategies and tactics. For example, in news about an armed standoff protest like MRO, more frequent portrayal of polarized actors would be expected; and indeed MRO stories had 146 polarization instances compared to 75 for OWS (see Appendices C and E). This is a variation of the pattern found previously, where MRO was disproportionately framed with more

\footnotetext{
${ }^{74}$ e.g., vertical- or horizontal-regulatory commercial, source ambivalent, \&/or narrative unclear
} 
detractors, underscoring the research showing that commercial news amplifies polarized conflict (Meyer 2007). However, the MRO 2016 episode is also entangled with deepseated elements of American culture related to guns and to the rural-urban divide. Disentangling these deeply polarized cultural issues from the potential MOS mechanisms is beyond the scope of this exploratory study. So, these polarization-related content dimensions will largely be left for future SM framing research (see Chapter VI).

\section{Collective Action Framing}

This study's adapted MOS model identifies a protest's most decisive news framing elements as collective action (Path $\mathrm{X}$ ) and contrasting dispersed passivity frames (Path Y; see Chapter III, Figure 1). These dimensions, highlighting the emergent pattern above, reveal some of the sharpest analytic contrasts between OWS 2011 and MRO 2016 news frames. As Table 9 shows below, frequencies of the Collective Action Frame components - identity, agency and injustice - for MRO (577 total) greatly outnumber those for OWS (386 total). This gap in Collective Action Frame (C.A.F.) components is wider still when comparing the protests' definitive Commercial-Government Perspectives. In conjunction with MRO's preferred Anti-Government perspective, 324 C.A.F. components were identified, while just 113 C.A.F. components were linked with OWS's preferred Anti-Corporate perspective. Moreover, MRO's collective action (C.A.F.) components appeared with their Anti-Government perspective more often than with any Other perspective - while OWS' collective action components appeared with their Anti-Corporate perspective less than half as often as with Other perspectives. That is, compared to OWS' preferred anti-corporate frame, MRO's preferred anti-government frame constituted about $50 \%$ more of all the news C.A.F. components. 
Table 9

Portrayal of Activists: Collective Action Frame (C.A.F.) Components

(Frequency of C.A.F./Path X Components by Commercial-Gov. Perspective)

OWS 2011

\begin{tabular}{|l|c|c|c|c|}
\multicolumn{1}{c}{$\begin{array}{c}\text { Anti- Gov/Regulatory } \\
\text { (Commercial }\end{array}$} & $\begin{array}{c}\text { Anti- } \\
\text { Corporate }\end{array}$ & Other & TOTAL \\
\hline Injustice & - & 44 & 105 & $\mathbf{1 4 9}$ \\
\hline Agency & - & 34 & 85 & $\mathbf{1 1 9}$ \\
\hline Identity & - & 35 & 83 & $\mathbf{1 1 8}$ \\
\hline TOTAL & - & $\mathbf{1 1 3}$ & $\mathbf{2 7 3}$ & $\mathbf{3 8 6}$ \\
\hline
\end{tabular}

$\underline{M R O} 2016 \quad$ Anti- Gov/Regulatory

(Commercial Anti-

\begin{tabular}{|l|c|c|c|c|}
\multicolumn{1}{c}{} & \multicolumn{1}{c}{-Corporate) } & \multicolumn{1}{c}{ Corporate } & Other & TOTAL \\
\hline Injustice & 85 & - & 42 & $\mathbf{1 2 7}$ \\
\hline Agency & 124 & - & 121 & $\mathbf{2 4 5}$ \\
\hline Identity & 115 & - & 90 & $\mathbf{2 0 5}$ \\
\hline TOTAL & $\mathbf{3 2 4}$ & - & $\mathbf{2 5 3}$ & $\mathbf{5 7 7}$ \\
\hline
\end{tabular}

The most definitive dimension, for the resonant news framing needed to promote SM action, is the Complete Collective Action Frame - where all three frame components coincide within a unit of news content (e.g. a headline, paragraph, or photo caption; see Appendices C \& E and Table 10 below). Continuing the observed pattern, the MRO stories in 2016 had a total of 60 Complete Collective Action Frames (C.C.A.F.), while OWS had only 33 . This $122 \%$ advantage for MRO then doubles, when considering only the protests' preferred perspectives - with MRO having 254\% more of its preferred antigovernment C.C.A.F.'s than OWS had of its preferred anti-corporate C.C.A.F.

\section{Table 10}

Frequency of Complete Collective Action Frames (C.C.A.F.)

\begin{tabular}{|c|c|c|c|c|}
\hline & $\begin{array}{c}\text { Anti- Gov/Regulatory } \\
\text { (Commercial } \\
\text {-Corporate) }\end{array}$ & $\begin{array}{l}\text { Anti- } \\
\text { Corporate }\end{array}$ & Other & TOTAL \\
\hline OWS & - & 13 & 20 & 33 \\
\hline MRO & 46 & - & 14 & 60 \\
\hline
\end{tabular}




\section{Dispersed Passivity Framing}

A Dispersed Passivity Frame (components of fate, passivity and dispersion; see Chapter III and Appendices C \& E) is the semantic opposite of a collective action frame's injustice, agency and identity components. For example, passivity and dispersion are shown in news describing "arrested" or "evicted" protesters; and the abstract component noted above (persons portrayed abstractly, e.g. "the people") magnifies any Dispersed Passivity Frame (D.P.F.). As such, it indicates a negation of collective action andbeyond internal SM demobilization - also suggests that media framing may be among the forces to constrain or neutralize a SM.

Necessarily less common than Collective Action components are for a SM, the three D.P.F. components occurred in similar total numbers for OWS and for MRO (see Table 11 below). However, in $N Y T$ and $O R G N$ especially, D.P.F. components appeared more often in the prominent first half of OWS stories, while for MRO the components were evenly divided between both halves of stories. Moreover, 25\% of MRO's total D.P.F. were linked with their preferred Anti-Government perspective, while less than $13 \%$ of OWS' total D.P.F. were Anti-Corporate. This suggests that even in retreat (or the less passive "surrender" which framed MRO but not OWS), MRO's message got more media resonance. 
Table 11

Portrayal of Activists: Dispersed Passivity Frame (D.P.F.) Components

(Frequency of D.P.F./Path Y Components by Commercial-Gov. Perspective)

OWS 2011

Anti- Gov/Regulatory

(Commercial Anti-

-Corporate) Corporate

\begin{tabular}{|l|c|c|c|c|c|c|}
\multicolumn{1}{c}{} & \multicolumn{1}{c}{-Corporate) } & \multicolumn{1}{c}{ Corporate } & \multicolumn{1}{c}{ Other } & \multicolumn{1}{c|}{ Subtotal } & TOTAL \\
\hline Fate & $/$ & $2 /$ & $5 / 2$ & $\mathbf{7} \mathbf{2}$ & $\mathbf{9}$ \\
\hline Passivity & $/$ & $5 / 2$ & $31 / 20$ & $\mathbf{3 6} / \mathbf{2 2}$ & $\mathbf{5 8}$ \\
\hline Dispersion & $/$ & $/$ & $30 / 13$ & $\mathbf{3 0} / \mathbf{1 4}$ & $\mathbf{4 4}$ \\
\hline (Abstract) & $/$ & $4 / 3$ & $8 / 6$ & $\mathbf{1 2} / \mathbf{9}$ & $\mathbf{2 1}$ \\
\hline TOTAL & $/$ & $\mathbf{1 1} / \mathbf{6}$ & $\mathbf{7 4} / \mathbf{4 1}$ & $\mathbf{8 5} / \mathbf{4 7}$ & $\mathbf{1 3 2}$ \\
\hline
\end{tabular}

$\underline{M R O 2016}$

$\left(1^{\text {st }}\right.$ half of story $/ 2^{\text {nd }}$ half of story $)$

\begin{tabular}{|c|c|c|c|c|c|}
\hline & A-G & A-C & Other & Subtotal & TOTAL \\
\hline Fate & $1 / 1$ & 1 & $1 /$ & $\begin{array}{ll}2 / 1 \\
\end{array}$ & 3 \\
\hline Passivity & $8 / 8$ & 1 & $23 / 25$ & $31 / 33$ & 64 \\
\hline Dispersion & $8 / 2$ & 1 & $15 / 20$ & $23 / 22$ & 45 \\
\hline (Abstract) & $2 / 1$ & 1 & $2 / 2$ & $4 / 3$ & 7 \\
\hline TOTAL & $19 / 12$ & 1 & $41 / 47$ & 60 / 59 & 119 \\
\hline
\end{tabular}

To be meaningful, the dispersed passivity frame (D.P.F.) more than other analytic dimensions must be contextualized with wider SM framing influences. First, besides the potential media influences on framing (see Chapter III), both the D.P.F. and collective action frame components also reflect the basic cycles of SM mobilization. Specifically, the more populous OWS, whose more varied factions and timelines thus faced more ongoing protest policing, experienced more total arrests and evictions - and D.P. framing - during the news sample timeframe. By contrast the smaller, more physically isolated MRO, due partly to these features as well as to being armed, largely deferred direct policing until the final days of occupation; so this is one factor behind the less frequent and less front-loaded D.P. framing for MRO compared to OWS.

Alternatively, D.P. framing within the news is also associated with demobilization - which, if news-driven, is called neutralization - and is defined in relative opposition to 
the collective action (C.A.) framing crucial for SM mobilization. Since mobilization requires C.A. to be more frequent than D.P. framing, it can be expressed as a ratio; and then comparing the contrasting news frame ratios between OWS and MRO (see Table 12 below) can control for some of their objective structural or cultural protest differences noted above. This is because, instead of a fully inverse relation, some increases in C.A. framing (e.g., "Occupy protesters block banks") can also provoke increased D.P. framing (e.g., more populated protest sites and police interactions often mean more "arrests"). So, comparing the ratios of Collective Action to Dispersed Passivity Frame components this study's most integrative news frame dimension - shows MRO with a dramatic C.A. framing advantage over OWS. This ratio in Table 12, along with the final analytic dimension in Table 14 below, may then confirm a key part of this study's double-edged questions (see Chapters III and VI).

Table 12

Ratio of Collective Action (C.A.F.) to Dispersed Passivity Frame (D.P.F.) Components

\begin{tabular}{|l|c|}
\hline Occupy Wall Street (OWS) & $2.92: 1$ \\
\hline Malheur Refuge Occupation (MRO) & $4.85: 1$ \\
\hline
\end{tabular}

\section{Rational Actors \& Commercially-Framed Activism?}

One analytic dimension that reflects this study's particular quantitative and qualitative synthesis is the comparison of Rational and Irrational SM actor framing. Viewed quantitatively, OWS and MRO frequencies are quite similar (see Table 13 below and Appendix E). Moreover, news story excerpts are often comparable, ranging from 'rational' OWS (“no problem with capitalism ...but...financial system”) and MRO statements ("returning...land to...people"), to portrayals of OWS ("getting rowdy") and 
MRO as irrational/extreme ("could turn violent"). At the same time, about $10 \%$ more of the MRO stories feature actors framed as either rational or as irrational.

Table 13

Portrayals of Rational SM Actors

\begin{tabular}{|lc|c|c|c|}
\cline { 2 - 5 } \multicolumn{1}{c|}{} & \multicolumn{2}{c|}{ OWS } & \multicolumn{3}{c|}{ MRO } \\
\cline { 2 - 6 } \multicolumn{1}{c|}{} & Frequency & Stories, of 30 & Frequency & Stories, of 30 \\
\hline Rational Actors or Actor Statements & 51 & 24 & 52 & 27 \\
\hline Irrational Actors or Actor Statements & 48 & 22 & 56 & 26 \\
\hline
\end{tabular}

Yet in at least two instances, the prominent top half of MRO news stories (headline, lead, etc.) obscure narratives that eventually reveal glaring activist irrationality or extremism. In "A bizarre end...," noted above, only the story's final paragraph reveals that the armed occupier was actually threatening suicide. And below another headline, "Occupier files complaint...," it is not revealed until the story's final line that the occupier's legal complaint seeks $\$ 666$ billion versus “works of the devil”! So with such MRO stories, only the most careful news reader eventually gets an opportunity to reframe the protesters as irrational, extreme or at least hyperbolic.

The final analytic dimension below, in conjunction with the previous one shown in Table 12 above, addresses one key part of this study's dual questions - that greater protest news frame resonance may accompany commercially-framed activism in news. So, the news that is framed with more collective action - as well as more of protesters' preferred perspective - is expected to also be accompanied by more instances that commercially frame protest (describe activism with market metaphors/ terminology). For example, OWS protesters "withdrew their money" from big banks, and MRO protesters sought to "use these lands as free men". 
Yet for an explicitly anti-corporate OWS, how does such news portrayal frame or re-frame SM action? Indeed as could be expected, commercially-framed activism was portrayed less for OWS than for MRO (in 54 versus 68 instances respectively; see Table 14 below \& Appendix E). Although this difference is modest compared to most other analytic dimensions above, such portrayals directly undermine the anti-corporate OWS while amplifying the anti-government/ pro-commercial MRO. So this small gap in comparative news portrayals can be interpreted as having quite large framing impacts for ideologically opposing SMs. Moreover, as predicted, the protest that was most commercially framed or 'sells best' - the framing for MRO - was also the one with the most frequent collective action framing (in Table 12 above).

Table 14

Commercially Framed Activism

\begin{tabular}{|l|c|c|}
\multicolumn{1}{c}{} & Frequency & Stories, of 30 \\
\hline OWS & 54 & 24 \\
\hline MRO & 68 & 25 \\
\hline
\end{tabular}

Most of these 15 analytic dimensions, viewed individually, indeed suggest that certain media-SM contexts differentially frame some protest as 'more equal than others'. And when viewed together, as summarized in the subsequent Chapter VI Conclusion, these framing patterns take further shape as fairly striking analytic findings. Yet such patterns must be contextualized, by revisiting the core theory question of whether these frames are more media- or more movement-generated, as well as by suggesting potential mechanisms for such framing dynamics - largely to be explored in future research. 


\section{Chapter VI}

CONCLUSION 


\section{DISCUSSION OF RESULTS}

The Chapter V content analysis results, comparing news framing for Occupy Wall Street (OWS) and Malheur Refuge Occupation (MRO), when viewed as separate dimensions suggest fairly distinct differences. Yet viewed in full, as Summary Framing... in Tables 15 and 16 below, these patterns crystallize into pronounced analytic findings. Overall news frames for OWS - while initially more sympathetic and for far larger protests than $\mathrm{MRO}$ - were surprisingly less potent, personal, and vocal than for MRO. Moreover, the distant twin protest frames in early- $21^{\text {st }}$-century media outlets suggest wider contexts where commercial news 'sells protest' (Table 15) but can also 'undersell protest' with neutralizing or demobilizing frames (Table 16).

Table 15

Selling Protest? Summary Framing Advantages: Media Opportunity Structure (MOS)

\begin{tabular}{|c|c|c|}
\hline & OWS & $M R O$ \\
\hline Aggregate national news volume & $\mathbf{X}$ & \\
\hline \multicolumn{3}{|l|}{ HEADLINES \& PHOTO CAPTIONS } \\
\hline Personified \&/or photographed activism & & * \\
\hline$\frac{\text { Frequency of Collective Action Frame Components }}{\text {...Injustice }}$ & $\mathrm{x}$ & \\
\hline ...Agency & & $\mathbf{X}$ \\
\hline Headline frames more positively (than story) & & * \\
\hline \multicolumn{3}{|l|}{ NEWS STORIES } \\
\hline Frequency of Attributions & & * \\
\hline Total Discrete Sources & & * \\
\hline Frequency of Preferred Commercial-Gov. Perspective & & \# \\
\hline Prominence of Preferred Commercial-Gov. Perspective & & \# \\
\hline Frequency of Polarization & & $\mathbf{X}$ \\
\hline \multirow{2}{*}{$\frac{\text { Frequency of Collective Action (CA) Frame Components }}{\ldots \text { Injustice }}$} & & $\mathrm{x}$ \\
\hline & $\mathrm{x}$ & \\
\hline ...Agency & & $\mathbf{X}$ \\
\hline ...Identity & & $\mathbf{X}$ \\
\hline Frequency of COMPLETE Collective Action Frames & & * \\
\hline RATIO of C.A. over Dispersed Passivity Frame Components & & $\mathrm{x}$ \\
\hline Frequency of COMMERCIALLY FRAMED ACTIVISM & & $\mathbf{X}$ \\
\hline
\end{tabular}

( $\mathbf{X}=$ expected,$*=$ unexpected, $\mathrm{x}=$ no expectation $)$ 
This chapter concludes by discussing some study limitations and lessons, as well as potential future research. First, I outline this comparative study's analytic findings, as designed and conducted in Chapters III - V, and I revisit the wider contexts of movement-media framing initially explored in Chapters II - III theory/research questions. For the randomly sampled news stories about OWS and MRO in The New York Times, USA Today and The Oregonian, the 15 content analysis dimensions revealed dramatic framing differences between the two social movement (SM) protest episodes. These summary differences (Table 15 above and Table 16 below) - after the pre-analysis/ shallow news frames of sympathetic OWS vs. MRO opponents - reveal deeper, disproportionately large frame advantages for the small, rightwing MRO protest.

Beyond the initially sympathetic news tone, Framing Advantages (Table 15 above) that clearly favored OWS were found in just two areas: aggregate national news volume and more frequent injustice Collective Action (CA) Frame Components - and only the latter is an actual content dimension. In contrast, the analytic dimensions revealed 14 news Framing Advantages for MRO, including more: Personified \& photographed activism; Headlines that frame more positively than the story; frequent Attributions; Discrete Sources; frequent \& prominent Preferred (anti-government) Perspective; Polarization; agency \& identity Components of CA; frequent Complete CA Frames; Ratio of CA over Dispersed Passivity Frame Components; and frequent Commercially-Framed Activism.

Some of these MRO framing advantages might be expected, based on the internal SM dynamics for a small, armed protest with relatively charismatic authority structure 
and an individualist culture (e.g., see Tilly 1999) ${ }^{75}$; and in Table 15 above, these four or five dimensions such as Polarization, that would be expected to reveal an MRO advantage (e.g. reflecting their 'unity' and armed 'commitment'), are indicated by a bold 'X'. However, more of MRO's framing advantages (7 of 14, shown by ' $*$ ' in Table 15) were found in news content dimensions that would instead be expected to favor OWS for being the more accessible protest - and with the larger crowd "numbers" ( $c f$. Tilly 1999). So these seven unexpected MRO Framing Advantages ${ }^{76}$, that would instead be expected to favor the larger and more accessible OWS (geographically and symbolically), need further analysis. For example, despite the wider messaging reach of OWS' mediaready 'Occupy Wall Street' name/meme (that in itself has two of three components of a complete collective action frame), MRO had nearly twice the frequency of complete collective action frames. Also, MRO's dramatic advantage in framing its Preferred perspective (anti-government, see Table 15 above and Chapter V - Table 7) suggests looking beyond MRO's media/ cultural resonance as 'armed white men' - to reexamine the theorized framing influence of corporate liberalism atop the news hierarchy of influences in Chapters II - III. In theory then, the frequency of MRO's unexpected Framing Advantages indeed suggest that the media framing side of media opportunity structure (MOS) particularly requires further study (see below, and final section).

Alternatively, most SM Framing Disadvantages (FDs), with five identified in Table 16 below, are likely seen by traditional theory as 'unexpected' for SMs exhibiting

\footnotetext{
${ }^{75}$ E.g., News often framed MRO, in its isolated and harsh setting, with displays of worthiness, unity and commitment. (Tilly 1999)

${ }^{76}$ Personified \& photographed activism, frequent Attributions, Discrete Sources, frequent \& prominent Preferred (anti-government) Perspective, frequent Collective Action (CA) Frame Components and Complete CA Frames (see Table 15 above).
} 
active mobilization (e.g. Benford \& Snow 2000; McCarthy \& Zald 1977; Tilly 1999). Yet for OWS which had four out of the five Disadvantages, two of its FDs (shown by bold ' $\mathrm{Y}$ ' in Table 16) could actually be expected as internal features of OWS protest encampment structure. In stark contrast with the remote MRO, the OWS encampments were densely populated and accessible - and thus more intensively policed and with far more frequent arrests. So, more news of "arrests" was then coded as more frequent Abstract Components and/or Dispersed Passivity (DP) Frame Components - suggesting a constraining or demobilizing MOS as theorized and modeled in Chapters II and III.

Table 16

Underselling Protest? Summary Framing Disadvantages (A constraining Media Opportunity Structure)

\begin{tabular}{|l|c|c|}
\hline $\begin{array}{l}\text { HEADLINES \& PHOTO CAPTIONS } \\
\text { Headline frames more negatively (than story) }\end{array}$ & \\
\hline Frequency of Abstract Frame Components (e.g. "arrests") & $\mathbf{Y}$ & \\
\hline $\begin{array}{c}\text { NEWS STORIES } \\
\text { Frequency of Dispersed Passivity (DP) Frame Components }\end{array}$ & $\mathbf{Y}$ & \\
\hline Frequency of Irrational/extreme SM actor-statements & & $\mathrm{y}$ \\
\hline Frequency of COMMERCIALLY FRAMED ACTIVISM & $\mathrm{y}(?)$ & \\
\hline
\end{tabular}

However, among OWS' four Framing Disadvantages, the relatively unexpected one was frequent Commercially Framed Activism (labeled ' $y$ ' in Table 16 above), unexpected because OWS' preferred news framing perspective was anti-corporate. This framing dimension, at the core of my adapted MOS model, is thus unique for its asymmetry - as a Framing Disadvantage for OWS but a Framing Advantage for antigovernment/pro-commercial MRO. And so, for these ideologically contrasting or distant twin protest episodes, similarly frequent portrayals of commercially framed activism (see Chapter V - Table 14) signifies dramatically contrasting news frames. 
Does this pattern, of commercially framed activism accompanying greater protest news frame resonance, thus confirm this study's dual questions? The summarized results show - as predicted - that 1) MRO news, versus OWS, was framed with more frequent collective action and protesters' preferred perspective (anti-government) as well as with commercially framed protest; and 2) OWS news by contrast was framed with more frequent dispersed passivity, or neutralizing frames and slightly less commercial/market metaphors/terminology). Yet the initial theoretical question, or conundrum, remains: Is this framing more news-driven or more movement-driven?

One incomplete answer is that the comparatively 'disadvantaged' OWS news frame was simply SM-driven, as the more arrest-prone, anti-commercial movement. A better but still partial approximation, as no single study can fully answer such a multivariate question, may come directly from the news content data - by tallying the proportion of unexpected Framing Advantages (FAs, in Table 15 above) as well as Disadvantages (FDs, in Table 16 above). For example if 1,000 OWS protesters and 100 MRO protesters got the same headline, "Hundreds protest....", then this imbalanced news (independent of SM influence no matter how anarchic or 'silly' OWS was) thus codes as a more news-driven frame - and an unexpected FA for MRO. And from Tables 15 and 16, half of the FAs for MRO were unexpected (and $1 / 4$ of the FDs for OWS were unexpected). So while the better, approximate answer might therefore be that half of MRO's framing advantage was media-driven, to reliably interpret or generalize from such FA proportions will first require further research (as suggested below). 


\section{Methodology \& Findings}

This study's research design adapted a media opportunity structure (MOS) model (Gamson 1998) to consider a hierarchy of influences on news coverage of ideologically opposed but morphologically congruent 40- to 60-day protest occupations. Occupy Wall Street (OWS) in 2011 and the 2016 Malheur Refuge Occupation (MRO or Citizens for Constitutional Freedom /Patriot militia) were subjects of comparative news frame analysis. The sampled time periods, during the actual encampments/ occupations in Portland, OR and New York City (OWS) and in Malheur National Wildlife Refuge, Oregon (MRO), also correspond with transitional years in commercial print news media - thus affording a view of perhaps accentuated news content patterns.

The protest episode coverage, from three top national or state print news outlets (The New York Times [NYT], USA Today [USAT], and The Oregonian [ORGN]), was analyzed from multistage random samples of the full population of stories published during the periods of occupation. Using textual content analysis in successive rounds of inductive-based coding, the qualitative and quantitative findings include frequencies of the constituent frames of MOS - which especially reveal the relative volume/prominence of a SM's collective voice (Johnston 2002, 2005; also see Michel, et al. 2011).

The comparative research results, based on 15 coding dimensions accenting news framing of collective action and commercially-framed activism, showed some evidence for the 'selling protest' question. Combined tallies of both protests' Summary Framing Advantages and Disadvantages then yielded this study's most distinct finding: Although anti-corporate Occupy Wall Street (OWS) was far larger, with more widespread media 
coverage, the comparative overall media frame for the small, remote, anti-government Malheur Refuge Occupation (MRO) was far more potent, vocal and resonant.

\section{Research Contribution}

This study has explored how SM messages and claims are framed in commercial news media. Any SM, especially anti-systemic or anti-corporate, has only partial framesetting agency, which underscores key theoretical questions. Viewing SMs and media as interacting systems, to what extent: 1) are frames/ framing more movement- or more media- driven; and 2) do media not just enable but also constrain SMs? By sampling from periods of systemic challenges (for SMs and media), this research also explored potentially more pronounced news framing patterns.

The research questions' movement side reflects movement framing views that highlight SMs' own narratives and cultural micro-mobilization, and that since the 1980s had more influence largely by offering more empirical (and narrow) measures than the media framing side (e.g. Benford \& Snow 2000, vs. Scheufele 1999). Yet the more contextually embedded media framing views emphasize the need to address wider macrostructural contexts such as news media influence (e.g. Gitlin 1980) - and the constraints they may pose for SMs.

To bridge this gap between the two views and better analyze constraints that news media may pose for SMs, an adapted MOS (Gamson 1998) was modeled in Chapter III, to then study contrasting protest episodes in Chapters IV - V. Exploring new ways of illuminating how media and SMs interactively frame protest news, this study specifically asked if commercial news framing of collective action: 1) commercially frames or 'sells' even anti-corporate protests; or 2) instead marginalizes or neutralizes such protests. 
Comparing media-and-movement framing of two contrasting yet both 40-day protest occupations, then finds some support for the 'selling (or underselling) protest' question. As a theory contribution, this comparative frame analysis bridges micro- and macrolevels, to address the dual gap in movement-media research literatures outlined in Chapter II and thereby better grasp SMs' and media's respective roles in protest news framing, including by identifying potential mechanisms for future research.

\section{LIMITATIONS \& LESSONS}

As interpretive research that used a relatively small sample of newspaper story data for quantitative content analysis, this study has certain limitations. While it leaves opportunity for future research, there are inherent tradeoffs between the small- $n$ study that allows richer depth and granularity in comparing the two cases - versus employing a larger protest news sample that would be more representative. The small $\mathrm{n}$ is indeed more prone to potential anomalous or outlier results, yet it also affords the granular focus and depth needed to develop this comparative study's exploratory model and methodology. Also related to the small sample ( $13 \%$ of the news story population was coded) is the challenge of capturing the full sequences of the occupations - as the small $\mathrm{n}$ likely accentuates the gaps between actual events and their media representation (an issue for all content analysis). And this can be addressed in future research, below.

Another study limitation involves the differing SM cases. While OWS and MRO's stark contrasts helped accentuate key aspects of movement-media framing, their cultural and structural differences leave questions as to the framing influences of media, versus of the protests themselves. For example, the large and sometimes defiantly 
anonymous OWS population certainly exerted some direct influence often seen as being against their SM framing interests - versus MRO's much smaller size and perhaps more distinctive or all-American spokespersons enjoying a mass audience appeal. Another less common yet still typical left-vs.-right factor was perhaps the most important for OWSMRO comparison: MRO was armed. From the study results, this likely shaped more than just the initial 'formidable opponents' frame. While such confounding factors are inherent to the media-SM framing literature (also see Chapters I and IV), they might still be further addressed such as by coding scheme revisions or other news coverage choices. A further limitation is in this study's use of traditional print news media - and the absence of social media or other new media platforms. Daily newspaper circulations not only still outnumber unique daily news website visitors - but may also support the bulk of in-depth and investigative journalism (Pew Research Center 2018). Yet the recent leading trends in activism, SM organizing and protest - from \#BlackLivesMatter to \#MeToo or \#MarchForOurLives - have largely developed online. At the same time, social media has been widely critiqued for failing to uphold journalistic values - and their truncated and transitory message formats are often simply unable to accommodate deep stories. Still, social media are noted as an area for future research below.

Partly extending from these limitations, there are also lessons to draw from this study approach. First, as the "Selling Protest..." title suggests, SM activists - and news or other media actors - could gain potential SM marketing insights, from this study's theory modeling to the methods and results. Given the penetrating power of commercial-market imperatives, these insights may be defensive or offensive. The coding methods and results can broadly sensitize activists and organizers to more fully consider various paths 
of protest and SM mobilization - as greatly interrelated with media. This includes the double-edged promise and peril of selling protest. In particular, this research can enable more strategic approaches to SM messaging - not only aligning language and actions with movement goals, but also avoiding dispersed passivity frames.

Other lessons can apply to movement scholarship, especially to one of the most influential standards for assessing strength/resonance of SM framing - by their displays of worthiness, unity, numbers and commitment or WUNC (Tilly 1999; also see Chapter I). Whether viewed directly or via media frames, WUNC is seen as analytically important yet highly interpretive (if less so for the numbers). So this study's somewhat quantitative approach - as well as OWS vs. MRO focus - can further illuminate such a standard. First, there is the potential to better measure $\mathrm{W}$ or $\mathrm{U}$, with the dimensions of collective action as proxies. More notable still for WUNC are the OWS-MRO focal cases, which if viewed together are virtual archetypes: OWS for the numbers, and MRO for the unity. And while MRO by this analysis likely displayed more W and C, the distant twins' mutually brief (40-day) unauthorized occupations may have thus prevented them from displaying 'enough' worthiness or commitment. So between their similarities and differences, such as these mutual inadequacies in WUNC, both OWS and MRO may offer further rich insights for SM-media episodes to come.

Finally, given this project's small sample size, much can be learned through deliberatively (if reluctantly) narrowing the scope of research - yet staying cognizant of wider contexts. As this project was reduced to the study's present size, from a metamovement-and-media scale (spanning hundreds of protests for dozens of SMs across decades of global media, see Chapter IV, footnote 64), it was in effect cut from a multi- 
volume series by a team of scholars - to something one researcher could eventually complete. And while painstaking, there is crucial value in settling on the two research cases (OWS and MRO) deliberatively - so that they reflect a relevance to broader global patterns. So, given these limits and lessons - including that the interpretive and contextual coding process is also a notable strength - this exploratory approach can hopefully extend to broader research applications as discussed in the next section.

\section{FUTURE RESEARCH}

This multivariate exploratory study leaves a number of questions for future research. First, from the existing sample, subdividing the summary coding data between NYT, USAT and ORGN stories could enable even more granular analysis to then suggest patterns of national versus local framing, or between fiscally sound versus struggling news outlets. Also, as a minor extension from existing data, a new pair of exploratory interviews, about MRO, could yield useful follow-up to the OWS 2011 interview themes. Another future research area, drawing from wider data, can incorporate new and social media (also see Chapter II, Part B and Chapter III). This study's methodology can then be used to examine the common assumption that social media greatly enhances activists' media opportunity and thus SM mobilization.

With this study's relatively small sample size, future research can look to expand the sample - and project - size. Emphasizing the distinctive 40-day occupations, further analysis could focus on how news frames shift over the length of the occupations - and how the sequence (e.g. week one vs. week six) matters. For example, an "initiating effect" could be examined in terms of how protest was launched and then worked to 
influence coverage. A parallel question can ask how news cycles related to the 40-day occupations, as events: How did the occupations, as developing stories over the sequence of weeks (regardless of media), then become magnets for news coverage - and how might this differ from longer periods studied? (e.g. Gitlin 1980) Further, a large-sample, sequential timeline study of OWS-vs.-MRO can ask how summary coverage compares to spot news - or how coverage may truncate certain protests like OWS that in some places lasted many months.

\section{What's in a SM name? (another comparative framing dimension)}

The major lingering question is to what extent the results of comparative news frame analysis for OWS and MRO - despite their distant twin forms as anti-systemic, 40to 60-day occupations - simply reflect basic cultural and structural differences between the protests themselves (also see Chapters I and III). While the study design and methodology sought to address this SM/protester agency, the challenge of isolating it from media influences is suggested by one of the first questions any SM research encounters (yet might not explicitly ask, see Chapter I): What is the movement called?

Naming, as an even more basic question for SMs than the pre-analytic shallow frames initially identified in this study, is another key area for future research (theorized ${ }^{77}$ in Chapter II). If there is one consensus name, is it more SM- or media- chosen? And how accurately does the name reflect actual movement goals and collective action? Using these questions, as with the other analytic dimensions, to compare the dominant names “Occupy Wall Street” and "Malheur Refuge Occupation” can reveal further dynamics of movement-media interactions and MOS.

${ }^{77}$ See Jenson (1995) or Lofland (1995), regarding SM naming. 
For example, how closely did "Occupy Wall Street" - a largely movement-chosen name - actually resemble a typical militant/militarist-style occupation? Previous SM occupations, from Coxey's Army to Alcatraz, often involved some degree of hierarchy who made material claims (Clemens 1996); but for those loose autonomous assemblies in 2011, occupying Wall Street mainly symbolized wider political-economic policy goals. By contrast, "Malheur Refuge Occupation" was largely a media-given name, as the initial occupiers - some who came from various patriot militia factions - actually gathered in 2016 as Citizens for Constitutional Freedom. Then in occupation style, the armed militants displayed traditional authority structures, restricted the normal public access, and made material demands (e.g. federal public land transfer to local or private hands).

Also note that for the protest with the more media-framed name ('MRO'), this study found far more news framing advantages than 'OWS', with its SM-chosen name. For future research then, how might the origin of a SM's name relate to broader framing and mobilization? ( $c f$. Jenson 1995) The contrasting OWS and MRO name etymologies could be subjects of deeper comparative case study, or crucial data points for research across many movements (e.g. Clemens 1996).

\section{Elaborating the Study Design \& Methodology}

Future research can also benefit by adding to or revising other aspects of this comparative study's design and methodology - such as other frame analysis dimensions. Specifically, the key coding dimension 'commercial-government perspective' - with the binary of anti-government versus anti-corporate - could be revised to use a more nuanced anti-federal (instead of -government) and thus yield a possibly more representative and precise news content analysis. Another design/method revision to improve this study's 
precision (and reliability) could incorporate a double-blind news content comparison - by redacting all place, person, or movement names from samples prior to analysis. Yet another less labor-intensive methodological innovation extending from this study could apply computer-based textual analysis - to assess larger sample sizes and yield more generalizability. From this, a key predictive goal could then be to compile multiple CAFto-DPF ratios (Chapter V, Table 12), to derive a 'Threshold Framing Ratio' - an average point at which these news framing ratios are associated with actual shifts from collective action to demobilization.

\section{Extended Research Applications \& Contexts}

Finally, this comparative-based content methodology - with relatively precise and granular coding dimensions - can be fruitfully applied to other SMs as well as entirely

different research contexts. For example, extending this study's distant twin left- $v s$.-right MOS model to compare other SMs with more similarly situated occupations (e.g. rural Dakota Access Pipeline protest versus rural MRO) could have more analytic validity than urban OWS versus rural MRO. Additionally, my interpretive-quantitative coding method may be adapted to other comparative applications that require its granular precision, such as rubric-based scoring to assess written student coursework. Or, in our current socio-political climate of concern about malicious distortion of media information, my comparative news coding template (Appendix D) can be readily adapted and broadly deployed as a precise, replicable and reliable test for so-called 'fake news'.

\section{\#\#\#}




\section{REFERENCES}

Agarwal, S.D., M.L. Barthel, C. Rost, A. Borning, W. L. Bennett \& C.N. Johnson. 2014. "Grassroots organizing in the digital age: considering values and technology in Tea Party and Occupy Wall Street”. Information, Communication \& Society, 17(3): 326-341.

Aiden, Erez and Jean-Baptiste Michel. 2013. Uncharted: Big Data as a Lens on Human Culture. NY: Riverhead.

Anderson, Alison. 2009. "Media, Politics and Climate Change: Towards a New Research Agenda", Sociology Compass, 3(2): 166-182.

Andrews, K.T. and Neal Carena. 2010. "Making the News: Movement Organizations, Media Attention, and the Public Agenda." American Sociological Review, 75(6): 841-866.

Anduiza, Deva, Camilo Cristancho, \& José M. Sabucedo. 2014. "Mobilization through online social networks: the political protest of the indignados in Spain."

Information, Communication \& Society, 17(6): 750-764.

Appadurai, Arjun. 1988. The Social Life of Things: Commodities in Cultural Perspective. NY: Cambridge Univ. Press 1996. Modernity at Large: Cultural Dimensions of Globalization, pp. 1-47. Minneapolis: University of Minnesota Press.

Bagdikian, Ben. 2000. The Media Monopoly, $6^{\text {th }}$ ed. Boston: Beacon Press.

Bartley, Tim. 2003. "Certifying Forests and Factories: States, Social Movements, and the Rise of Private Regulation in the Apparel and Forest Products Fields," Politics \& Society, 31(3): 433-464.

Beck, Ulrich. 2000. What Is Globalization? Malden, MA: Blackwell.

Bello, Walden. 2004. "The Global South," pp. 49-69 in Mertes (ed.).

Benford, R.D. and D.A. Snow. 2000. "Framing Processes and Social Movements: An Overview and Assessment," Annual Review of Sociology, 26: 611-639.

Bennett, W. Lance. 1996. "An Introduction to Journalism Norms and Representations of Politics". Political Communication, 13(4): 373-384

Benski, T., L. Langman, I. Perugorría, B. Tejerina. 2013. "From the streets and squares to social movement studies: What have we learned?" Current Sociology, 61(4): 541561.

Berg, Bruce L. 2007. Qualitative Research Methods for the Social Sciences, $6^{\text {th }}$ ed. (pp. 303-339). Boston: Prentice Hall/Allyn \& Bacon.

Bernstein, Mary. 1997. "Celebration and suppression: The strategic uses of identity by the lesbian and gay movement". American Journal of Sociology, 103(3): 531-565.

Bielsa, Esperanca. 2008. "The Pivotal Role of News Agencies in the Context of Globalization: a Historical Approach.” Global Networks, 8(3): 347-366.

Billig, Michael. 1995. "Rhetorical Psychology, Ideological Thinking, and Imagining Nationhood," pp. 64-81 in Johnston and Klandermans (eds.).

Blee, Kathleen M. \& Verta Taylor. 2002. "Semi-Structured Interviewing in Social Movement Research,” pp. 92-117 in Klandermans \& Staggenborg (eds.).

Blee, Kathleen M. and Kimberly A. Creasap. 2010. "Conservative and Right-Wing Movements". Annual Review of Sociology, 36: 269-286. 
Boykoff, Jules. 2006. "Framing Dissent: Mass-Media Coverage of the Global Justice Movement," New Political Science, 28(2): 201-228.

Boykoff, Maxwell T. \& Jules M. Boykoff. 2007. "Climate change and journalistic norms: A case-study of US mass-media coverage." Geoforum, 38(2007): 1190-1204.

Buechler, Steven M. 2007. "The Strange Career of Strain \& Breakdown Theories of Collective Action," pp. 47-66 in Snow, D., S. Soule, and H. Kriesi (eds.).

Burawoy, Michael. 2000a. "Introduction: Reaching for the Global," pp. 1-40 in Burawoy, et al. . 2000b. "Grounding Globalization," pp. 337-350 in Burawoy, et al.

Burawoy, Michael, et al. 2000. Global Ethnography: Forces, Connections \& Imaginations in a Postmodern World. Berkeley: Univ. of California Press.

Butz, A. 1997. Urban sprawl, media monopoly, and citizen participation: a longitudinal case study of daily newspapers in Portland, Oregon. Portland State University. Dept. of Sociology.

Cadena-Roa, Jorge. 2005. "Strategic Framing, Emotions, \& Superbarrio -- Mexico City's Masked Crusader," pp.69-86 in Johnston and Noakes (eds.).

Caiani, M., Della Porta, D. and Wagemann, C. 2012. Mobilizing on the extreme right: Germany, Italy, and the United States. NY: Oxford University Press.

Calhoun, Craig. 2013. "Occupy Wall Street in perspective". The British Journal of Sociology, 64(1): 26-38.

Carragee, Kevin M. and Wim Roefs. 2004. "The Neglect of Power in Recent Framing Research". Journal of Communication, 54(2): 214-233.

Carroll, William K. and R.S. Ratner. 1996. "Master Framing and Cross-Movement Networking in Contemporary Social Movements," The Sociological Quarterly, 37: 601-625.

Castañeda, Ernesto. 2012. "The Indignados of Spain: A Precedent to Occupy Wall Street". Social Movement Studies, 11(3-4):309-319.

Castells, Manuel. 1983. The City \& The Grassroots: A Cross-Cultural Theory of Urban Social Movements. Berkeley: Univ. of Calif. Press. 2008 [2000]. "Materials for an Exploratory Theory of the Network Society," pp. 551-562 in Social Theory: Roots and Branches, Peter Kivisto (ed.). NY: Oxford Univ. Press. . 2008. "The New Public Sphere: Global Civil Society, Communication Networks \& Global Goverance". The ANNALS of the American Academy of Political \& Social Science, 616(1): 78-93.

Castells, Manuel. 2012. Networks of Outrage and Hope: Social Movements in the Internet Age. Cambridge, MA: Polity Press.

Charmaz, Kathy. 2001. "Grounded Theory”, pp. 335-352 in Contemporary Field Research: Perspectives and Formulations, $2^{\text {nd }}$ ed., Robert M. Wilson (ed.). Prospect Heights, IL: Waveland Press.

Chase-Dunn, Christopher. 2006. “Globalization: A World-Systems Perspective,” pp. 79108 in Global Social Change, Christopher Chase-Dunn \& Salvatore J. Babones (eds.). Baltimore: Johns Hopkins Univ. Press.

Clemens, Elisabeth S. 1996. "Organizational Form as Frame: Collective Identity \& 
Political Strategy in the American Labor Movement, 1880-1920," pp. 205-226 in McAdam, et al.

Clemens, Elisabeth S. \& Martin D. Hughes. 2002. "Recovering Past Protest: Historical Research on Social Movements," pp. 201-230 in Klandermans and Staggenborg (eds.).

Corrigall-Brown, Catherine \& Rima Wilkes. 2012. "Picturing Protest: The Visual Framing of Collective Action by First Nations in Canada". American Behavioral Scientist, 56(2): 223-243.

Cornell, Andrew. 2011. Oppose and Propose! Lessons from Movement for a New Society. Oakland, CA: AK Press.

Cottle, Simon. 2008. "Reporting demonstrations: The changing media politics of dissent." Media, Culture \& Society, 30: 853-872.

Croteau, David and W. Hoynes. 2014 [2003]. Media/Society: Industries, Images, and Audiences, $5^{\text {th }}\left[3^{\text {rd }}\right]$ ed. Thousand Oaks, CA: Pine Forge Press.

Dauvergne, Peter and Genevieve LeBaron. 2014. Protest Inc: The Corporatization of Activism. Malden, MA: Polity.

della Porta, Donatella. 1996. "Social Movements \& The State: Thoughts on the Policing of Protest," pp. 62-92 in McAdam, D., J.D. McCarthy and M.N. Zald (eds.). . 1999. "Protest, Protesters and Protest Policing: Public Discourses in Italy and Germany from the 1960s to the 1980s," pp. 66-96 in Giugni, McAdam and Tilly (eds.).

della Porta, Donatella. 2002. "Comparative Politics \& Social Movements," pp.286-313 in Klandermans, Bert and Suzanne Staggenborg (eds.). .2005. "Making the Polis: Social Forums and Democracy in the Global Justice Movement," Mobilization: An International Quarterly 10(1): 7394. (ed). 2007. The Global Justice Movement: Cross-national and Transnational Perspectives. Boulder, CO: Paradigm.

della Porta, D. and L. Mosca. 2005. "Global-net for global movements? A network of networks for a movement of movements". Journal of Public Policy, 25(1): 165190.

DeLuca, K. M., Lawson, S. and Sun, Y. 2012. "Occupy Wall Street on the Public Screens of Social Media: The Many Framings of the Birth of a Protest Movement". Communication, Culture \& Critique, 5: 483-509.

Diani, Mario. 2007. "Networks \& Participation," pp. 339-359 in Snow, et al. (eds.).

Doherty, Brian and Timothy Doyle. 2006. "Beyond Borders: Transnational Politics, Social Movements and Modern Environmentalisms," Environmental Politics, 15(5): 697-712.

Earl, Jennifer. 2003. "Tanks, Tear Gas, and Taxes: Toward a Theory of Movement Repression". Sociological Theory, 21(1): 44-68.

Earl, Jennifer. 2007. "The Cultural Consequences of Social Movements," pp. 508-530 in Snow, et al. (eds.). , A. Martin, J.D. McCarthy \& S. Soule. 2004. "The use of newspaper data in the study of collective action," Annual Review of Sociology 30: 65-80.

Edwards, Bob \& John D. McCarthy. 2007. "Resources and Social Movement 
Mobilization," pp. 116-152 in Snow, et al. (eds.).

Eltantawy, N., \& J.B. Wiest. 2011. "The Arab Spring | Social Media in the Egyptian

Revolution: Reconsidering Resource Mobilization Theory". International Journal of Communication, 5(18). http://ijoc.org/index.php/ijoc/article/view/1242 (accessed 2/19/18).

Entman, Robert M. 1993. "Framing: Toward Clarification of a Fractured Paradigm." Journal of Communication, 43(4): 51-58.

Ericson, Richard and Aaron Doyle. 1999. "Globalization and the Policing of Protest: The Case of APEC 1997,” British Journal of Sociology, 50: 589-608.

Ertman, Martha and J. Williams. 2005. Rethinking Commodification: Cases and Readings in Law and Culture. NYU Press.

Fantasia, Rick and Eric L. Hirsch. 1995. "Culture in Rebellion: The Appropriation and Transformation of the Veil in the Algerian Revolution," pp. 144-159 in Johnston and Klandermans (eds.). \& Judith Stepan-Norris. 2007. "The Labor Movement in Motion,” pp. 555575 in Snow, et al. (eds.).

Fine, Gary Alan. 1995. "Public Narration and Group Culture: Discerning Discourse in Social Movements," pp. 127-143 in Johnston and Klandermans (eds.).

Frank, Thomas. 1998. The Conquest of Cool: Business Culture, Counterculture, and the Rise of Hip Consumerism. Chicago: Univ. of Chicago Press.

Gamson, William. 1990. The Strategy of Social Protest, $2^{\text {nd }}$ ed. Belmont, CA:Wadsworth. . 1992. Talking Politics. Cambridge: Cambridge University Press. . 1995. "Constructing Social Protest," pp. 85-106 in Johnston and Klandermans (eds.). 1998. "Social Movements and Cultural Change," pp. 57-77 in Giugni, McAdam, \& Tilly (eds.). 2007. "Bystanders, Public Opinion, \& the Media," pp. 242-261 in Snow, et al. (eds.). \& David S. Meyer. 1996. "Framing Political Opportunity,” pp. 275290 in McAdam, et al. (eds.).

Gamson, William A. and Gadi Wolfsfeld. 1993. "Movements and Media as Interacting Systems," The Annals of the American Academy of Political and Social Science, 258: 114-125.

Gallaher, Carolyn. 2016. "Placing the Militia Occupation of the Malheur National Wildlife Refuge in Harney County, Oregon". ACME: An International Journal for Critical Geographies, 15(2): 293-308.

Gans, Herbert J. 1979. Deciding What's News. New York: Pantheon. 2012. "Against culture versus structure". Identities: Global Studies in Culture and Power, 19(2): 125-134.

Gans, Herbert. 2018. "Sociology and Journalism: A Comparative Analysis". Contemporary Sociology, 47(1): 3-10.

Garrett, R. Kelly. 2006. "Protest in an Information Society: a review of literature on social movements and new ICTs". Information, Communication \& Society, 9(2): 202-224.

Gelman, Andrew \& Eric Loken. 2014. "The Statistical Crisis in Science". American 
Scientist, 102(6): 460.

Giddens, Anthony. 1979. Central Problems in Social Theory: Action, structure and contradiction in social analysis. London: Palgrave.

Giddens, Anthony. 2007 [1990]. "The Consequences of Modernity", pp. 245-256 in Contemporary Sociological Theory, $2^{\text {nd }}$ ed. Craig Calhoun, et al. (eds.) Malden, MA: Blackwell Publishing.

Gitlin, Todd. 1980. The Whole World Is Watching: Mass Media in the Making and Unmaking of the New Left. Berkeley: Univ. of Calif. Press.

2012. Occupy Nation: The Roots, The Spirit \& The Promise of Occupy Wall Street. NY: HarperCollins/itbooks.

Giugni, Marco. 1998. "Social Movements and Change: Incorporation, Transformation, And Democratization," pp. xi-xxv in Giugni, McAdam \& Tilly (eds.). 1999. "How Social Movements Matter: Past Research, Present Problems, Future Developments," pp. xiii-xxxiv in Giugni, McAdam \& Tilly (eds.). Doug McAdam, and Charles Tilly (eds.). 1999. How Social Movements Matter. Minneapolis: Univ. of Minnesota Press.

Giugni, Marco, Doug McAdam, and Charles Tilly (eds.). 1998. From Contention to Democracy. Lanham, MD: Rowman \& Littlefield.

Gladwell, Malcolm. 2010. "Small Change: Why the revolution will not be tweeted." The New Yorker, (Oct. 4) http://www.newyorker.com/magazine/2010/10/04/smallchange-malcolm-gladwell (accessed 3/18/18).

Goffman, Erving. 1974. Frame Analysis: An Essay on the Organization of Experience. NY: Harper \& Row.

Goodwin, Jeff, James M. Jasper \& Francesca Polletta. 2007. "Emotional Dimensions of Social Movements," pp. 413-432 in Snow, et al. (eds.).

Graeber, David. 2004. "The New Anarchists," pp. 202-215 in Mertes (ed.).

Gramsci, Antonio. 2005 [1971]. "State and Civil Society," pp. 28-34 in The Global Resistance Reader, Louise Amoore (ed.). New York: Routledge.

Granovetter, Mark. 1985. "Economic Action and Social Structure: The Problem of Embeddedness." American Journal of Sociology, 91(3): 481-510.

Guillén, Mauro F. 2001. "Is Globalization Civilizing, Destructive or Feeble? A Critique of Five Key Debates in the Social Science Literature." Annual Review of Sociology, 27 (Aug.): 235-260.

Habermas, Jurgen. 1989 [1964]. "The Public Sphere” pp. 231-236 in Jurgen Habermas on Society and Politics: A Reader, Steven Seidman (ed.) Boston: Beacon Press.

Habermas, Jurgen. 2007 [1996]. "Civil Society and the Political Public Sphere," pp. 388407 in Contemporary Sociological Theory, $2^{\text {nd }}$ ed. Craig Calhoun, et al. (eds.). Malden, MA: Blackwell Publishing.

Halvorsen, Sam. 2015. "Taking space: Moments of rupture and everyday life in occupy London". Antipode, 47(2): 401-417.

Hewitt, Lyndi \& Holly J. McCammon. 2005. "Explaining Suffrage Mobilization: Balance, Neutralization, \& Range in Collective Action Frames," pp. 33-52 in Johnston and Noakes (eds.).

Hsieh, H. F. \& S. E. Shannon. 2005. "Three approaches to qualitative content analysis". Qualitative Health Research, 15(9), 1277-1288. 
Jaffee, Daniel. 2012. "Weak Coffee: Certification and Co-Optation in the Fair Trade Movement". Social Problems, 59(1): 94-116.

Jenson, Jane. 1995. "What's in a Name? Nationalist Movements and Public Discourse," pp. 107-126 in Johnston and Klandermans (eds.).

Johnston, Hank. 1995. "A Methodology for Frame Analysis: From Discourse to Cognitive Schemata," pp. 217-246 in Johnston and Klandermans (eds.). . 2002. "Verification and Proof in Frame and Discourse Analysis," p. 6291 in Klandermans and Staggenborg (eds.). 2005. "Comparative Frame Analysis," pp. 237-260 in Johnston and Noakes (eds.). and Bert Klandermans (eds.). 1995. Social Movements and Culture. Minneapolis: University of Minnesota Press. and John A. Noakes (eds.). 2005. Frames of Protest: Social Movements and the Framing Perspective. Lanham, MD: Rowman \& Littlefield.

Johnston, Hank \& Pamela E. Oliver. 2005. "Breaking the Frame," pp. 213-216 in Johnston and Noakes (eds.).

Juris, Jeffrey S. 2008. "Performing politics: Image, embodiment, and affective solidarity during anti-corporate globalization protests". Ethnography, 9(1): 61-97.

Kellner, Douglas. 2008 [2002]. "Theorizing Globalization," pp. 502-521 in Social Theory: Roots and Branches, Peter Kivisto (ed.) NY: Oxford Univ. Press.

Kellner, Douglas. 2012. Media Spectacle and Insurrection, 2011: From the Arab Uprisings to Occupy Everywhere. NY: Bloomsbury.

Klandermans, Bert. 1992. "The Social Construction of Protest and Multiorganizational Fields," pp. 77-103 in Frontiers in Social Movement Theory, Aldon D. Morris and Carol McClurg Mueller (eds.). New Haven: Yale University Press. . 2007. "The Demand \& Supply of Participation: Social-Psychological Correlates of Participation in Social Movements," pp. 360-379 in Snow, et al. (eds.). \& Sjoerd Goslinga. 1996. "Media Discourse, Movement Publicity, \& the Generation of Collective Action Frames: Theoretical \& Empirical Exercises in Meaning Construction," pp. 312-337 in McAdam, et al. (eds.). and Suzanne Staggenborg (eds.). 2002. Methods of Social Movement Research. Minneapolis: University of Minnesota Press.

Klandermans, Bert, Suzanne Staggenborg \& Sidney Tarrow. 2002. "Blending Methods \& Building Theories in Social Movement Research," pp.314-350 in Klandermans and Staggenborg (eds.).

Klein, Naomi. 1999. No Logo: Taking Aim at the Brand Bullies. New York: Picador. 2002. Fences and Windows: Dispatches from the Front Lines of the Globalization Debate. Toronto: Vintage Canada.

Klein, Naomi. 2004. "Reclaiming the Commons," pp. 219-229 in Mertes (ed.).

Koopmans, Ruud. 2004. "Movements and Media: Selection Processes and Evolutionary Dynamics in the Public Sphere," Theory and Society, 33(3-4): 367-391. . 2007. "Protest in Time \& Space: The Evolution of Waves of Contention," pp. 19-46 in Snow, et al. (eds.). \& Jasper Muis. 2009. "The rise of right-wing populist Pim Fortuyn in 
the Netherlands: A discursive opportunity approach". European Journal of Political Research, 48: 642-664.

Koopmans, Ruud \& Dieter Rucht. 2002. "Protest Event Analysis," pp.231-259 in Klandermans and Staggenborg (eds.).

Korten, David C. 1996. When Corporations Rule the World. San Francisco: BerrettKoehler.

Kriesi, Hanspieter. 1996. "The Organizational Structure of New Social Movements in a Political Context," pp. 152-184 in McAdam, et al. (eds.). (eds.). . 2007. "Political Context and Opportunity," pp. 67-90 in Snow, et al.

Langman, Lauren. 2005. "From Virtual Public Spheres to Global Justice: A Critical Theory of Internetworked Social Movements." Sociological Theory, 23(1): 42-74.

Lee, Ching Kwan. 2007. Against the Law: Labor Protests in China's Rustbelt and Sunbelt. Berkeley: Univ. of California Press.

Lichterman, Paul. 2002. "Seeing Structure Happen: Theory-Driven Participant Observation," p.118-145 in Klandermans and Staggenborg (eds.).

Lofland, John. 1995. "Charting Degrees of Movement Culture: Tasks of the Cultural Cartographer," pp. 188-216 in Johnston and Klandermans (eds.).

Lubitow, Amy. 2013. "Collaborative Frame Construction in Social Movement Campaigns: Bisphenol-A (BPA) and Scientist-Activist Mobilization". Social Movement Studies, 12:4, 429-447

Lule, Jack. 2015. Globalization \& Media: Global Village of Babel, $2^{\text {nd }}$ ed. Lanham, MD: Rowman \& Littlefield.

Marullo, Sam and David S. Meyer. 2007. “Antiwar and Peace Movements,” pp. 641-665 in Snow, et al.

Matthews, Jamie. 2018. "Occupation as refrain: territory and beyond in Occupy London". Social Movement Studies (23 Jan): 1-17.

McAdam, Doug. 1996a. "Conceptual Origins, Current Problems, Future Directions," pp. 23-40 in McAdam, et al. (eds.). 1996b. "The Framing Function of Movement Tactics: Strategic Dramaturgy in the American Civil Rights Movement," pp. 338-355 in McAdam, et al. (eds.). , John D. McCarthy and Meyer N. Zald (eds.). 1996. Comparative Perspectives on Social Movements: Opportunities, Mobilizing Structures and Framing. NY: Cambridge University Press. . 1998. "The Future of Social Movements", pp. 229-245 in Giugni, et al, eds. Lanham, MD: Rowman \& Littlefield.

McAdam, Doug, Sidney Tarrow, and Charles Tilly. 2001. Dynamics of Contention. NY: Cambridge Univ. Press.

McCarthy, John D. 1996. "Constraints \& Opportunities in Adopting, Adapting, \& Inventing," pp. 141-151 in McAdam, et al. (eds.).

McCarthy, John D., Jackie Smith, \& Mayer Zald. 1996. “Accessing Public, Media, Electoral, \& Governmental Agendas," pp. 291-311 in McAdam, et al. (eds.). and Mayer N. Zald. 1977. "Resource Mobilization and Social Movements: A Partial Theory," American Journal of Sociology 82(6): 1212-1241. 
McChesney, Robert W. 2004. The Problem of the Media: U.S. Communication Politics in the $21^{\text {st }}$ Century. NY: Monthly Review Press.

McChesney, Robert W. and John Nichols. 2010. The Death and Life of American Journalism: The Media Revolution That Will Begin the World Again. NY: Nation Books.

McMichael, Philip. 2012 [2004]. Development and Social Change: A Global Perspective, $5^{\text {th }}\left[3^{\text {rd }}\right]$ ed. Thousand Oaks, CA: Pine Forge Press.

Melucci, Alberto. 1995. "The Process of Collective Identity," pp. 41-63 in Johnston and Klandermans (eds.).

Mertes, Tom (ed.). 2004. A Movement of Movements: Is Another World Really Possible? NY: Verso.

Meyer, David S. 2007. The Politics of Protest: Social Movements in America. Oxford University Press.

Meyer, David S. and Suzanne Staggenborg. 1996. "Movements, Countermovements, and the Structure of Political Opportunity," American Journal of Sociology, 101(6): 1628-1660.

Michel, Jean-Baptiste, Y.K. Shen, A.P. Aiden, A. Veres, M.K. Gray, Google Books Team, J.P. Pickett, D. Hoiberg, D. Clancy, P. Norvig, J. Orwant, S. Pinker, M. Nowak, \& E.L. Aiden. 2011. "Quantitative Analysis of Culture Using Millions of Digitized Books". Science, 331(6014): 176-182.

Minkoff, Debra C. 2002. Macro-Organizational Analysis,” pp.260-285 in Klandermans, and Staggenborg (eds.).

Molotch, Harvey and John Logan. 1984. "Tensions in the Growth Machine: Overcoming Resistance to Value-Free Development," Social Problems, 31:5.

Mumford, Lewis. 1970. The Pentagon of Power: The Myth of the Machine, Vol. 2. NY: Harcourt Brace Jovanovich.

Nederveen Pieterse, Jan. 2004. Globalization and Culture. Lanham, MD: Rowman \& Littlefield.

Ngwane, Trevor. 2004. "Sparks in the Township," pp. 111-134 in Mertes (ed.).

Noakes, John A. 2005. "Official Frames in Social Movement Theory: The FBI, HUAC, \& the Communist Threat in Hollywood," pp. 89-111 in Johnston \& Noakes (eds.).

Noakes, John A. \& Hank Johnston. 2005. "Frames of Protest: A Road Map to a Perspective," pp. 1-29 in Johnston and Noakes (eds.).

Oberschall, Anthony. 1996. "Opportunities \& Framing in the Eastern European Revolts of 1989," pp. 93-121 in McAdam, et al. (eds.).

Oliver, Pamela E. \& Hank Johnston. 2005. "What A Good Idea! Ideologies \& Frames in Social Movement Research," pp. 185-203 in Johnston and Noakes (eds.).

Oregonian, The (editors). 2017. "Oregon standoff timeline: 41 days of the Malheur refuge occupation and the aftermath". The Oregonian/OregonLive (Feb. 14).

http://www.oregonlive.com/portland/index.ssf/2017/02/oregon_standoff_timeline _41_da.html (accessed 5/15/18).

Peters, Chris and Marcel Broersma (eds.). 2013. Rethinking Journalism: Trust and Participation in a Transformed News Landscape. NY: Routledge.

Pew Research Center. 2018. "State of the News Media". http://www.pewresearch.org/topics/state-of-the-news-media/ (accessed 6/14/18). 
Pickerill, Jenny and John Krinsky. 2012. "Why Does Occupy Matter?" Social Movement Studies, 11(3-4): 279-287.

Piven, Frances Fox and Richard A. Cloward. 1979. Poor Peoples Movements: Why They Succeed, How They Fail. NY: Vintage/Random House.

Polanyi, Karl. 2001 [1944]. "Part One: The International System," pp. 3-30 and "The Self-Regulating Market and the Fictitious Commodities: Labor, Land, and Money," pp. 71-80 in The Great Transformation: The Political and Economic Origins of Our Time. Boston: Beacon Press.

Reese, Stephen D. 2010. "Journalism and Globalization," Sociology Compass, 4(6): 344353.

Ritzer, George. 2015 [2000]. The McDonaldization of Society, $8^{\text {th }}$ [rev.] ed. Thousand Oaks, CA: Pine Forge Press.

Robertson, Alexa. 2015. "What's Going on? Making Sense of the Role of the Media in the Arab Uprisings". Sociology Compass, 9(7): 531-541.

Rootes, Christopher. 2007. "Environmental Movements," pp. 608-640 in Snow, et al. (eds.).

Rose, Fred. 2000. Coalitions Across the Class Divide: Lessons from the Labor, Peace, and Environmental Movements. Ithaca, NY: Cornell University Press.

Roszak, Theodore. 1969. The Making of a Counter Culture: Reflections on the Technocratic Society and Its Youthful Opposition. NY: Doubleday \& Co.

Rucht, Dieter. 1996. "The Impact of National Contexts on Social Movement Structures: A Cross-Movement \& Cross-National Comparison," pp. 185-204 in McAdam, et al. (eds.). . 1999. "The Impact of Environmental Movements in Western Societies," pp. 204-224 in Giugni, McAdam \& Tilly (eds.). . 2007. "Movement Allies, Adversaries, and Third Parties," pp. 197-216 in Snow, et al. (eds.).

Rydgren, Jens (ed). 2018. The Oxford Handbook of the Radical Right. NY: Oxford University Press.

Sader, Emir. 2004. "Beyond Civil Society: The Left after Porto Alegre," pp. 248-261 in Mertes (ed.).

Sampedro, Victor. 1997. "The Media Politics of Social Protest". Mobilization: An International Quarterly, 2(2): 185-205.

Scheufele, Dietram A. 1999. "Framing as a theory of media effects," Journal of Communication, 49(1): 103-122.

Schwartz, Mattathias. 2011. "PRE-OCCUPIED: The Origins \& Future of Occupy Wall Street". The New Yorker (Nov. 28).

Sellers, John. 2004. "Raising a Ruckus," pp. 175-191 in Mertes (ed.).

Shoemaker, Pamela and Stephen Reese. 1991. Mediating the Message: Theories of Influences on Mass Media Content, $2^{\text {nd }}$ ed. White Plains, NY: Longman.

Simmons, J.P., Nelson, L.D., \& Simonsohn, U. 2011. "False-positive psychology: Undisclosed flexibility in data collection and analysis allows presenting anything as significant". Psychological Science, 22, 1359-1366.

Sklair, Leslie. 2006. "Competing Conceptions of Globalization," pp. $59-78$ in Global 
Social Change, Christopher Chase-Dunn and Salvatore J. Babones (eds.).

Baltimore: Johns Hopkins Univ. Press.

Skocpol, Theda and Vanessa Williamson. 2011. The Tea Party \& the Remaking of

Republican Conservatism. NY: Oxford.

Smith, Jackie. 2001. "Globalizing Resistance: The Battle of Seattle and the Future of Social Movements," Mobilization: An International Quarterly, 6(1): 1-19. (eds.). 2007. "Transnational Processes \& Movements," pp. 311-335 in Snow, et al.

2011. "How Elite Media Strategies Marginalize the Occupy Movement" (Dec. 11). https://www.commondreams.org/views/2011/12/11/how-elite-mediastrategies-marginalize-occupy-movement (accessed 2/20/18).

and Tina Fetner. 2007. "Structural Approaches in the Sociology of Social Movements", pp. 13-57 in Handbook of Social Movements Across Disciplines, Bert Klandermans and Conny Roggeband (eds.). NY: Springer.

Smith, J., J.D. McCarthy, C. McPhail, B. Augustyn. 2001. "From Protest to Agenda Building: Description Bias in Media Coverage of Protest Events in Washington, D.C." Social Forces, 79(4): 1397-1423.

Snow, David A. 2007. "Framing Processes, Ideology, \& Discursive Fields," pp. 380-412 in Snow, et al. (eds.).

. \& Robert Benford. 2005. "Clarifying the Relationship Between Framing \& Ideology," pp. 205-211 in Johnston and Noakes (eds.).

Snow, David A., Burke Rochford, Jr., Steven A. Worden, Robert D. Benford. 1986. "Frame Alignment Processes, Micromobilization, and Movement Participation," American Sociological Review, 51(4): 464-481. , Sarah Soule, and Hanspeter Kriesi (eds.). 2007 [2004]. The Blackwell Companion to Social Movements. Oxford: Blackwell. and Danny Trom. 2002. "The Case Study and the Study of Social Movements," pp. 146-172 in Klandermans, Bert and Suzanne Staggenborg (eds.). Sobieraj, Sarah. 2011. "A Sociologist's View of the 'Occupy' Camps: Movements in a Shifting Media Landscape." ASA footnotes, 39(9). http://www.asanet.org/footnotes/dec11/occupy_1211.html (accessed 2/18/18).

Snyder, D. and W.R. Kelly. 1977. "Conflict Intensity, Media Sensitivity and the Validity of Newspaper Data." American Sociological Review, 42: 105-123.

Stedile, Joao Pedro. 2004. "Brazil's Landless Battalions: The Sem Terra Movement," pp. 17-48 in Mertes (ed.).

Strauss, Anselm and Juliet Corbin. 1998. Basics of Qualitative Research. Thousand Oaks, CA: Sage Publications.

Swank, Eric. 2000. "In Newspapers We Trust? Assessing the Credibility of News Sources that Cover Protest Campaigns". Research in Social Movements, Conflicts, and Change, Vol. 22: 27-52.

Swidler, Ann. 1995. "Cultural Power and Social Movements," pp. 25-40 in Johnston and Klandermans (eds.).

Tarrow, Sidney. 1996. "States \& Opportunities: The Political Structuring of Social Movements," pp. 41-61 in McAdam, et al. (eds.). 1998a. Power in Movement: Social Movements and Contentious Politics, 
$2^{\text {nd }}$ ed. NY: Cambridge Univ. Press.

1998b. "Social Protest and Policy Reform: May 1968 and the Loi

d'Orientation in France," pp. 31-56 in Giugni, McAdam \& Tilly (eds.).

Tarrow, Sidney. 2005. The New Transnational Activism. NY: Cambridge Univ. Press.

Taylor, Verta \& Nancy Whittier. 1995. "Analytical Approaches to SM Culture: The Culture of the Women's Movement," pp.163-187 in Johnston and Klandermans. \& Nella Van Dyke. 2007. “'Get up, Stand up': Tactical Repertoires of

Social Movements," pp. 262-293 in Snow, et al.(eds.).

Tilly, Charles. 1999. "From Interactions to Outcomes in Social Movements", pp. 253-70 in Giugni, McAdam, \& Tilly (eds.). 2003. The Politics of Collective Violence. NY: Cambridge Univ. Press.

Tilly, Charles \& Sidney Tarrow. 2015. Contentious Politics, $2^{\text {nd }}$ ed. NY: Oxford U. Press.

Touraine, Alain. 2008 [2001]. "The Subject and Societal Movements," pp. 533-543 in Social Theory: Roots and Branches. Peter Kivisto, ed. NY: Oxford Univ. Press.

Van Dyke, Nella and Sarah A. Soule. 2002. "Structural Social Change and the Mobilizing Effect of Threat: Explaining Levels of Patriot and Militia Organizing in the United States". Social Problems, 49(4): 497-520.

Voss, Kim. 1996. "The Collapse of a Social Movement: The Interplay of Mobilizing Structures, Framing \& Political Opp's in the Knights of Labor," pp. 227-258 in McAdam, et al.

Walgrave, Stefaan \& Jan Manssens. 2005. "Mobilizing the White March: Media Frames as Alternatives to Movement Organization," pp. 113-140 in Johnston and Noakes (eds.).

Wallerstein, Immanuel. 2004. "New Revolts Against the System," pp. 262-273 in Mertes (ed.).

Weiss, Robert S. 1994. Learning From Strangers: The Art and Method of Qualitative Interview Studies. NY: The Free Press.

Westby, David L. 2005. "Strategic Imperative, Ideology, \& Frames," pp. 217-235 in Johnston and Noakes (eds.).

White, Micah. 2016. The End of Protest: A New Playbook for Revolution. Toronto: Knopf Canada.

Williams, Rhys H. 2007. "The Cultural Context of Collective Action: Constraints, Opportunities, and the Symbolic Life of Social Movements," pp. 91-115 in Snow, et al. (eds.).

Wouters, Ruud \& Stefaan Walgrave. 2017. "Demonstrating Power: How Protest Persuades Political Representatives". American Sociological Review, 82(2): 361383.

Xu, Kaibin. 2013. "Framing Occupy Wall Street: A Content Analysis of The New York Times and USA Today." International Journal of Communication, 7: 2412-2432.

Zald, Mayer N. 1996. "Culture, Ideology, \& Strategic Framing," pp. 261-274 in McAdam, et al.

Zdravomyslova, Elena. 1996. "Opportunities \& Framing in the Transition to Democracy: The Case of Russia," pp. 122-137 in McAdam, et al. (eds.). 


\section{APPENDIX A - Transnational Social Movements}

An increasingly global economy - with mass media as well as immigration - has "escaped the national state" and created conditions for transnational social movements (TSMs) which have also rapidly diffused across national boundaries (Tarrow 1996: 61). As a key response to globalization's inequities, and in parallel with national SMs (Smith 2007: 329), TSMs especially provide new communicative mechanisms to diffuse collective action frames to "resource-poor domestic actors" (Tarrow 1998a: 189). Yet transnational organizations and institutions also have increasingly been deployed "to combat and pacify social movements." (ibid: 195)

Global justice movements in particular, seen from an approach of 'nested' political opportunity structures (local/national/ international), present complex "“conflicting globalizations"” (Guidry in Smith 2007: 318) - in that globalization-related struggles within a global public sphere might actually undermine national-level democratic structures and strengthen non-democratic global institutions (Smith 2007: 319). These TSMs, as a movement of movements, thus pose challenges as well as opportunities for deliberative democracy (della Porta 2005). Moreover, TSMs especially protest transnational governance structures (e.g. World Trade Organization) - which have often split movements "between those that have become governance [policy making] movements" and those (e.g. Friends of the Earth) "that remain closer to social movement and emancipatory forms" (Doherty \& Doyle 2006: 700, 709). And while many question whether there is continuing evidence of TSM protest innovation, ongoing globalization and transnational protest appear to have "enduring effects" on SM organization and character. (Smith 2001: 1) 


\section{APPENDIX B - The Sample $(\mathrm{n}=60)$ :}

The New York Times, The Oregonian, USA Today

\section{OCCUPY WALL STREET (OWS 2011) PROTEST STORIES, n=30 (pop.=255)}

1 - COLIN MOYNIHAN. "Wall Street Protest Begins, With Demonstrators Blocked." The New York Times Blogs (City Room). (September 17, 2011 Saturday ): 724 words. LexisNexis Academic.

9 - N. R. KLEINFIELD and CARA BUCKLEY (contrib: Natasha Lennard and Colin Moynihan). "Wall Street Occupiers, Protesting Till Whenever." The New York Times. (October 1, 2011 Saturday ): 1246 words. LexisNexis Academic.

21 - BRIAN STELTER. "Coverage Grows for Wall Street Protest." The New York Times Blogs (Media Decoder). (October 5, 2011 Wednesday ): 699 words. LexisNexis Academic.

46 - AL BAKER. "Overtime, Solidarity and Complaints in Wall St. Protests." The New York Times Blogs (City Room). (October 13, 2011 Thursday ): 894 words. LexisNexis Academic.

57 - BUCKLEY, CARA and RACHEL DONADIO (NY \& Rome; contrib: Jack Ewing/Frankfurt, Nicholas Kulish/Berlin, Joseph Goldstein,Elizabeth Harris,Colin Moynihan,Christopher Maag/NY, Catherine Garcia/L.A., Raphael Minder/Madrid, Ron Nixon/Washington, Ravi Somaiya/London). "Rallies Across the Globe Protest Economic Policies." The New York Times. (October 16, 2011 Sunday ): 1472 words. LexisNexis Academic.

79 - OLEN, HELAINE. "For Children's Sake, Taking to the Streets." The New York Times. (October 27, 2011 Thursday ): 921 words. LexisNexis Academic.

95 - EDITORIAL. "Occupying the National Debate." The New York Times. (November 5, 2011 Saturday ): 270 words. LexisNexis Academic.

103 - THE ASSOCIATED PRESS. "Pressure Is Growing to Shut Down 'Occupy' Camps Across the Nation." The New York Times. (November 12, 2011 Saturday ): 235 words. LexisNexis Academic.

114 - JESS BIDGOOD, DAN FROSCH and MALIA WOLLAN (Bidgood from Boston, Frosch from Denver, \& Wollan from Oakland. contrib: Steven Yaccino/Chicago, Ian Lovett/Los Angeles, Lee van der Voo/Portland, Robbie Brown/Atlanta, and Elizabeth A. Harris \& Timothy Williams/New York). "Other Sites Hope N.Y. Raid Will Energize Cause." The New York Times. (November 16, 2011 Wednesday ): 1355 words. LexisNexis Academic.

123 - BRIAN STELTER. "Officers Placed on Leave After Pepper-Spraying Protesters." The New York Times Blogs (The Lede). (November 20, 2011 Sunday ): 848 words. LexisNexis Academic.

3 - HABERMAN, MARGARET. "Thousands march through downtown." Oregonian, The (Portland, OR) 7 Oct. 2011, Sunrise, Local News: NewsBank.

5 - Sarasohn, David. "Occupy Portland: Message(s)." Oregonian, The (Portland, OR) 8 Oct. 2011, Sunrise, Editorial: NewsBank.

18 - SAKER, ANNE. "Eight arrests, but peace reigns." Oregonian, The (Portland, OR) 14 Oct. 2011, Sunrise, Local News: NewsBank.

24 - "Protest keeps one eye on itself." Oregonian, The (Portland, OR) 21 Oct. 2011, Sunrise, Local News: NewsBank.

28 - SAKER, ANNE. "Protesters say up to \$20,000 missing." Oregonian, The (Portland, OR) 27 Oct. 2011, Sunrise, Local News: NewsBank.

47 - FRANCIS, MIKE. "A peaceful protest to remember, remember." Oregonian, The (Portland, OR) 6 Nov. 2011, Sunrise, Local News: NewsBank.

48 - Smith, Owen. "One group claims responsibility, another denounces bank damage Hours after a group calling itself "The Real Occupy Portland" claimed responsibility for vandalizing two bank offices, police received a second email Sunday from a similarly named gr...." Oregonian, The (Portland, OR) 7 Nov. 2011, Sunrise, Local News: NewsBank.

67 - TERRY, LYNNE. "Stroll ends in arrest, bruises." Oregonian, The (Portland, OR) 15 Nov. 2011, Sunrise, Local News: NewsBank.

71 - SAKER, ANNE. "PSU rallies 'round Occupy." Oregonian, The (Portland, OR) 17 Nov. 2011, Sunrise, Local News: NewsBank.

84 - Beth Slovic. "Occupy: from city parks to City Hall?.... Cameron Whitten, a twice-arrested Occupy Portland protester, filed a prospective petition Nov. 16 to run for Portland mayor, signaling a new wave in the 2-month-old Occupy Portland demonstration: campaigning. If h...". Oregonian, The (Portland, OR) 26 Nov. 2011, Sunrise, Metro Portland Neighbors: In Portland: NewsBank.

1 - Bly, Laura. "Wall St. rallies are new brand of tourism; Arrests drive interest in anti-greed protests." USA TODAY. October 4, 2011 Tuesday . Date Accessed: 2016/05/20. www.lexisnexis.com/hottopics/lnacademic.

8 - "Five good reasons why Wall Street breeds protesters." USA TODAY. October 12, 2011 Wednesday. Date Accessed:2016/05/20. www.lexisnexis.com/hottopics/lnacademic.

11 - Bacon, John (w/ staff \& wire reports)."NYC protesters vow to defy order to leave park." USA TODAY. October 14, 2011 Friday. Date Accessed: 2016/05/20. www.lexisnexis.com/hottopics/lnacademic.

19 - Trinko, Katrina. "Millennials, don't just 'occupy'; do something; Every generation has its hill to climb. Our challenge is to ask tough questions and to reinvent the American Dream.." USA TODAY. (October 26, 2011 Wednesday): 877 words. LexisNexis Academic. Web.

22 - Staff \& wire reports. "Occupy London protest shakes up St. Paul's; Camp outside church puts strain on clergy leaders." USA TODAY. (November 1, 2011 Tuesday): 524 words. LexisNexis Academic.

24 - Strauss, Gary. "Former Marine's injury spurs vets to join Occupy movement; Former Marine hurt in protest." USA TODAY. (November 2, 2011 Wednesday): 513 words. LexisNexis Academic.

26 - Bacon, John (w/ staff \& wire reports)."Occupy protesters finger bad apples." USA TODAY. (November 4, 2011 Friday): 610 
words. LexisNexis Academic.

30 - Hampson, Rick. "Violent fringe could fray 'Occupy'; Peaceful movement's message could get lost in the scuffle, experts warn." USA TODAY. (November 14, 2011 Monday): 835 words. LexisNexis Academic.

32 - Bello, Marisol. "Poll: 6 in 10 are indifferent about Occupy movement; Public uncertainty fueled by protests' undefined goals." USA TODAY. (November 22, 2011 Tuesday): 354 words. LexisNexis Academic.

34 - Leinwand Leger, Donna. "Occupy protesters wear out welcome in L.A., Philadelphia; Evictions pending, as cities try to relocate, limit demonstrations." USA TODAY. (November 28, 2011 Monday ): 387 words. LexisNexis Academic.

\#\#\#

MALHEUR REFUGE OCCUPATION (MRO 2016) PROTEST STORIES, n=30 (pop.=213)

2 - JOHNSON, KIRK, RICHARD PEREZ-PENA \& ERICK ECKHOLM. "Armed Protesters Vow to Stay on Oregon Refuge Indefinitely." The New York Times. (January 4, 2016 Monday): 1286 words. LexisNexis Academic.

15 - EDITORIAL BOARD, THE. "Guns, Anger and Nonsense in Oregon." The New York Times. (January 7, 2016 Thursday): 648 words. LexisNexis Academic.

24 - TURKEWITZ, JULIE. "Fervor at an Oregon Wildlife Refuge, Concern Just Outside It." The New York Times. (January 13, 2016 Wednesday ): 1216 words. LexisNexis Academic.

28 - FEUER, ALAN. "Standoff in Oregon Attracts Supporters Bearing Disparate Grievances." The New York Times. (January 17, 2016 Sunday ): 1117 words. LexisNexis Academic.

36 - TURKEWITZ, JULIE and JACK HEALY. "Protester Who Was Killed Was Group's Defiant Voice." The New York Times. (January 28, 2016 Thursday ): 724 words. LexisNexis Academic.

38 - VICTOR, DANIEL. "Facebook Video Gives Account of Oregon Arrests." The New York Times. (January 28, 2016 Thursday ): 313 words. LexisNexis Academic.

45 - JOHNSON, KIRK "Both Sides in Takeover Face Off in Oregon." The New York Times. (February 2, 2016 Tuesday): 484 words. LexisNexis Academic.

47 - JOHNSON, KIRK "F.B.I. Encircles 4 Holdouts at Oregon Wildlife Refuge." The New York Times. (February 11, 2016 Thursday): 788 words. LexisNexis Academic.

51 - McPHATE, MIKE. "Michele Fiore, a Nevada Assemblywoman, Finds Unlikely Role at Oregon Standoff's End." The New York Times. (February 12, 2016 Friday ): 1490 words. LexisNexis Academic.

55 - JOHNSON, KIRK. "25 Plead Not Guilty in Standoff at Wildlife Refuge in Oregon." The New York Times. (February 25, 2016 Thursday ): 777 words. LexisNexis Academic.

5/6 - Les Zaitz. "At occupied refuge, a calm resolve." Oregonian, The (Portland, OR) 4 Jan. 2016, 1M, A: 04. NewsBank. (with)-"A/Key Players." Oregonian, The (Portland, OR) 4 Jan. 2016, 1M, A: 04. NewsBank.

52 - Laura Gunderson. "Patience thins as occupation drags on." Oregonian, The (Portland, OR) 15 Jan. 2016, 1M, A: 01. NewsBank.

53 - Rob Davis. "Before Burns, dispute played out over mine." Oregonian, The (Portland, OR) 15 Jan. 2016, 1M, A: 10. NewsBank.

58 - "A/Timeline." Oregonian, The (Portland, OR) 17 Jan. 2016, 1M, A: 12. NewsBank.

88 - Maxine Bernstein. "Standoff leaders are denied release." Oregonian, The (Portland, OR) 28 Jan. 2016, 1M, A: 04. NewsBank.

103 - Maxine Bernstein. "Grand jury indicts Harney County occupiers." Oregonian, The (Portland, OR) 4 Feb. 2016, 1 M, A: 02. NewsBank.

122 - Les Zaitz. "Peaceful end, sighs of relief - Harney County welcomes the end of the Malheur refuge takeover after the last four holdouts give up." Oregonian, The (Portland, OR) 12 Feb. 2016, 1M, A: 01. NewsBank.

133 - "TIMELINE." Oregonian, The (Portland, OR) 14 Feb. 2016, 1M, A: 18. NewsBank.

137 - Maxine Bernstein. "Occupier files complaint against feds." Oregonian, The (Portland, OR) 18 Feb. 2016, 1M, A: 04. NewsBank.

140 - Maxine Bernstein. "One Malheur holdout is released, with conditions." Oregonian, The (Portland, OR) 20 Feb. 2016, 1M, A: 02. NewsBank.

1 - "All eyes on militia standoff in Oregon; Sheriff says group wants to 'spark a movement' to depose government." USA TODAY. (January 4, 2016 Monday ): 419 words. LexisNexis Academic.

2 - "Takeover in Oregon has roots in family." USA TODAY. (January 4, 2016 Monday): 289 words. LexisNexis Academic.

3 - "Ore. ranchers to seek clemency; Group invokes the Constitution as standoff continues." USA TODAY. (January 5, 2016 Tuesday): 641 words. LexisNexis Academic.

5 - "Takeover of federal refuge in Oregon breaks the law." USA TODAY. (January 5, 2016 Tuesday ): 526 words. LexisNexis Academic.

7 - "Oregon standoff: 'We will not back down'." USA TODAY. (January 6, 2016 Wednesday ): 390 words. LexisNexis Academic.

8 - "An Old west standoff forced on a modern millennium; In cowboy gear and camouflage, packing guns and gizmos, the armed occupiers of an Oregon wildlife refuge defy a government they say is out to oppress free spirits." USA TODAY. (January 8, 2016 Friday): 873 words. LexisNexis Academic.

10 - "Half-dozen hold out at Oregon refuge; Sheriff says that 'there doesn't have to be bloodshed'." USA TODAY. (January 28, 2016 Thursday): 596 words. LexisNexis Academic.

11 - "Video of Ore. protester's shooting death released; Move aims to allay concerns over "inflammatory" accounts of incident." USA TODAY. (January 29, 2016 Friday): 400 words. LexisNexis Academic.

13 - "IN BRIEF." USA TODAY. (February 5, 2016 Friday ): 471 words. LexisNexis Academic.

14 - "A bizarre ending to Oregon refuge saga; Last holdout makes rambling phone call streamed online." USA TODAY. (February 12, 2016 Friday): 570 words. LexisNexis Academic. 


\section{APPENDIX C - Sample Coding Glossaries}

\section{NEWS STORY CODING: SAMPLE GLOSSARY (OWS 2011)}

CITATION: Buckley, C. \& Donadio R. 2011. "Rallies Across the Globe Protest Economic Policies".

The New York Times. (October 16), pg. A4.

\section{Source Attribution}

$\begin{array}{lllll}\text { expressing } & \text { estimated } & \text { warned } & \text { honked...support } & \text { messages } \\ \text { sentiments } & \text { said } & \text { decried } & \text { lawprohibiting } & \text { debated } \\ \text { warning } & \text { asked } & \text { discuss } & \text { called } & \text { cries }\end{array}$

Commercial-vs.-Regulatory Perspectives

Anti- Gov./Regulatory, Commercial Corporate (A-G)....

Anti-Corporate (A-C): "discontent...economic tides" • "opposing...corruption ...privatization" • "business as usual...crisis is everywhere" • "people...beholden to corporate interests"

Other (e.g., Vertical- or Horizontal- Regulatory Commercial, source ambivalent, narrative unclear): "police asked ...branch ...to close" • "discuss...Europe's debt" • "no problem with capitalism ...but ...bail out the people" • "decried...unemployment" • "put their money into smaller banks" • "police estimated... dozens" • "police...warned" • "honked...support" • "opposition to...Obama" • "opposing nuclear power" - "cries of ... 'the 99\%" • "culmination of a dream" • "variety of messages".

\section{Components of Collective Action Frame}

Injustice: "protest economic policies" • "...expressing discontent" • "protesters...tried to leave...locked inside" • "...don't feel represented" • "financial system... unethical" • "about global financial inequities"

Agency: "protesters...withdrew their money".

Identity: "We don't feel represented..." • "We feel..." • "We're upset...".

\section{Complete C.A.F.....}

\section{Components of Dispersed Passivity Frame}

Fate:

Passivity: "protesters...locked inside by bank employees" • "arrested"

Dispersion: ....

(abstract actor[s]): "the people"

Polarization

"clashing with police" • "defied [police] orders" • "arrested" • "protesters...very disruptive"

$\underline{\text { Rational Actors }}$

"no problem with capitalism ...but ...financial system ...unethical" • "economic climate...crisis is everywhere."

Irrational/Emotional Actors

"restive young people ...riot" • "getting rowdy" • "very disruptive" • "We're upset..."

\section{Commercially Framed Activism}

"protesters... withdrew their money" • "resources we give...compete with the larger bank" 


\section{NEWS STORY CODING: SAMPLE GLOSSARY (MRO 2016)}

CITATION: Johnson, Kirk and Jack Healy. 2016. "Armed Protesters Vow to Stay on Oregon Refuge Indefinitely.” The New York Times, (Jan. 4), pg. A1.

\section{Source Attribution}

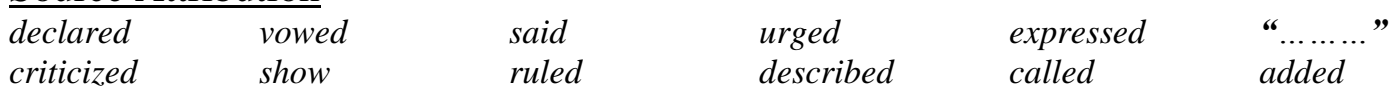

\section{Commercial-vs.-Regulatory Perspectives}

Anti- Gov./Regulatory, Commercial Corporate (A-G): "antigovernment group seized" • "liberation of public lands" • "government...overreach" • "anger over federal land policies" • "attempt to overthrow... county...gov" • "protest group ...did not allow entry [to gov. bldgs.]" • "anti-government activists" • "use these lands as free men" • "tyrannical...federal authority" .... "

\section{Anti-Corporate (A-C):....}

Other (e.g., Vertical- or Horizontal- Regulatory Commercial, source ambivalent, narrative unclear): "attempt to overthrow...federal gov" • "federal judge ruled" • "county isn't supportive of what's being done here" • "Oregon ...Police urged people to stay away" • "his own view... a bit conflicted" • "they said were efforts to protect their property" • "said her husband would surrender" • "contingent declared...it was taking a stand"

\section{Components of Collective Action Frame (C.A.F.)}

Injustice: “...protesters vow" • "protesters arrived...” • "described...tyrannical use” • “...see who's...right" • "group's...liberation" • "to...'use ... as free men"”

Agency: "armed protesters vow" • "protesters arrived ...declared" • "occupying group blocked" • "members did not allow entry" • "group's...liberation of public lands" • "use these lands as free men"” - "battle over land"

Identity: "the occupying group..." • "members..." •"[Bundys] described...tyrannical use" • "we'll...read the Constitution..."

Complete C.A.F: "armed antigovernment group seized" • "the group's action ... a liberation" • "group was prepared to... 'use these lands as free men", • "his group... 'stand against...overreach"' • (headline)

\section{Components of Dispersed Passivity Frame}

Fate: ....

Passivity: ....

Dispersion: ....

(abstract actor[s]): ....

\section{Polarization}

"standoff" • "attempt to overthrow" • "outsider militia group" • "'bunch... who live without the county", • "organizing opposition" • "a battle" • "see who's on the right side"

\section{Rational Actors}

"talked about returning ... land to...people” • "'sentiments in regards to...mngmnt of our country"” • "said none of the bldgs had been damaged" • "when the people of Harney County 'can use these lands", - "'a symptom of ...problem'” • "said the group was not violent" • "'we'll...read the Constitution'”

Irrational/Emotional Actors

"could turn violent"

\section{Commercially Framed Activism}

"landowners and ranchers [struggle]" • "use these lands as free men" • "posted to Facebook" 


\section{APPENDIX D-Coding Template \& Summary Code Sheet}

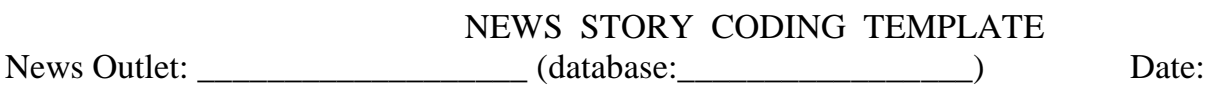

Citation (Byline, Headline): *

Subhead? * $\quad(*=$ Collective action $[$ or abstract] components: )

Summary:

Photo? _ caption?__ (collective action components?__ abstract components?__ WC Agreement:...Headline-Story? yes__no__ (mixed__ ...Lead-Story? yes__ (no__) (mixed__),

\section{Sources:}

Un-sourced Portrayals:

Frequency of Attributions ('source type' by 'commercial-gov. perspective'):

\begin{tabular}{|c|c|c|c|c|c|}
\hline & $\begin{array}{l}\text { Anti- Gov/regulatory } \\
\text { (Commercial } \\
\text {-Corporate) }\end{array}$ & $\begin{array}{c}\text { Anti- } \\
\text { Corporate }\end{array}$ & Other $^{78}$ & Sympathizers & Detractors \\
\hline Government & \begin{tabular}{l|l|} 
& 1
\end{tabular} & \# / & I & I & / \\
\hline Business & I & I & I & I & I \\
\hline Citizen/Indep & I & I & I & I & I \\
\hline Academic & 1 & 1 & 1 & 1 & 1 \\
\hline (anonymous) & I & I & I & I & I \\
\hline
\end{tabular}

Portrayal of Activists:

(Dispersed Passivity [path $\boldsymbol{y}$ ] or Collective Action [path $\boldsymbol{x}$ ] Frames by 'commercial-gov. perspective')

\begin{tabular}{|c|c|c|c|}
{$[y]$...or... $[\boldsymbol{x}]$} & A-G & A-C & Other \\
\hline Fate..........Injustice & $/$ & $/$ & $/$ \\
\hline Passivity.......Agency & $/$ & $/$ & $/$ \\
\hline Dispersion....Identity & $/$ & $/$ & $/$ \\
\hline (Abstract) & $/$ & $/$ & $/$ \\
\hline (complete C.A.F.s) & $/$ & $/$ & $/$ \\
\hline \multicolumn{5}{|c|}{$I^{\text {st }}$ half of story / 2d $^{\text {nd }}$ half of story }
\end{tabular}

Dominant Perspective in Story: Balance

\begin{tabular}{|l|l|l|l|}
\multicolumn{1}{c}{ A-C } & Other & \multicolumn{1}{l}{$\begin{array}{l}\text { Between } \\
\text { Perspectives }\end{array}$} \\
\hline & & & \\
\hline
\end{tabular}

Polarization (instances):

Rational SM actor/statement (instances):

Irrational /dramatic/emotional SM actor/statement (instances):

Commercially-framed activism (market metaphor/ terminology), instances:

78 e.g.: vertical- or horizontal- regulatory commercial, source ambivalent, \&/or narrative unclear 
SUMMARY NEWS CODE SHEET ( $\mathrm{n}=30$ News Stories, from total pop.= )

Year:

News Outlets:

Story Citations

Bylines: $\quad(\mathrm{n}=30)$

Photos?__ $(\mathrm{n}=30)$ [collective action__labstract__ ]

Headline/Subhead: collective action components? Injustice:

Headlines/Summary ( $\mathrm{n}=30)$

w/ Activists named/personified? _ $(\mathrm{n}=30) \quad$ [abstract components?

NYT ([ave. wordcount $[\max , \min ]$ ):

ORGN (ave. wordcount NA):

USAT (ave. wordcount: $[\max , \min ])$ :

Headline-Story Agreement ( $\mathrm{n}=30)$

H-S? y:__ n:___ (+/-):__ . *Where do H-S disagree?

Number of Different Sources:

Un-Sourced Portrayals:

Frequency of Attributions ('Source Type' by 'Commercial-Gov. Perspective'):

Anti- Gov/Regulatory

(Commercial

Anti-

-Corporate) Corporate

Other ${ }^{79}$ TOTAL Sympathizers Detractors

\begin{tabular}{|l|c|c|c|c|c|c|}
\multicolumn{2}{c}{-Corporate) } & \multicolumn{1}{c}{ Corporate } & Other & TOTAL & Sympathizers & Detractors \\
\hline Government & $/$ & $/$ & $/$ & $/$ & $/$ & $/$ \\
\hline Business & $/$ & $/$ & $/$ & $/$ & $/$ & $/$ \\
\hline Citizen/Indep & $/$ & $/$ & $/$ & $/$ & $/$ & $/$ \\
\hline Academic & $/$ & $/$ & $/$ & $/$ & $/$ & $/$ \\
\hline (anonymous) & $/$ & $/$ & $/$ & $/$ & $/$ & $/$ \\
\hline TOTAL & $/$ & $/$ & $/$ & $/$ & & \\
\hline
\end{tabular}

Lead (first) Perspective Portrayed in Stories $(n=30)$ :

\begin{tabular}{|l|l|l|l|l|}
\multicolumn{2}{c}{ A-G } & A-C & \multicolumn{1}{c|}{ Other } & \multicolumn{1}{c|}{ TOTAL } \\
\hline Government & & & & \\
\hline Business & & & & \\
\hline Citizen/Indep & & & & \\
\hline Academic & & & & \\
\hline (anonymous) & & & & \\
\hline TOTAL & & & & \\
\hline
\end{tabular}

${ }^{79}$ e.g., vertical- or horizontal- regulatory commercial, source ambivalent, \&/or narrative unclear 
$(\mathbf{n}=30$ News Stories $)$

Year:

Portrayal of Activists: Collective Action Frame

(Frequency of 'Path X Components' by 'Commercial-Gov. Perspective')

\begin{tabular}{|c|c|c|c|c|}
\hline & $\begin{array}{c}\text { ti- Gov/Regul } \\
\text { (Commercial } \\
\text {-Corporate) }\end{array}$ & $\begin{array}{l}\text { y Anti- } \\
\text { Corporate }\end{array}$ & Other $^{80}$ & TOTAL \\
\hline Injustice & 1 & 1 & 1 & 1 \\
\hline Agency & 1 & 1 & 7 & 7 \\
\hline Identity & 1 & 1 & 1 & 1 \\
\hline TOTAL & 1 & 1 & 1 & 1 \\
\hline complete $\boldsymbol{C} . \boldsymbol{A} . \boldsymbol{F} . \mathrm{s}$ & 1 & 1 & 1 & 1 \\
\hline
\end{tabular}

Portrayal of Activists: Dispersed Passivity Frame

(Frequency of 'Path $Y$ Components' by 'Commercial-Gov. Perspective')

\begin{tabular}{|l|c|c|c|c|}
\multicolumn{1}{c}{ A-G } & A-C & Other & TOTAL \\
\hline Fate & $/$ & $/$ & $/$ & $/$ \\
\hline Passivity & $/$ & $/$ & $/$ & $/$ \\
\hline Dispersion & $/$ & $/$ & $/$ & $/$ \\
\hline (Abstract) & $/$ & $/$ & $/$ & $/$ \\
\hline TOTAL & $/$ & $/$ & $/$ & $/$ \\
\hline
\end{tabular}

Dominant Perspective in Story $(n=30)$ :

\begin{tabular}{|c|c|c|c|}
\hline Anti-Gov/Regulator & & & Balance \\
\hline $\begin{array}{c}\text { (Commercial } \\
\text {-Corporate) }\end{array}$ & $\begin{array}{c}\text { Anti- } \\
\text { Corporate }\end{array}$ & Other & $\begin{array}{l}\text { Between } \\
\text { Perspectives }\end{array}$ \\
\hline
\end{tabular}

Polarization: instances / stories

\section{Rational SM actor/statement: ___ instances / __ stories}

Irrational /dramatic/emotional SM actor/statement: ____instances / ___ stories

Commercially-framed activism (w/ market metaphor/ terminology): ___ instances / stories

\footnotetext{
${ }^{80}$ e.g., vertical- or horizontal-regulatory commercial, source ambivalent, \&/or narrative unclear
} 


\section{APPENDIX E-Summary Data (Code Sheets)}

\section{SUMMARY NEWS CODE SHEET ( $\mathrm{n}=30$ News Stories, from total pop. $=255$ )}

Protest: Occupy Wall Street (OWS)

Year: 2011

News Outlets: The New York Times (10, total pop.=134); The Oregonian (10, total pop.=87); USA Today (10, total pop.=34)

Story Citations

Bylines: $26(\mathrm{n}=30) \quad$ Photos? 6 ( $\mathrm{n}=30)$ [collective action 7 / abstract 1 ] ]

Headline/Subhead: collective action components? Injustice: 18 Agency: 16 Identity: 12 (full C.A.F: 6 )

Headlines/Summary $(\mathrm{n}=30)$

$$
\text { w/ Activists named/personified? } \underline{9}(\mathrm{n}=30) \quad \text { [abstract } \text { components? } 16 \text { ] }
$$

NYT (ave. wordcount $734[\max 1246, \min 235])$ : ‘...Protest Begins... Blocked*' ‘. . Till Whenever*' ‘..Solidarity* \& Complaints'. OWS coverage $\boldsymbol{\lambda}$. 'Rallies*...globe...'. ‘...Children's...Streets'. '...National Debate'.'Pressure*...Shut Down' ‘ ...hope NY raid...' 'Officers...Pepper-Spray'. ORGN (ave. wordcount NA): 'Thousnds*march...' 'OccupyPDX: Messages'. '8 arrests*'. 'Protest...eye on itself'. 'Protesters $\$ 20,000$ missing*'. 'protest to*remembr'. 'One claims another denounces'. 'Stroll*...bruises'. 'PSU...Occupy'. ‘...parks to*CityHall?...'. USAT (ave. wordcount: 405 [max 835, min 139]): 'WallSt rallies...tourism; Arrests*....' ‘....reasons why ...protesters'. '...protesters... defy order*...' ' ... don't just Occupy...'. 'Occupy London... St. Paul's...strain.' '...Marine's injury... vets...Occupy...' '...protesters...bad*apples'. 'Violent fringe....msg could get lost...scuffle*.... '...indifferent* about Occupy... undefined goals'. 'Occupy... wear out welcome in...Philadel*; Evictions...'.

Headline-Story Agreement $(\mathrm{n}=30)$

H-S? y: 13 n: 2 (+/-): 15 . *Where do H-S disagree? NYT: 'blocked' from WallSt near NYSE only. Beyond 'Till Whenever', diverse occupiers! 'Solidarity'?...Occupiers \& police, 'we're 99\%'. Story (vs. headline), police clash (1 case unrelated to_OWS!). Police 'Pressure'-> politicians but $2 / 3$ deaths self-inflicted. ORGN: 'March' headline but encampment story. ' 8 arrests' but police 'stunned by cooperation'! ‘.. \$20K'could be missing. Arrest/bruised elder not just bystander but 'show support'. Whitten arrest-focus vs. mayor campgn. Headline historic refernc unexplained til story end. USAT: No 'arrest' info, minimal 'tourism' seen. Is 'order' by prop. owner?? Who R 'Bad apples'? Who 'Scuffle'?( police). Poll: public uncertain not 'indifferent'! (+goals complex, not 'undefined'). Philad? no prior 'welcome' shown.

Number of Different Sources: $129 \quad 72 \quad 82$

Un-Sourced Portrayals: $\frac{151}{15 Y T} \quad$\begin{tabular}{ll} 
ORGN & 109 \\
\hline USAT
\end{tabular}

Frequency of Attributions ('Source Type’ by 'Commercial-Gov. Perspective'):

Anti- Gov/Regulatory (Commercial Anti-

-Corporate) Corporate Other $^{81}$

\begin{tabular}{|c|c|c|c|c|c|c|}
\hline & -Corporate) & Corporate & Other ${ }^{81}$ & TOTAL & Sympathizers & Detractors \\
\hline Government & 1 & 1 & $48.5 / 46$ & $48.5 / 46$ & 15 & $3 / 3$ \\
\hline Business & 1 & I & $17 / 14$ & $18 / 14$ & $2 / 1$ & 13 \\
\hline Citizen/Indep & I & $-32 / 24$ & $107.5 / 124$ & $139.5 / 148$ & $3 / 11$ & $1 / 2$ \\
\hline Academic & 1 & & $6 / 12$ & $6 / 13$ & $1 / 1$ & I \\
\hline (anonymous) & I & $25 / 14$ & $86 / 65$ & $111 / 79$ & $7 / 7$ & $6 / 2$ \\
\hline TOTAL & $1 /$ & $57 / 39$ & $265 / 261$ & 323 / 300 & $13 / 25$ & $10 / 10$ \\
\hline
\end{tabular}

$1^{\text {st }}$ half of story $/ 2^{\text {nd }}$ half of story

Lead (first) Perspective Portrayed in Stories $(n=30)$ :

\begin{tabular}{|l|c|c|c|c|}
\multicolumn{2}{c}{ A-G } & A-C & Other & TOTAL \\
\hline Government & & & 2.5 & $\mathbf{2 . 5}$ \\
\hline Business & 1 & & & $\mathbf{1}$ \\
\hline Citizen/Indep & & 3.5 & $10-$ & $\mathbf{1 3 . 5}$ \\
\hline Academic & & & & \\
\hline (anonymous) & & 5.5 & $7.5(2)^{\prime}$ & $\mathbf{1 3 . 5 ( 2 )}$ \\
\hline TOTAL & $\mathbf{1}$ & $\mathbf{9}$ & $\mathbf{2 0}$ & $\mathbf{3 0}$ \\
\hline
\end{tabular}

${ }^{81}$ e.g., vertical- or horizontal- regulatory commercial, source ambivalent, \&/or narrative unclear 


\section{SUMMARY NEWS CODE SHEET [continued]}

$(\mathbf{n}=30$ News Stories $)$

Year: 2011

Portrayal of Activists: Collective Action Frame

(Frequency of 'Path X Components' by 'Commercial-Gov. Perspective')

\begin{tabular}{|c|c|c|c|c|}
\hline & $\begin{array}{r}\text { ti-Gov/Regul } \\
\text { (Commercial } \\
\text {-Corporate) }\end{array}$ & $\begin{array}{l}\text { ory } \\
\text { Anti- } \\
\text { Corporate }\end{array}$ & Other $^{82}$ & TOTAL \\
\hline Injustice & 1 & $34 / 10$ & $58 / 47$ & $92 / 57$ \\
\hline Agency & 1 & $25 / 9$ & \begin{tabular}{|l|l|}
$45 \quad 40$ \\
\end{tabular} & $\begin{array}{ll}70 / 49 \\
\end{array}$ \\
\hline Identity & 1 & $23 / 12$ & $48 / 35$ & $71 / 47$ \\
\hline TOTAL & 1 & $82 / 31$ & $151 / 122$ & $233 / 153$ \\
\hline complete $\boldsymbol{C} . \boldsymbol{A} . \boldsymbol{F} . \mathrm{s}$ & $\frac{1}{1}$ & $11 / 2$ & $13 / 7$ & $24 / 9$ \\
\hline
\end{tabular}

Portrayal of Activists: Dispersed Passivity Frame

(Frequency of 'Path $Y$ Components' by 'Commercial-Gov. Perspective')

\begin{tabular}{|c|c|c|c|c|}
\hline & A-G & $\mathrm{A}-\mathrm{C}$ & Other & TOTAL \\
\hline Fate & 1 & 21 & $\begin{array}{lll}5 & / & 2 \\
\end{array}$ & $7 / 2$ \\
\hline Passivity & 1 & $5 / 2$ & $31 / 20$ & $\begin{array}{ll}36 \quad 22 \\
\end{array}$ \\
\hline Dispersion & 1 & $/ 1$ & $30 / 13$ & $30 / 14$ \\
\hline (Abstract) & 1 & $4 / 3$ & $8 / 6$ & $12 / 9$ \\
\hline TOTAL & I & $11 / 6$ & $74 / 41$ & 85 / 47 \\
\hline
\end{tabular}

Dominant Perspective in Story $(n=30)$ :

\begin{tabular}{|c|c|c|c|}
\hline Anti- Gov/Regulato & & & Balance \\
\hline $\begin{array}{c}\text { (Commercial } \\
\text {-Corporate) }\end{array}$ & $\begin{array}{l}\text { Anti- } \\
\text { Corporate }\end{array}$ & Other & $\begin{array}{l}\text { Between } \\
\text { Perspectives }\end{array}$ \\
\hline & 7.3 & 22.7 & \\
\hline
\end{tabular}

Polarization: $\_\underline{75}$ instances / _ _ 26 stories

Rational SM actor/statement: _ 51 instances / _ 24 s stories

Irrational /dramatic/emotional SM actor/statement: _ $\underline{48}$ instances / _ $\_\underline{22}$ stories

Commercially-framed activism (w/ market metaphor/ terminology): _ $\underline{54}$ instances / _ 24 _ stories

\footnotetext{
${ }^{82}$ e.g., vertical- or horizontal-regulatory commercial, source ambivalent, \&/or narrative unclear
} 
SUMMARY NEWS CODE SHEET ( $\mathrm{n}=30$ News Stories, from total pop.=213)

Protest: Malheur Refuge Occupation (MRO)

Year: 2016

News Outlets: The New York Times (10, total pop.=56); The Oregonian (10, total pop.=143); USA Today (10, total pop.=14)

Story Citations

Bylines:_26 $(\mathrm{n}=30) \quad$ Photos?_19 $(\mathrm{n}=30)$ [collective action_9+_labstract__]

Headline/Subhead: collective action components? Injustice:_6__Agency:_24_Identity:_15_(full C.A.F:_3 $)$

Headlines/Summary $(\mathrm{n}=30)$

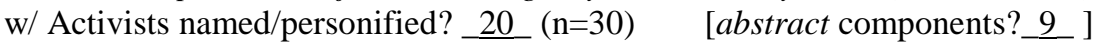

NYT (ave. wordcount $822[\max 1216, \min 235]):$ 'Armed Protesters...Refuge'. 'Guns...Nonsense... . 'Fervor...Refuge, Concern*... Outside...' 'Standoff...*Grievances'. 'FB video': Finicum. 'Protester...Killed... ' 'Both*Sides...Takeover'. 'FBI Encircles*...' 'NV legislator*...' '25 Plead*N.Guilty...' ORGN (ave. wordcount NA): 'occupied refuge...**resolve'. 'Patience*...occupation ...' 'Before Burns, dispute*...' 'Timeline'. 'leaders... denied'. '...jury indicts...occupiers'. 'Peaceful end*...holdouts give up'. 'Timeline'. 'Occupier files*...' 'Malheur holdout...released...' USAT (ave. wordcount: 475 [max 641, min 184]): '...standoff... Sheriff: group...to depose*gov.' 'Takeover...*family' . '...ranchers seek clemency* ... as standoff...' 'Occupiers... defy'. Editors-'Takeover... breaks*law'. '..."We will not* back down"'. '1/2-dozen... refuge; Sheriff: “... doesn't have to be blood...”. 'IN BRIEF...holdouts can't leave w/o charges'. 'Video.... shooting'(FBI)*. '. . bizarre end... refuge saga; Last holdout: rambling* call...'.

Headline-Story Agreement $(\mathrm{n}=30)$

H-S? y:_13 n:__ (+/-):_17 . *Where do H-S disagree? NYT: 'Concern' really local opposition! 'Grievances' all farrightwing! Local opponents' motives vary (not just ' 1 side'). FBI, but2nd1/2Fiore. "Unlikely role" <how? > Judge: swift! ORGN:

"Calm resolve" $<$ ?... armed outsiders isolated!>. Patience thins, locals \& outdoor grps (but Feds?). What kind of 'dispute'? "Peaceful', but suicide thrt,1/2 melodrama-zealous 'mediation' by Fiore/Graham (omitted by 'Timeline'). "files complaint" < ?But final line 'seeks \$666B vs "works of devil”": frivolous stunt?! USAT: Sheriff-“false pretenses' ('depose' euphemism for overthrow!). Family interaction omitted. 'Clemency minor part of story; land 'return' [false demand] is story core! Breaks law?(Occupiers claim 'defend...Constitution'.) Omits weak legal case \& divided community. +Bundy-' go home’. Last holdout armed, threatened suicide!

Number of Different Sources: $\underset{N Y T}{133} \quad \underline{122} \quad \underline{8} \quad \underline{85}$

Un-Sourced Portrayals: $\underset{N Y T}{203} \underset{\frac{268}{O R G N}}{\frac{1444}{U S A T}}$

Frequency of Attributions ('Source Type' by 'Commercial-Gov. Perspective'):

\begin{tabular}{|c|c|c|c|c|c|c|}
\hline & $\begin{array}{c}\text { nti- Gov/Regulator) } \\
\text { (Commercial } \\
\text {-Corporate) }\end{array}$ & $\begin{array}{l}\text { Anti- } \\
\text { Corporate }\end{array}$ & Other ${ }^{83}$ & TOTAL & Sympathizers & Detractors \\
\hline Government & $15 / 14$ & 1 & $92+/ 113.5$ & $107+/ 127.5$ & $5 / 10$ & $13 / 8$ \\
\hline Business & $21.5 / 11.5$ & 1 & $26 / 45$ & $47.5 / 56.5$ & $1 /$ & 21 \\
\hline Citizen/Indep & $-75 / 46$ & 1 & $67 / 98.5$ & $142 / 145.5$ & $3 / 6$ & $5 / 5$ \\
\hline Academic & I & I & I & I & I & I \\
\hline (anonymous) & $46.5 / 20$ & 1 & $61 / 48$ & $107.5 / 68$ & $7 / 9$ & $10 / 4$ \\
\hline TOTAL & $158 / 91.5$ & 1 & $246+/ 305$ & $404 / 397.5$ & $16 / 25$ & 30 / 17 \\
\hline
\end{tabular}

Lead (first) Perspective Portrayed in Stories $(n=30)$ :

\begin{tabular}{|l|c|c|c|c|}
\multicolumn{2}{c}{ A-G } & A-C & Other & \multicolumn{1}{c|}{ TOTAL } \\
\hline Government & 1 & & 7.5 & $\mathbf{8 . 5}$ \\
\hline Business & 3.5 & & 1.5 & $\mathbf{5}$ \\
\hline Citizen/Indep & 3 & & 5 & $\mathbf{8}$ \\
\hline Academic & & & & \\
\hline (anonymous) & 1.5 & & 7 & $\mathbf{8 . 5}$ \\
\hline TOTAL & $\mathbf{9}$ & & $\mathbf{2 1}$ & $\mathbf{3 0}$ \\
\hline
\end{tabular}

${ }^{83}$ e.g., vertical- or horizontal- regulatory commercial, source ambivalent, \&/or narrative unclear 


\section{SUMMARY NEWS CODE SHEET [continued]}

$(\mathbf{n}=30$ News Stories $)$

Year: 2016

Portrayal of Activists: Collective Action Frame

(Frequency of 'Path X Components' by 'Commercial-Gov. Perspective')

\begin{tabular}{|c|c|c|c|c|}
\hline & $\begin{array}{r}\text { ti-Gov/Regul } \\
\text { (Commercial } \\
\text {-Corporate) }\end{array}$ & $\begin{array}{l}\text { Anti- } \\
\text { Corporate }\end{array}$ & Other $^{84}$ & TOTAL \\
\hline Injustice & $51 / 34$ & 1 & $26 / 16$ & $77 / 50$ \\
\hline Agency & $88 / 36$ & 1 & $69 / 52$ & $157 / 88$ \\
\hline Identity & $75 / 40$ & 1 & $50 / 40$ & $125 / 80$ \\
\hline TOTAL & $214 / 110$ & 1 & $145 / 108$ & $359 / 218$ \\
\hline complete $\boldsymbol{C} . \boldsymbol{A} . \boldsymbol{F} . \mathrm{s}$ & $38 / 8$ & 1 & $9 / 5$ & $47 / 13$ \\
\hline
\end{tabular}

Portrayal of Activists: Dispersed Passivity Frame

(Frequency of 'Path $Y$ Components' by 'Commercial-Gov. Perspective')

\begin{tabular}{|c|c|c|c|c|}
\hline & A-G & A-C & Other & TOTAL \\
\hline Fate & $1 / 1$ & 1 & $\begin{array}{ll}1 \\
\end{array}$ & \begin{tabular}{l|l|}
2 & $/ 1$ \\
\end{tabular} \\
\hline Passivity & $8 / 8$ & 1 & $23 / 25$ & $31 / 33$ \\
\hline Dispersion & $8 / 2$ & 1 & $15 / 20$ & $23 / 22$ \\
\hline (Abstract) & $2 / 1$ & 1 & $2 / 2$ & $4 / 3$ \\
\hline TOTAL & $19 / 12$ & I & $41 / 47$ & 60 / 59 \\
\hline
\end{tabular}

Dominant Perspective in Story $(n=30)$ :

\begin{tabular}{|c|c|c|c|}
\hline Anti- Gov/Regulato & & & Balance \\
\hline (Commercial & Anti- & & Between \\
\hline \begin{tabular}{|c|}
-Corporate) \\
14.66
\end{tabular} & Corporate & $\begin{array}{c}\text { Other } \\
1534\end{array}$ & Perspectives \\
\hline
\end{tabular}

Polarization: $\_146$ instances / _ $\_\underline{30}$ stories

Rational SM actor/statement: _ 52 instances / _ 27 stories

Irrational /dramatic/emotional SM actor/statement: __66_instances / _ 26** stories

Commercially-framed activism (w/ market metaphor/ terminology): _ $\underline{68}$ instances / _ 25 _ stories

* In 1 story, activist's irrational motive (vs. "works of... devil”) is notably downplayed/obscured.

\footnotetext{
${ }^{84}$ e.g., vertical- or horizontal-regulatory commercial, source ambivalent, \&/or narrative unclear
} 


\title{
APPENDIX F - Pilot Study
}

\author{
'The GLOBALIZATION of PROTEST in the NEWS: \\ MOVEMENTS as MASS MEDIA COMMODITY?' (A preview sample case)
}

From a perspective of movements and media as interacting systems, my proposed research explores how recent media globalization may alter the news coverage or framing of social movements that are globalization-focused. This pilot study analyzes a preliminary case for broader research that will contribute to the literatures on how both globalizing social movements as well as mass media overlap as complex, interacting processes. However, two key gaps in this movements and media globalization literature are the movement framing model's neglect of wider structural contexts and the media framing model's neglect of movement agency. My research addresses these gaps by adapting the concept of media opportunity structure (MOS) to examine globalizing news media's relationship with globalization-related social movements. (See Model diagram above).

I will especially highlight how globalization-focused social movements (SMs), which may be growing more diffused ${ }^{85}$ and diverse, interact with mainstream media that have become more commercialized and conglomerated. In particular, I ask how the interaction may affect the resonance of movement messages that are anti-commercial. By adapting previous research that has analyzed SM collective action frames, I highlight the potential for a countervailing trend toward commercial news portrayals of movement actors as neutralized - a pattern I introduce as the dispersed passivity frame.

To in part operationalize the dispersed passivity frame, this pilot study innovatively combines news content analysis with interviews - of one actor who is portrayed and also of one actor who produced the news. This approach can then be extended and incorporated with the broader proposed research that will compare framing across regions, movements, news outlets and time periods. Such a comparative, mixed methodology can help reveal how decisive to movement resonance or success is media framing (or media effects) - versus the movement's own mobilization. Beyond contributing to the literatures on media framing (and the view that consolidated media ownership distorts or diminishes news quality) as well as on globalization-related movements (and the view of media as potentially constraining SM opportunities/MOS), the proposed research can also yield insights on mass media's relative openness to democratic social change discourses.

\section{METHODS}

A convenience sample of one news story was drawn from a wider sample frame of 1,955 stories (see footnote 64) covering globalization-focused economic justice SM areas ${ }^{86}$ from 1991 through 2011 (the media consolidation era, pre- and post-1996 U.S. Telecomm Act). In order to obtain a news story more likely to reveal actors who can be reached for interview, I selected stories that are more local and recent (i.e., from The Oregonian on Occupy Portland 2011). Because many stories cite un-named or

\footnotetext{
${ }^{85}$ That is, proliferated and decentralized

${ }^{86}$ Labor/anti-NAFTA/Zapatista, anti-WTO/World Social Forum, anti-tax/pro-austerity/Tea Party, EU antiausterity/ Occupy Wall Street
} 
pseudonymous sources, or are not locally produced, re-sampling was then done until an appropriate story was obtained (see below).

With the sample news story, "Protest keeps one eye on itself", an initial round of open coding was done while also screening for potentially available interview subjects. ${ }^{87}$ Contact was initiated online by Google search and social network (i.e., Facebook \& LinkedIn); informed consent and further details were gained via email; and two interviews (one SM actor and one news reporter) were conducted by phone. During the scheduling, interviews and transcriptions, the content analysis coding scheme was further adapted and refined.

The second and third rounds of axial coding focused on: sorting source attributions by institutional type; identifying sources' explicit or implicit perspectives on globalization \&/or commercialism (broadly interpreted via semantic or contextual narrative elements); and quantifying/tallying these instances within the story. Successive coding rounds then identified collective action (and contrasting dispersed passivity) frames - and also incorporated relevant interview content. (See Coding Sheets, below.)

Semi-structured interviews were conducted with one SM actor and one news reporter, in order to triangulate and thus help 'ground' the news story, as well as to refine coding schemes. Questions were emailed to interviewees in advance. The phone interviews were 55 minutes and 30 minutes duration respectively, with transcripts typed simultaneously. Although it was a recent local story, both interview subjects since 2011 are now located outside of Portland and engaged in different occupations. (See Interview Protocols \& Transcripts, below.)

These outlined methods were relatively time- and labor-intensive (12-18 hours). Yet the intensiveness, after this pilot study, will significantly decrease in further iterations. Moreover, shifting from manual coding to computer-aided coding/analysis will likely add efficiency.

\section{RESULTS}

Among the most basic findings in any news content analysis are attribution frequencies and placements within a story, which indicate who speaks and how loudly and prominently. Citizen/protesters were attributed or cited more frequently, but they often remained anonymous - while the story named the government sources and named them first. Both 'commercial' and 'anti-commercial' perspectives were portrayed, but the dominant globalization perspective (seen via prominent placement in the top half of the story) was 'regulatory commercial'.

The story "Protest keeps one eye on itself" portrayed at least one complete collective action frame (injustice, agency \& identity components) yet also one or more dispersed passivity frames (fate, passivity \& dispersion components in an abstract narrative) for the SM actors, although the protest was just two weeks old. A form of commercialized activism (where market metaphors or terminology are used to describe the activism) was portrayed in two instances in the top half of the story. (See Coding Sheet, below.)

\footnotetext{
${ }^{87}$ The first activist-source cited in the news story was unable to be located during the 1-week time period allotted. (Another, quoted by photo caption, was dismissed as pseudonymous.)
} 
From the interviews, some basic agreement/continuity emerged between the reporter's and the activist's views of the story and recollections of related events. However, the activist noted general SM antipathy toward mainstream media and especially mixed feelings or frustration with The Oregonian. For example, while the story highlighted controlled substance use, e.g. marijuana, the activist (known at the time as Occupy Portland's "Mr. Info") noted that he was not the only SM actor/'facilitator' whose lifestyle actively avoids substance use including alcohol. Finally, and most notably, both actors/interviewees recognized that this particular news story largely omitted the wider context of the Occupy Wall Street movement. (See Transcripts, below.)

\section{\# \# \#}

\section{SAMPLE NEWS STORY (see News Story Coding Sheet, below)}

"Occupy Portland opens third week camped downtown with focus on policing itself" http://www.oregonlive.com/portland/index.ssf/2011/10/in_downtown_occupy_portland_op.html (online version, with photo/caption): A protester at the Occupy Portland camp downtown, a young man who said he legally changed his name to Earth Child, spends time in a tent with friends and a dog named Mackenzie. Mayor Sam Adams has warned protesters that marijuana use in the parks, even by medical cardholders and even inside the tents, is prohibited.

"Protest keeps one eye on itself" (PRINT/ Newsbank edition: CONTENT ANALYZED) Oregonian, The (Portland, OR) - Friday, October 21, 2011

Author/Byline: The Oregonian

Edition: Sunrise. Section: Local News

sources say $=$ a source attribution

SUMMARY: Occupy Portland camp learns the $99 \%$ includes people there Just fo party

Now two weeks encamped downtown, organizers of Occupy Portland say one of their biggest challenges is mediating the fine line between the people who have come to protest and the people who have come to party.

The organizers say this week's two arrests in and around the camp, one for marijuana possession and one for disorderly conduct, aren't surprising, given the number of people living in two city parks with only two public bathrooms and an all-volunteer labor force. But Occupy Portland has stepped up its effort to police itself, especially after Mayor Sam Adams warned that the occupiers' behavior will determine how the city will deal with them.

"It's almost all we've been talking about around the clock for a few days now," says Andrea Thompson, one of the demonstration's "facilitators." "The police have been really, really great, and we have been doing a lot of the security work ourselves. But that is something we have to pay a lot of attention to."

About 500 people settled into the tent village established in Lownsdale and Chapman squares on Oct. 6, the first day of Occupy Portland when the entire group marched through the city. Camping in city parks is against the law, but Adams repeated Thursday that the camping ordinance would not be enforced as long as protesters lawfully exercise their free-speech rights.

As of late Thursday afternoon, police had made 10 arrests since the camp began; eight came on Oct. 13, when police opened Southwest Main Street between Third and Fourth avenues. A man was arrested Tuesday for having a mason jar of marijuana, and police arrested a 32-year-old man 
Wednesday who they say flashed a handgun while videotaping the protest.

"This is a day-to-day discretion," Adams told a news conference Thursday morning before leaving on a 10-day trade mission to Asia. "The place matters, the location matters because of the practical realities, and behavior can change from day to day. ... We're taking this on a day-byday basis, and the details matter. The behavior really does matter."

Occupy Portland vigorously resists the concept of "leaders" and instead calls organizers "facilitators." _ a facilitator who has been at the campsite since Oct. 6, said demonstrators walk a blurred line between protesting the nation's economic disparities and caring for the chronically homeless and mentally ill who have moved into the camp with a less political purpose in mind --such as partaking of the free meals served daily.

"They are, after all, protesting, too, by the life they have to live," said. "We are learning that as we go along, too. They have a lot to teach us. I had one guy talk to me for five days straight, and I didn't understand a thing he was saying until this morning, and he's a genius. And a lot of them are stepping up and volunteering here. But we do recognize that a large fraction of people here are not as politically motivated."

When questioned about their views, many of the young men and women lounging on the park benches or in their tents with their dogs and kittens simply reply, "We are the 99 percent," and decline to comment further. The expression is a slogan of the Occupy movement across the nation to indicate that 1 percent of Americans own 40 percent of the nation's wealth.

In an effort to control the Occupy Portland campsite, the movement's consensus government imposed rules of conduct Monday night for participants, including no weapons and no derogatory language. More volunteers are wearing white strings around their arms indicating they are camp "peacekeepers" with authority to calm disputes.

Adams warned Occupy Portland on Wednesday that marijuana use in the parks is prohibited, even in tents, which slowed traffic in the special smoke tent set aside at the northwest corner of Lownsdale Square for holders of medical marijuana cards. On Thursday, the open marijuana smoking in the parks was dramatically reduced, but a bystander deeply inhaling could easily reckon that cannabis intake had not appreciably fallen off.

ILLUSTRATION: Adams "The behavior really does matter"

Staff writer Beth Slovic contributed to this story.

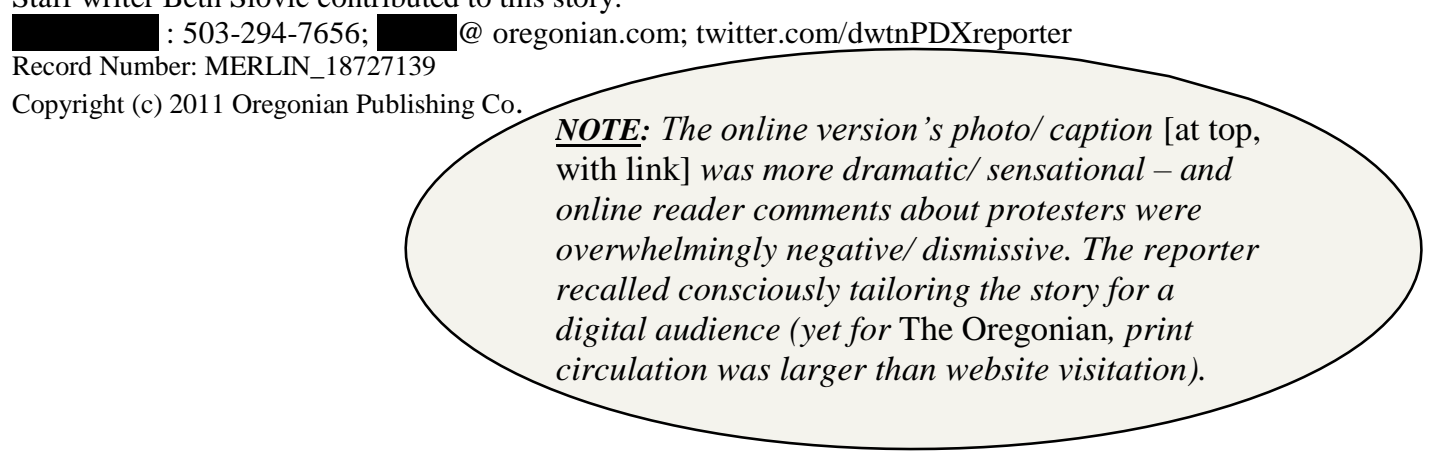


News Outlet: The Oregonian

Date:_10/21/2011 (10/20/11) http://www.oregonlive.com/portland/index.ssf/2011/10/in_downtown_occupy_portland_op.html Placement?_Section: Local News (Sunrise Edition) Story varied by edition? Yes: headline, photo

Citation (Byline, Headline): "Protest keeps* one eye on itself”[PRINT] “Occupy Portland opens third week with focus on policing* itself"[ONLINE] Subhead? _ No. $(*=$ Collective action $[$ or abstract] components:_agency_)

Summary:_Occupy Portland, 500+ occupant-campers in 2 sq. blocks during 2+ weeks, mediates line between 'protesters' \& 'partiers'. Police: 10 arrests including pot, threats of violence. Mayor warns, 'behave yourselves...'

Style ('Straight news'): _ ('News-feature'): X ('Feature'): _ Photo?_1+graphic

Continuity: Headline/Story? yes_X $($ no_$)$ (mixed_)...Author/Activist reviews? yes_X (no_) (mixed_), General agreement btwn author \& activist account. Both noted: story largely omitted the wider movement context.

Sources:_organizers/Occupy Portland, Mayor Adams, Andrea Thompson, 'the law', police,

Un-sourced Portrayals: people come to protest/party, man, homeless/mentally ill, volunteers/peacekeepers

Frequency of Attributions ('source type' by 'globalization perspective'):

\begin{tabular}{|c|c|c|c|c|c|c|}
\hline & $\begin{array}{c}\text { Corporate } \\
\text { Anti-Regulatory } \\
\text { Commercial }\end{array}$ & $\begin{array}{c}\text { Vertical } \\
\text { Regulatory } \\
\text { Commercial } \\
\end{array}$ & $\begin{array}{r}\text { Horizontal } \\
\text { Regulatory } \\
\text { Commercial } \\
\end{array}$ & $\begin{array}{c}\text { Anti- } \\
\text { Commercial } \\
\end{array}$ & $\begin{array}{c}\text { source } \\
\text { ambivalent }\end{array}$ & $\begin{array}{l}\text { narrative } \\
\text { unclear }\end{array}$ \\
\hline Government & I & $\begin{array}{lll}1 / 1 \\
\end{array}$ & 21 & I & $1 / 1$ & I \\
\hline Business & I & / & I & / & / & I \\
\hline Citizen/Indep & I & I & $1 /$ & $1 / 2$ & $1(\#) / 3$ & I \\
\hline Academic & I & I & I & I & I & I \\
\hline (anonymous) & I & I & I & $1 /$ & $2 / 3$ & 1 \\
\hline
\end{tabular}

Portrayal of Activists:

(Dispersed Passivity [path $\boldsymbol{y}$ ] / Collective Action [path $\boldsymbol{x}$ ] Frames by 'globalization perspective')

\begin{tabular}{|c|c|c|c|c|c|c|}
\hline & C.A-R.C. & V.R.C. & H.R.C. & $\mathrm{A}-\mathrm{C}$ & s.a. & n.u. \\
\hline Fate $/$ Injustice & $y / x$ & I & I & $/ 1$ & $1 / 1$ & I \\
\hline Passivity / Agency & / & / & $/ / 1$ & 12 & $1 / 3$ & I \\
\hline Dispersion / Identity & I & I & $/ 1$ & $/ 1$ & 21 & I \\
\hline (Abstract) & & & & & 2 & \\
\hline
\end{tabular}

Dominant Globalization Perspective:

C.A-R.C. $\quad$ V.R.C. $\quad$ H.R.C.

A-C

Between

\begin{tabular}{|l|c|c|c|c|c|c|}
\hline & $\mathrm{x}$ & $\mathrm{x}$ & $\mathrm{x})$ & $\mathrm{X}$ & & \\
\hline
\end{tabular}

Polarization (instances): _ 3

Rational SM actor/statement (instances): _ 3

Irrational /dramatic/emotional SM actor/statement (instances): _ 4

Commercialized activism (market metaphor/ terminology used for activism), instances: _ 2 


\section{INTERVIEW PROTOCOL (news worker)}

1. Thinking about the news story you were involved in (http://www.oregonlive.com/portland/index.ssf/2011/10/in_downtown_occupy_portland_op.html), how well do you recall key details? (e.g., the newsworthy event[s], issues that perhaps competed with your story's intended focus, \&/or persons who were covered)

2. How well do you feel the story informed the audience about...

- ...who the protesters/demonstrators were?

- ...what their goals were?

- ...why they were roused/mobilized to action?

3. Are there certain ways you feel this story reflected...

- ...The Oregonian's model, standards or editorial influence for covering this kind of issue? (and how satisfied are you with this?)

- ...general news industry models, standards or influence for covering this kind of issue? (and how satisfied are you with this?)

4. Focusing just on the issue that was being protested, do you have other thoughts or recollections about the news story?

5. Beyond this particular news story...

- ...how strong do you feel The Oregonian's coverage of this particular protest issue was?

(...and how about the wider news industry's coverage?)

- ...how reasonable in their goals and their conduct do you feel the protesters were?

\section{INTERVIEW PROTOCOL (movement activist)}

1. Thinking about the protest events in which you were involved - and that appeared in The Oregonian news story

(http://www.oregonlive.com/portland/index.ssf/2011/10/in_downtown_occupy_portland_op.html) - how well do you recall: ...details of the particular event(s)? ...or major competing issues/perspectives that were at play? ...or other participants/actors who were involved?

2. Thinking about it again, how well do you feel the news story represented...

- who the protesters/demonstrators were? (or who you are?)

- what the protest's purpose was? (or what your aim was?)

- the reasons why people were roused to do something?

- the other major news media coverage you received of this issue?

3. Beyond this news story, what kind of a job do you feel The Oregonian has done in covering this issue? (and in comparison with the mainstream media in general?)

- For example, how comprehensive has coverage been compared to what is typically seen for weather, sports or business?

4. How do you feel the general news coverage of this issue has influenced or impacted the related activism? 


\section{INTERVIEW TRANSCRIPT (movement activist, 11/5/15)}

\section{THINKING ABOUT EVENTS COVERED IN The Oregonian STORY [10/21/11] .. -RECALL EVENT?}

...I didn't know about the pot arrests... not a lot of communication with police. Hard to filter info. You knew what happened in your vicinity...

\section{-COMPETING NARRATIVES?}

[They were] both within the camps \& outside. Began as protest-focused. Then the march stopped, encampment. Whole thing blossoms for 6 weeks. Evolved a lot. Protesters worked well together. Common goal was... a lot of goals! Not just one topic or issue, for people in movement/ protesters: housing crisis. newly homeless people. combination of street kids, Insane Clown Posse, street people. Anarchist group: political anarchists/coffee shop types + street/punk anarchists (aggressive, violent, alcohol). I.C.P (heroin, hard stuff). Street/anarchist (pot, alcohol). Various substances w/ the more hardcore groups. Melting pot of lifestyles. 50-year-old hippies. The Police. Mayor's office. Businesses - downtown PDX Business Association [Alliance] especially! They pushed hard vs. Occupy because 'not good for business'.

\section{-OTHER ACTORS?}

The symbol is the hydra. OWS didn't believe in leaders, to its detriment. People would rise up, get their head cut off. Doomed to fail in leadership positions. Like a bull ride. But, one woman 'Girl in the red hat' $\sim\langle$ WHO?>>, used bullhorn, a leader; very good with the call \& response, energy, captured attention (lives in N.PDX, part of performance-fest culture/bike jousting...). Mostly images for me, many of the names tough to recall now. A lot of these people, subversive, anonymous; trying to protect their identity [** SEE BELOW]. Also, a number of people found to be police or gov agents, working undercover to dismantle movement. BUT one of the fire chiefs was really good. It all developed so quickly. Wasn't really about the individuals. Fast changing situation. First a protest $w /$ an ideology. Then overrun $w /$ all this homelessness, which became the need of the moment. I remember when they closed the bathrooms, \& turned off the water... Are you kidding me? Hundreds of people w/ no place to go.

[**FROM ABOVE] There were official [legal] names [of activists], vs. the name they were using. I went by 'Mr. Info'. One guy Piper. Piper \& his partner, 'Miss Information', ran the coffee space. Another group was the Rainbow Family group!....Big role there, \& people who were Festival organizers. Food Not Bombs, a huge element. But managers of the kitchen lasted a week before they burnt out. It was 24-7. Michael Whitney, an interesting guy. Had been to Katrina. But he actually split some of us at the top level, as people wanted to be transparent. You were basically a leader if you were someone actively connecting people. Whitney works on tiny houses now. Also, Right2Dream2 was new then. Not a part of us, but kind of a brother-sister camp.

\section{HOW WELL THE STORY COVERED...} -WHO?

The title is OK. We definitely had our own security. Blue armband. But this doesn't really talk about Occupy goals. It's about reasons we could get shut down. Fear-mongering. Some weird stories in it, like the guy that flashed his gun. Was he a protester, or not? So, the story was not that focused. It's about police, fear of getting arrested. So this is really just...'how long will we be there'? Some [substantive] stuff in here [the story/article] but mixed in w/ talk of marijuana possession. This news, who are their readers? People who aren't at the camp. There were so many intelligent, amazing people there they could have talked to. A lot of animosity toward news, after the stories ran. ...Part of what we're protesting, this corp-controlled media. [For example], 
this Asperger [syndrome] guy [I think]: a genius, he thought it was possible to make the place exist forever. Said 'You need engineering, etc,' renaming of streets.... So I needed to stop talking, \& listen to him for a long time, ...to see beyond the stigmas \& social facade.

<<ASIDE: Food distribution [concerns]!? ([For example,] did people get dosed? [i.e. mood altering substance in food?] I'm not a substance user. But there were days when people were just off, \& in groups! One day in particular for myself, I was very off, out of sorts!)>>

\section{-WHAT THE PURPOSE WAS?}

The story didn't really cover the purpose. Has some slogan signs of the ' $99 \mathrm{vs.} 1 \%$ '. But intent of article was about Occupy policing themselves. What I learned in festival culture... [was this was quite a successful feat]. I don't think we had a single death. 600-800 people camped for 6 weeks! Definitely a few fights. The danger that they discuss [in news], a lot of fear, vs. the reality of what actually happened. The policing thing was used as the excuse to take the camp down. Ignored fact of, where would all these people go? No talk about that at all.

I don't think the protesters were prepared for that... the evictions, people out of their homes. But article does decent job of: "Occupy's doing stuff...". on some level showing sort of an evenhanded view. But ignores 100 positive things being discussed/done at our library, etc. So this whole article could be a paragraph in another article.

\section{-REASON WHY MOBILIZED/ROUSED?}

This article doesn't really touch on that at all. ...Person just had house taken by mortgage banker. Deeper thing, of what does this mean, not talked about.

And Wall Street, a huge thing, economic collapse, none of that is in there.

\section{-OTHER MEDIA?}

I don't know if I remember reading an article that asked: 'where do these people go?' There were other more negative stories for sure. I remember the anger of other protesters. Emotion of response to some of the articles. But the [emerging view is]: We have our own social media, we don't need these news media sources necessarily. PR was a nightmare. Who talks to the media? If people at the top don't talk to media, someone's gonna talk to them. Sometimes it's not a protester, just a homeless person who wants attention. I was like: 'we can talk to media if we find the right people to talk to.' But then it became: 'Just don't talk to them; it's not worth it.' Also, NPR was great. [ADB/INTERVIEWER asks to clarify] ...No, actually it was the KBOOFM booth. When Michael Moore came, it was a ridiculous media frenzy. [In general, it was] so organic \& flash mob-ish. Didn't have time to call [media] \& say 'hey this is gonna happen'....

\section{JOB OF OREGONIAN?}

The media is the media. Not really paid to inform. Paid to tell a story. Promote owners' interests. I remember thinking, 'we can talk to The Oregonian'. But then, no, [from their reporting] that's not happening. [And I] remember an Oregonian reporter really caring -- but they're not the editor. It's this group machine that decides \& dictates what gets told, released, what they show. Definitely there were $\sim$ some good articles. But there could have been better ones. The stories that they came looking for [were like], when you have a bias \& assume something... How you ask a question can really determine the answer.

\section{INFLUENCE on ACTIVISM?}

I think activism has gone much more toward social media. Would have happened anyway. But now you can do your own stuff. Reporters like 'Kari' <Koch?>, started making their own media. A 
guy, Mike w/ blue hair, videotaped the whole thing. Occupy reporters. Used their tech to show what was going on 24-7, their view as a protester.

[Regarding post-camp relocation of Occupy PDX]...I was one of the people named on the lease at St. Francis [buildings where long-term Occupy office located]. It really shifted after that. Initially it was protesters. Then a huge influx of homeless. Camp was right across from the jail, \& people were released right into camp! A lot of people burnt out, moved to other things. In the end, the Occupy movement... brought likeminded people together who bonded, \& then moved on to other projects. We are seeing some movement on issues. Bankers, maybe not just a slap on wrist. This kind of stuff takes a lot of time. Yet amazing how fast some of this stuff happened. Pot legalization, Occupy movement [helped push toward that]. Now w/ other activism, it's technology, w/ social unrest, police \& body cameras. Cell phones \& smart media able to show [protesters'] own view. Not just words, but from view of protester, not just media corp's. Now at least we're getting bias in both directions, not just corporate. So it pushed the edge toward social media. Already using tech in our personal lives. A lot of people got connected to meet other activists. They'd think: where can we meet these people? [For example] I know half of the Greenpeace-vs.Shell/bridge activists were at Occupy. You just need enough people [to make change].

\section{...NOW, PERSONAL OUTLOOK}

Part of me wants to jump back into it....

Definitely one of the best times of my life, for sure. But I had burnout, PTSD.... 


\title{
INTERVIEW TRANSCRIPT (news worker, 11/12/15)
}

\author{
1. THINKING ABOUT EVENTS COVERED IN The Oregonian STORY [10/21/11] \\ -RECALL EVENT? \\ I remember it pretty well.
}

\section{-COMPETING ISSUES/NARRATIVES?}

There was the overarching issue: challenge of Occupy PDX, its presence, in parks for 6 weeks in the middle of the city. These stories arose out of that presence. When there are that many in that tight a space, there were many issues that I could not fully address. Where are they going to the bathroom? Where are they getting food? [Focus was on Occupy doing their own policing], but not that great a job policing! This was 2 weeks in, early on! The tension \& stress of the occupation was palpable.

-PERSONS COVERED? << talk to: Cameron Whitten! >> They had an info desk in camp. That was usually the place I'd go to find someone authorized to speak. [Occupy] prided itself on being leaderless. I could ask something of one person, could give their opinion, but might not be binding on the rest of the organization. The evening meetings were where a lot of decision making got done. [So I would find] who was facilitating, by going to those meetings. But it was rarely the same person twice.

\section{HOW WELL STORY COVERED...}

-WHO? $\quad$ < ASIDE: This was 1 of 50 or 60 stories I did on Occupy. >

Of course, I thought we did a very good job. Really just a snapshot, of any given moment. A

flavor of what was happening. Really, it was the best I could do under the circumstances.

\section{-WHAT THE PURPOSE WAS?}

Mainly it was about trying to tell readers, who's protesting the overall socio/political/economic environment? ... and who's here for the free food? Hard to cover the broader national spectrum. (I didn't mention the broader movement; that was a flaw in this story.)

But by this time, it was a turning point, \& even the hippy-dippyest in PDX were like: 'I like to eat my lunch in this park, \& I can't do that'. So the citizenry in PDX were upset about how the parks were treated. They were trashed. [And it] probably took $\$ 100,000$ to revitalize those parks. So by this time [of the story] the charm was wearing thin. [Locals saying, 'I'm with Occupy about] shaking fist at 'the man', but I can't take my kids through there.'

\section{-REASON WHY MOBILIZED/ROUSED?}

I think it [Occupy Portland] got up to 1000 people living in these 2 parks. And there came a point where citizens were saying: 'I'm getting kinda tired of this.' I THOUGHT it was a very cool thing. But once they occupied the squares, [I think] they had no idea what they were gonna do next. [One big event...] There was the Molotov Cocktail incident too. People got tired of that. Someone actually built a M.C.; it was found over at the World Trade Center [Portland]. And ingredients from the camp were found.

\section{WAYS STORY REFLECTED OREGONIAN'S MODEL?}

It was my story. <<ADB/INTERVIEWER: For example, the headline changed?>> Yes, we learned if we goose the headline, we could get more eyeballs on the story. At this time, the reporters were writing their own headlines. [So I'm] pretty sure I wrote the headline. [Part of] learning to be more nimble online: Feed the beast earlier in the day. <<ADB: Oregonian 
model?>> I'd come in [to The Oregonian, \& say]: this is what I saw; they'd say 'go write it up'. [Also at this point,] you didn't always have an editor reading your copy behind you.

-(GENERAL NEWS INDUSTRY MODELS?)

This is the paradigm shift; so this is what we do. [I was on] the hyper-local team. Our focus: to be digital first. And I was [the person] doing downtown.

\section{FOCUSING ON ISSUE OF PROTEST, OTHER THOUGHTS?}

Most news organizations did their very best to take it seriously. But at a certain point, news media gets tired. Staying power is a weak suit in media. A lot of reporters/editors got tired. I didn't; I thought it was interesting all the time. [But, with Occupy] their solution was to tear it all down \& start over. I was hoping there would be something else. [But there were] lingering effects: one could argue it contributed to Obama's reelection. The slogan "the 99\%" touched a deep nerve in America. "1\% owning 40\%"...[it was stated by] Occupy in a way that the middle class could understand. ...Incredibly valuable.

5. BEYOND PARTICULAR NEWS STORY...

-Oregonian's COVERAGE OF ISSUE? << See above, \#4. >>

-PROTESTERS REASONABLE IN GOALS/CONDUCT?

It was a fun story to cover. It really was. But I wish there'd been a more tangible result from it. 